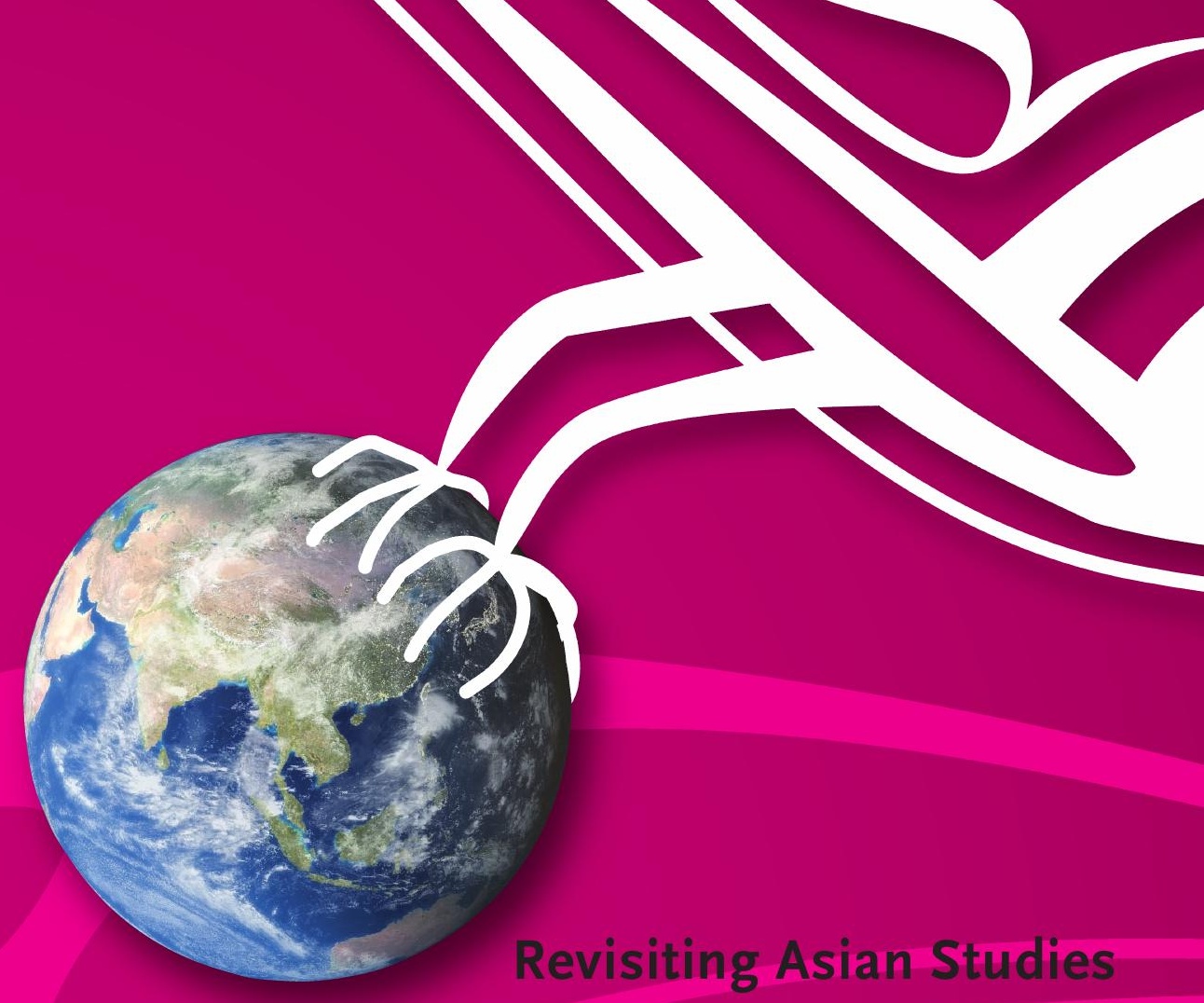

What about

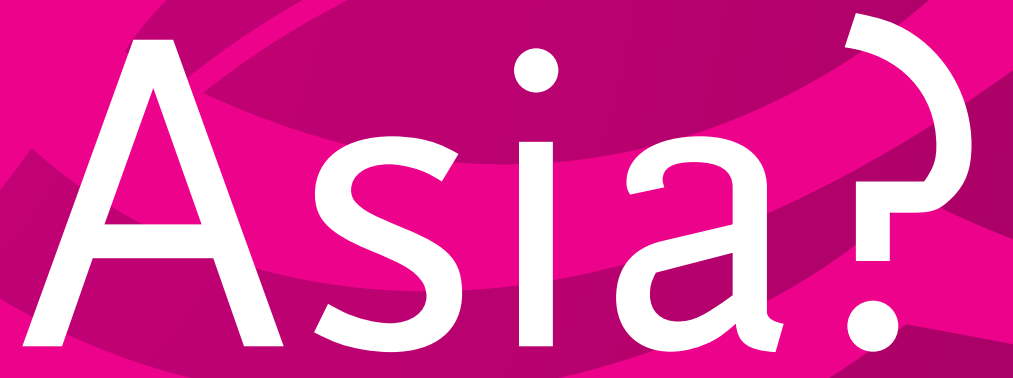

Edited by Josine Stremmelaar and Paul van der Velde

Amsterdam University PRESS 
What about Asia? 


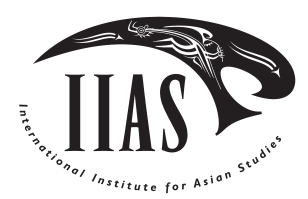

The International Institute for Asian Studies (IIAS) is a postdoctoral research centre based in Leiden and Amsterdam, the Netherlands. Its main objective is to encourage the interdisciplinary and comparative study of Asia and to promote national and international cooperation in the field. The institute focuses on the human and social sciences and on their interaction with other sciences.

The IIAS acts as an international mediator, bringing various parties together. This entails activities such as providing information services, constructing international networks, and setting up international cooperative projects and research programmes such as the European Alliance for Asian Studies and the International Convention of Asia Scholars (ICAS). IIAS considers academic cooperation indispensable to toplevel research, hence it believes that, in the present environment of globalization, the distinctive national traditions of research and scholarship need to be brought together into complementary partnerships. IIAS, therefore, actively promotes, facilitates, and initiates academic cooperation between different research groups and institutes, which results are disseminated through the IIAS Newsletter and IIAS Publications. For more information: www.iias.nl 


\section{What about Asia? \\ Revisiting Asian Studies}

Edited by Josine Stremmelaar and Paul van der Velde 


\section{IIAS}

Sponsored by the International Institute for Asian Studies (Leiden / Amsterdam) and the Faculty of Arts of Leiden University

Cover design and layout: JB\&A raster grafisch ontwerp, Delft

ISBN-13 9789053569597

ISBN-10 9053569596

NUR 761

(C) IIAS / Amsterdam University Press, Amsterdam 2006

All rights reserved. Without limiting the rights under copyright reserved above, no part of this book may be reproduced, stored in or introduced into a retrieval system, or transmitted, in any form or by any means (electronic, mechanical, photocopying, recording or otherwise) without the written permission of both the copyright owner and the author of the book. 


\section{Table of Contents}

What about Asia? Revisiting Asian Studies

Josine Stremmelaar and Paul van der Velde

Asian Studies and the Discourse of the Human Sciences

Gananath Obeyesekere

Area Studies in a Changing World

Peter van der Veer

Asia as a Form of Knowledge: of Analyses, (Re)Production, and Consumption

Shamsul A.B.

'A Little Knowledge is a Useful Thing': Paradoxes in the Asian Studies Experience in Australia

Robert Cribb

The Ebb and Flow of ASEM Studies

Yeo Lay Hwee

Re-orienting Asian Studies

Paul van der Velde

Abbreviations

Contributors 



\title{
What about Asia? Revisiting Asian Studies
}

\author{
Josine Stremmelaar and Paul van der Velde
}

What about Asia? Revisiting Asian Studies brings together scholars from Asia, Europe and America to test the strength of a field of study which, considering the rise of Asia, should be gaining momentum. But is it? This is one of the many questions that the contributors to this volume ask themselves. In the past decade the use and legitimacy of area studies, and in particular Asian studies, have been passionately debated in conferences and academic journals. Questions have been raised in several issues of the IIAS Newsletter over the conceptualization of Asian studies and the kind of knowledge that Asia specialists produce. A variety of answers has been presented, but the issue is still far from settled.

Wim Stokhof, who has been a fervent debater and partisan of Asian Studies, has taken numerous initiatives during his directorate of the International Institute for Asian Studies (I993-2006) to stimulate this field of scholarship. To honour his contribution to Asian studies we have invited eminent scholars to reflect on and provide insight into the debate on the state of the art of Asian studies. Among the topics touched upon are: the conceptualizing of Asian Studies: what do they look like from a national, regional or global perspective? What is the relationship between Asian Studies and the societies that they cover? What contribution do Asian Studies make to Asian societies? What is the future for Asian Studies? Will interest in Asian Studies outside Asia continue, and will Asian Studies be 'Asianized'? What is the role of Asian diasporas in the conceptualization of Asia?

\section{From Enlightenment to All-inclusiveness}

In his article 'Asian Studies and the Discourse of the Human Sciences' Gananath Obeyesekere explores the issue of how the native Asian scholar, as opposed to the scholar of Asian studies, can relate the discourse of the human sciences to his 
own cultural heritage. There is a view widely prevalent among Asian nationalist scholars, and elsewhere in the world, that one should be able to construct an indigenous social science. Obeyesekere argues that this is an unrealizable goal at present and that we cannot avoid our contemporary cosmopolitan inheritance of Enlightenment discourse. He makes a case for a more realistic approach which would use terms, concepts and ideas from one's own cultural tradition to enrich the Western discourse of the human sciences.

Obeyesekere does so by employing Buddhist ideas of 'no-self' and the absence of essence within existence to critique the Cartesian paradigm, 'I think, I am'. Employing primarily Buddhist visionary experiences he argues that visions are 'showings' that occur without the mediation of the 'I'. He then brings in Nietzsche who boldly suggested that instead of the Cartesian cogito, one should be able to say 'It-thinks'. From here Obeyesekere moves to a form of 'aphoristic thinking' in the Buddha, Nietzsche and Wittgenstein that again entails the appearance of condensed thoughts without the mediation of the ' $\mathrm{I}$ '. And in this sense he brings about a dialogue between the European and the Buddhist Enlightenment. In other words the question he poses is: 'What are the areas of thinking where the self or ego does not exist and the Cartesian cogito does not operate?

Peter van der Veer in his 'Area Studies in a Changing World' demonstrates that area studies - in this context Asian studies - can contribute to the deepening of knowledge on globalization because it can put the 'national' into a global context. He first delineates the three main lines of criticism on area studies, namely that they do not produce universally valid knowledge; that they are intimately related to Western power interests and that they do not take into consideration the fluid boundaries of this age of globalization. Although Van der Veer finds truth in this criticism he points to the huge potential of area studies which allows for a more in-depth perspective on the variety of forms of globalization. According to Van der Veer, rather than a comparative stance, an all-inclusive point of departure should be taken in studying the West and the East.

He expounds this by using a case study of the relations between the Dutch state and Islam which edifies his all-inclusive approach. That such an approach is necessary is borne out by the jingoist attacks on mosques and Islamic schools that have taken place in the Netherlands in the wake of 9/II. The loyalty of Muslim immigrants to the Dutch way of life was questioned and a fierce debate ensued over the nature of Dutch society. It has only recently dawned on the North Sea Hollanders that their country is in fact a postcolonial society with a growing number of immigrants who adhere to Islam. This once again proves that the concept of la longue durée is unfortunately not embedded in political discourse because otherwise the debaters would have realized that only fifty years ago the 
Netherlands was a colonial society in which a vast majority of the population was Muslim.

Historical analysis of the colonial state could have provided clear insights into three dilemmas the postcolonial modern state has to come to grips with: how to make individuals into loyal citizens; how to substantially increase the political participation of its subjects, thereby entailing a public sphere in which civil society can operate; and how can the modern state protect the liberty and equality of its inhabitants? In this context another important question needs to be tackled: can the postcolonial state still be called a 'national' state or are we moving in the direction of what Manuel Castells labelled 'the Network Society'? Certainly cosmopolitans view the state as an obstacle to realizing their global ambitions when using their transnational networks, which are essential for creating transnational identities that are inspired more often than not by religion. They challenge the national state that can no longer counter confrontations with traditional national reflexes. Only by tackling these challenges from an all-inclusive perspective is there a chance that acceptable answers can be found.

\section{The intimate knowledge of Asia}

Shamsul A.B. in his 'Asia as a Form of Knowledge: of Analysis, (Re) Production, and Consumption' regards Asian studies as consisting of a number of regional studies, such as South Asian studies, Japanese studies and Southeast Asian studies. Asia is in Shamsul's eyes both a real and imagined area. It is real in terms of its physicality and the people that populate the region. It is imagined because it is situated in documents and texts that form a corpus of knowledge regarding the society and environment of the region that have been accumulated from the earliest of available records on leaves to the latest digitalized form.

In sum, Asia is a form of knowledge. This knowledge is called Asian studies and it has been constituted from accounts about its society and environment. It is organized along a baseline, a continuum between 'plurality' at one end and 'plural society' on the other. Both 'plurality' and 'plural society' are terms that describe the two different processes of social formation as well as types of society forms within Asia before and after the arrival of the Europeans in the fifteenth century.

The consolidation of 'plural society' in Asia led to the organization of knowledge about societies within the region into nation-states hence the development of nation-state based studies, such as Indonesian studies, Japanese studies and so on. Therefore the production and reproduction process of knowledge about Asia became increasingly detailed but highly compartmentalized hence the complex system of organization and bureaucracy that is involved. This, in turn, shapes the pattern of consumption of knowledge about Asia, both within and outside Asia. 
Robert Cribb in his 'A Little Knowledge is a Useful Thing': Paradoxes in the Asian Studies Experience in Australia' relates the history of Asian studies from the I950s to the present. Until the I950s there was no such thing as Asian studies in Australia. Academics interested in Asia worked within disciplines such as history or anthropology, or in an esoteric field generally called Orientalism. As of the fifties Asia began to loom large in the world; Asia as a whole seemed to have something special, something not to be found elsewhere. It became a place where important lessons could be learned, and the people to identify those lessons were Asianists.

Like the Orientalists, they spoke one or more Asian languages, but their orientation was on the present rather than the classical past. They typically drew insights from more than one discipline, blending history, politics, anthropology and economics. Since the late I980s, however, Asian studies came under attack from different corners. There were accusations that a cultural determinism was rife among Asianists and that they were staunch adherents to a pluralist stance in the Asian values debate which implicitly denied the universality of human rights. These attacks combined with the winds of economic realism blowing ever more strongly from the I980 onward caused a notable decline in academic and financial support for the field of Asian studies despite the increasing importance of Asia to the West.

Cribb then focuses his attention on the future of Asian studies in Australia against the background of the growing complexity of Australia's involvement with Asia beyond both bilateral government relations and the Asian studies world of the universities. Business engagements are growing and people-to-people contacts are multiplying in cultural, technological, religious and social fields. In academia, geologists, economists, engineers and a host of other researchers routinely include the study of Asia in their teaching and research. Many of them are discovering that much of modern Asia is no more difficult to understand than the United States or France. When Asia was a mystery, Asianists were the gatekeepers to a world of glittering promises and terrifying threats. As Asia becomes routine, those who want to take part in it feel that they can bypass Asianists. However, Cribb still sees a role for Asianists and Asian studies when he concludes that the risk of assuming that a little knowledge is enough will lead to insufficient specialists addressing complex issues that only those with a deep knowledge can tackle effectively.

\section{The Eurasian Space}

Yeo Lay Hwee in her contribution 'The Ebb and Flow of ASEM Studies' explores Europe's and Asia's 'rediscovery' of each other in I996 with the launch of the 
high profile leaders' summit in the form of Asia-Europe Meeting (ASEM). ASEM is the official abbreviation for the Asia-Europe Meeting, an informal forum for developing dialogue and cooperation between the members of the EU, the European Commission, China, Japan, Korea and the ten members of the Association for Southeast Asian Nations. It led to a burst of writings and literature on ASEM and Asia-Europe relations; this burst of energy saw economists, International Relations specialists, Europeanists, Asianists, and a string of political and news commentators rushing to analyse, dissect, and theorize on the ASEM process. ASEM was studied not only from a policy angle but from the perspectives of diplomacy, inter-regionalism and global governance.

Interest in and study of the ASEM process has waned as the process suffers from a lack of commitment and coherence. It could even be argued that because the ASEM process lacks progress, and has been criticized for the lack of substance and substantive results, interest could not be sustained. But the death knell has not rung for ASEM as the cooperation and conflict between Asia and Europe remain real and important. ASEM may not be a central theme but it is still one of the frameworks that should be mentioned in passing when examining EU-East Asia relations, and issues on regionalism and inter-regionalism.

How does one define ASEM studies - is it in the realm of economics, politics or the international political economy; is it in comparative studies, comparing Asia and Europe and their approaches to regionalism and internationalism? The article clusters the key studies and writings on ASEM, and examines how they have added to the understanding of such a process in the real world of politics and diplomacy. Yeo surmises that it is perhaps rash to talk about ASEM studies in the same breadth as Asian studies but by looking at ASEM from different disciplines one can get a more complex and nuanced picture of how the AsiaEurope relationship is perceived.

Paul van der Velde in his 'Re-orienting Asian Studies' concentrates on developments in the organization of the field of Asian studies from the beginning of the I990s to the present, highlighting the role played by Wim Stokhof. Four major initiatives are singled out and elaborated upon: the European Science Foundation Asia Committee; Programme for Europe-Asia Research Linkages; the European Alliance for Asian Studies and the International Convention of Asia Scholars.

The European Science Foundation Asia Committee was established in 1994 at a time when interest in Europe for Asia began to rise steeply; the Committee's purpose was to bring together the fragmented forces in Europe in the field of Asian studies and it operated successfully for six years. In essence the Committee significantly enhanced the value of local research funding by building bridges 
within Europe and between Europe and Asia. The same can be said of the European Alliance for Asian Studies, established in I997, which combines the individual strengths and endeavours of eight institutes of Asian studies in Europe. One of its goals is to intensify links and communication between academic research on Asia and non-academic institutions and actors. The Programme for EuropeAsia Research Linkages had an even wider scope. It was set up in I998 as a cooperative project between institutes in Asia and Europe and was to be a network of researchers with the aim of developing a Eurasian research culture wherein issues shared by the two regions would be the driving force of study.

While the previously mentioned initiatives were about cooperation between Europe and Asia, the International Convention of Asia Scholars, launched in I997, involves the entire world in the study of Asia. The IIAS played a major role in its foundation. The main goals of the International Convention of Asia Scholars are to transcend the boundaries between disciplines, between nations studied, and between the geographic origins of the Asia scholars involved. With the fifth convention coming up in Kuala Lumpur 2007 ICAS has grown into the largest biennial Asia studies event outside the US covering all subjects of Asian studies.

A clear line of development can be discerned in all these initiatives. What started out as a plan to make Asian studies more visible at a national level gradually developed through European and interregional stages into a global process, thereby transcending the prevailing paraochialism in Asian studies. Through joint action Asia scholars were enabled to interact beyond their own discipline and region, thus enriching other (non)academic platforms and making valuable contributions to discussions at all levels of society.

\section{Cosmopolitan orientation}

The contributors to this book share an understanding that the similarities between Asia and the West are of greater importance than the otherness of Asia on which the Orientalists focused their studies. Obeyesekere makes a strong plea for the cosmopolitan inheritance of Enlightenment discourse which leaves open the possibility to use terms, concepts and ideas from one's own cultural tradition to enrich the human sciences. Therefore area studies and Asian studies in particular are all but antiquated. In its all-inclusive jacket, as put forward by Van der Veer, it has the potential of a powerful tool to come to grips with the workings of the merging of the postcolonial state and the network society in the globalizing world of the $2 \mathrm{I}^{\text {st }}$ century.

This all-inclusive approach can not only be applied to the study of a problem within a national context but can also be used to study a process such as the 
Asia-Europe Meeting. This process, which focuses on the similarities between Europe and Asia rather than on the dissimilarities, can be regarded as an attempt to address Asia's and Europe's key societal questions, such as ageing, global warming and security, in a global context.

Here Asia scholars add value to debates with their intimate knowledge of the region. As Cribb so aptly states, 'A little knowledge is a useful thing' because at no other point in time has knowledge about plural Asia become so indispensable as well as widespread. However, this does not mean that Asia scholars should remain in their ivory tower. Instead they should without hesitation take on a cosmopolitan habitus and apply their fusion of local, regional and global knowledge to all domains of society and learning. Wim Stokhof would call this process the rich tapestry of life. 



\title{
Asian Studies and the Discourse of the Human Sciences
}

\author{
Gananath Obeyesekere
}

I wrote the first draft of my book Imagining Karma (2002) as a senior fellow at IIAS and any one who has worked there must surely know the intellectual and personal debt one owes to Wim Stokhof whose devotion to the Institute and to Asian studies we are celebrating in this volume.

In the aftermath of Imagining Karma, I have, over the last few years, tried to develop some of the ideas that were implicit in the book, specifically whether Buddhist epistemology could be useful for the theoretical or methodological discourses of the human sciences. I am not talking of a 'native social science' with each one of us creating his or her nation's social science. This to me is an un-realizable fantasy. We are products of the European enlightenment even when we rebel against it and there is no way, living as we are in the $2 \mathrm{I}^{\text {st }}$ century, that we can resist Western thought in the discourses of the human sciences. That thought has become part of cosmopolitan discourse. Thus for example Indian scholars have formulated the idea of 'subaltern studies' but this important turn remains essentially a Western discourse even when many of its proponents argue against established ways of writing history. Yet, it is hard to believe that although native Asian scholars use the conventional languages of the human sciences they do not bring in the insights they have from their own historical placement, for example, their experience with colonialism and modernity and their own cultural traditions. This is true of most of our writing, mine included. I could not have written any of my books without bringing to bear on them the 'prejudices' from my historical and cultural background and I can't imagine anyone being exempt from them.

Given my own background and socialization I believe that Buddhist concepts and ideas can enrich Western thought either by positing some consonance between Buddhist and Western thinkers or by more radically suggesting that Buddhist concepts can enrich the human sciences. In this essay I will deal with the former and less radical position where I will argue that the Buddhist idea 
of 'no self' and the absence of any enduring essence within existence can be fruitfully used to critique the Cartesian paradigm long dominant in the West: 'I think, I am.' The question I pose is: what are the areas of thinking where the self or ego does not exist and the Cartesian cogito does not operate? Although the initial insight that inspired my research derived from Buddhist thought I relate that to thinkers in the Western tradition who also questioned the primacy of the Cartesian cogito. And in this sense I try to bring about an imaginary meeting between the two different Enlightenments, the European and the Buddhist.

My current project might be called the phenomenology of the visionary experience and this article is a brief restatement of a few theoretical issues raised there. As in Imagining Karma, in my studies of the visionary experience also, I begin with the Buddha mytho-biography where the Buddha-to-be (Bodhisattva) lives in luxury as a prisoner of hedonism confined to his father's palace, undistracted by the world's ills. One day he leaves the palace with his charioteer and sees the 'four signs' on consecutive days: that of a feeble old man, a sick man, a dead man with relatives weeping over the bier and finally the detached figure of a yellow robed renouncer. Disillusioned with hedonism the Bodhisattva comes to the royal palace and there he sees the sleeping women of the harem in postures of disgust, snoring and spittle forming around their mouths -- the skull beneath the skin, as it were. He then finds that a son has been born to him and he steels his heart and, bidding his wife and infant silent farewell, leaves the palace for the homeless life. Cutting off his hair and shedding his royal clothes for the vestment of the renouncer, he studies under the ascetic gurus of his time practicing extreme asceticism, now becoming, one might say, a prisoner of asceticism. But then dissatisfied with both extreme hedonism and extreme asceticism he starts to meditate hoping to discover a 'middle way' between these two extremes by engaging in meditation. He initially commences his meditation under a banyan tree and then moves to the Bodhi tree (Ficus religiosa) nearby, the tree under which he would achieve an 'Awakening' or bodhi. Facing the East, again symbolizing a rising, he decides not to move until he had found out the truth of existence and it is this discovery and its implications that I want to focus on here.

In the first watch of the night the Bodhisattva entered into the four states of meditative trance $(d h y \bar{a} n a)$ leading to complete equanimity which permitted him to recollect in all details his former existences, hundreds and thousands and hundred thousands of them. In that continuing spirit, during the second watch, the Buddha saw with his newly acquired 'divine vision' the long panorama of the passing and rising of human beings through the operation of the universal action of karma and rebirth. And in the last watch which must surely be close to dawn and to a literal awakening, he discovered the nature of error and the Four Noble Truths of 
Buddhism, and according to some accounts, the critical theory of causality known as paticcasamuppāda or 'dependant origination'. After this experience when he became the Buddha or the Awakened One, he spent another seven weeks in meditation where he met with further spiritual adventures. The most famous of these is where the daughters of Mara ('Death') entice him with the sensual passions. They tell their father Mara that some men desire virgins, others women in the prime of life, while yet others prefer middle-aged or old women and that they would take all these guises to seduce the Bodhisattva. But the Buddha still meditating on the pāramitas, the exemplary acts of self-sacrifice he had performed in his past lives, remained unmoved. After the seven weeks are over, the hero is reborn again, or in Buddhist terminology, he is the 'Fully Awakened One' (sammā sambuddha), a term which European scholars influenced by their own Enlightenment thinkers have generously sanctified as 'the Enlightenment'. The double entendre of 'awakened' is, I think, very significant: first, the Buddha has passed the liminal stage and emerged into a new life form and the founding of a new order; second, his is a spiritual Awakening, a discovery of a way of salvific knowledge.

Modern Buddhist intellectuals see Buddhism as a 'rational' religion in the Enlightenment model. Yet, for me the Buddhist ratio is radically different from both the Greek and the European Enlightenments. The Buddha's discovered the truth of existence through meditative trance; or, to express it differently, truth was discerned through a special kind of intuition. Other Buddhas had discovered the same truths before; and when knowledge of the doctrine will have faded, yet other Buddhas will arise who will rediscover it. The Platonic type of Reason or European Enlightenment rationality has second place in Buddhism: the Buddhist ratio consists of the later elaboration and discursive exposition of the intuitively discovered truths. Yet, like its European and Greek parallels, Buddhism's ratio is full of abstract terms that describe the nature of the world and the release from it, even though, at least in the Buddhist dialogues, they are embodied in a specific type of narrative framework (which is also true of their Upanishadic and Platonic counterparts). Finally, relegation of the Buddhist ratio to secondary importance is once again apparent in its soteriological stance. As in the case of the Buddha's own Awakening, forms of discursive and rational thinking must be abandoned at a certain stage in the quest for salvation. I think one can even say that the Buddha's experience under the Bodhi tree is the mysterium tremendum of Buddhism.

\section{Empirical Time and Mythic Time}

In my projected work I treat the Buddha's two Awakenings as a kind of paradigm that permits me to speculate on the nature of visionary consciousness (or unconsciousness, if you will) in general. I begin with the first Awakening where 
he sees hundreds and thousands of his former existences in all their detail float before his dimmed consciousness in the first watch of the night, that is, over a period of about four hours. During the second watch, the vision develops in a different direction from the personal to the impersonal wherein he sees human beings being born and reborn owing to the workings of karma and rebirth, the latter ideas also represented visually, rather than in discursive language. In this kind of experience empirical time, or time as we normally understand it in our waking lives, gets stretched. There is a disparity between normal time and dream time, or between time measured by the clock and visionary experience, such that we can dream of long episodes in a few short time-bound moments. I would like to extend this thesis and make the case that in many ways the Buddha's experience has its precursor in the dream experience as Freud described it in his pioneer work, The Interpretation of Dreams.

Although Freud noted that the compression-expansion of time was a feature of dreams he, unfortunately, did not think it central to the dream work. Freud describes the experience of a 'dramatic author' named Casimir Bonjour who wanted to sit close to the stage during the first performance of one of his pieces. "[B]ut he was so fatigued that as he was sitting behind the scenes he dozed off just at the moment the curtain went up. During his sleep he went through the whole five acts of the play, and observed the various signs of emotion shown by the audience during the different scenes. At the end of the performance he was delighted to hear his name being shouted with the liveliest demonstrations of applause. Suddenly he woke up. He could not believe either his eyes or his ears for the performance had not gone beyond the first few lines of the first scene; he could not have been asleep for more than two minutes" (Freud I900: 536).

The brilliant psychotic Daniel Paul Schreber also mentions a similar compression-expansion of time in the visions he describes in his memoirs. "From the sum total of my recollections, the impression gained hold of me that the period in question, which, according to human calculation, stretched over only three to four months, had covered an immensely long period, it was as if single nights had the duration of centuries, so that within that time the most profound alterations in the whole of mankind, in the earth itself and the whole solar system could very well have taken place" (Schreber 2000: 76). Again: "I was sitting in a railway carriage or a lift driving into the depths of the earth and I recapitulated, as it were, the whole history of mankind or the earth in reverse order; in the upper regions there were still forests of leafy trees; in the nether regions it became progressively darker and blacker" (Schreber 2000: 78-79). He left the vehicle temporarily and saw a cemetery with his wife's gravestone. This is expectable because he is seeing mankind's 'devolution' not evolution, beginning in reverse 
order from time future into time-past, rather than the other way around. In other words he believes that the time expansion he experienced could have been just as real as the Buddha's vision of the arising and rebirth of countless existences. The difference is that the Buddha's is a vision of the past which is not the reversed time of Schreber. Yet, Schreber believes his expanded time was real time and that real devolutionary changes had taken place on earth. One might add that in driving down into the depths of the earth Schreber is also delving (albeit without selfawareness) into the depths of his psyche. I want to caution the reader, however, that although I show the striking parallelism between powerful religious visions, dreams and psychotic delusions I am not trying to reduce one to the other but to demonstrate the phenomenological similarity between these seemingly different substantive domains.

\section{The overcoming of space restrictions}

What about space and how are visions related to space? This is a complicated question because in Buddhist visions, especially in Mahayana and Tibetan Vajrayana, space is virtually illimitable and visionaries experience space adventures of a fantastic nature surpassing shamanic visionaries in their cosmic travels. The question of the visionary filling up space with images is too complex an issue for me to deal with here. Instead, following the preceding argument regarding empirical and mythic or episodic time, I shall deal with the visionary expansion of restricted empirical space, that is, a distinction between empirical space and mythic space. Visionary texts in all traditions abound in this kind of material but I shall simply give a few illustrative examples.

I. The first is from the Bhagavata Purāna, the great text of devotional Hinduism. "One day, when Krishna was still a little baby, some boys saw him eating mud. When his foster mother, Yasoda, learned of it, she asked the baby to open his mouth. Krishna opened his tiny mouth, and, wonder of wonders! Yasoda saw the whole universe - the earth, the stars, the planets, the sun, and the moon and innumerable beings - within the mouth of Baby Krishna. For a moment Yasoda was bewildered thinking, 'Is this a dream or a hallucination? Or is it a real vision, the vision of my little baby as God himself?”(Prabhavananda I943: I90).

2. Here is Julian of Norwich: "And I was still awake, and then our Lord opened my spiritual eyes and showed me my soul in the middle of my heart. I saw my soul as large as it were a kingdom; and from the properties that I saw in it, it seemed to me to be a glorious city. In the centre of that city sits our Lord Jesus, true God and true man, glorious, highest Lord: and I saw him dressed imposingly in glory" (Julian of Norwich I998: 33). In both the Bhagavata 
Purana and Revelations of Divine Love, the vision of expanded space could be simultaneously literal and symbolic or at the very least it is a parable about God. But there are many Christian mystics such as Saint Theresa of Avila who would stare at a small crucifix; and suddenly the vision expands as the mystic sees the whole historical scenario of the passion of Christ as it actually occurred.

3. And here is the Tibetan space traveler and seeker of hidden Buddhist texts Pemalingpa (I450-I5I9) writing in a similar vein but in his case dealing with the contraction of a large space into a miniscule one: "I had a bamboo hut erected on the hill called Sershong above the monastery and while we, the lord and his disciples, were staying there I made the disciples attend to their training. While I was staying in retreat there for three months I had sight of the whole world like a myrobalan flower placed in the palm of one's hand, entirely clear and pure" (Aris I989: 43).

Tibetan Buddhism is full of descriptions of visionary explorations of the Buddhist cosmos brought about through meditative trances. During trance states the virtuoso might even have visions within visions within visions and in them we can see in great detail multiple forms of space and the time contraction-expansion I have mentioned.

\section{Modes of Thought: the 'It' and the ' $\mathrm{l}$ ' in visionary experience}

Let me now go back to what I think is meant by the Buddha giving primacy to knowledge acquired through concentration which requires the abandonment and emptying of the mind of discursive knowledge and its re-adoption after the experience is over when he has to describe his experiences to his disciples or congregation. In my view a special kind of thought operates in his meditative askesis: the agency involved is not the 'I' of the discursively reasoning and active consciousness; rather it is the 'It', if one wants to use Nietzsche's term (not to be confused with the Freudian 'id' even though Freud was influenced by Nietzsche, at least indirectly and both used the German term das Es). Nietzsche says in Beyond Good and Evil: "A thought comes when 'it' wishes and not when 'I' wish, so that it is a falsification of the facts of the case to say that the subject ' $\mathrm{I}$ ' is the condition of the predicate 'think.' It thinks: but that this 'it' is precisely the famous old 'ego' is, to put it mildly, only a supposition, an assertion, and assuredly not an immediate certainty" (Nietzsche I956: 24). For Nietzsche even 'It-thinking' is tainted with agency, compelling one to think "according to grammatical habit" (Nietzsche I956: 24). When one analyses the phrase "I think," says Nietzsche, there are assumptions that are difficult, perhaps impossible, to prove: for example, that it is ' $\mathrm{I}$ ' who thinks; that there must be something that thinks; "that thinking is an 
activity and operation of the part of a being who is thought of as a cause, that there is an 'ego,' and, finally, that it is already determined what is to be designated by thinking - that I know what thinking is" (Nietzsche I956: 23). These erroneous views of the ego are the 'superstitions of logicians'. One cannot infer from our use of the 'I' an entity known as the Ego or Self and beyond that to an entity known as the soul (and of course God) which was how Descartes reasoned in his third and fourth discourse on method. It seems that Nietzsche is highlighting a form of thinking, seemingly without agency, and for purposes of convenience I will borrow his trope and call it 'It-thinking'. I do not, however, believe 'It-thinking' is the only way of knowing or that it is preferable to 'I-thinking'; except that it supplements I-thinking and it is a way of thinking that has virtually gone out of vogue in Europe with the Cartesian 'I think, I am.'

So with the Buddha: knowledge appears before the Buddha in his state of intense concentration which gives him the capacity for 'divine vision'. Not only can the Buddha see the coming into being and disappearance of people and worlds but thoughts also can appear before him. I believe that the Buddha's spiritual experience entails the furthermost development of the kind of 'thinking' that Freud formulated in the dream work. One must therefore return to the dream book to reconsider Freud's insights about 'It-thinking'. To begin with consider Freud's emphasis on the visuality of the dream emphasized by him in several memorable phrases. Thus dreams are "thoughts transformed into images". Or: "A thing that is pictorial is, from the point of view of a dream, a thing that is capable of being represented; it can be introduced into a situation in which abstract expressions offer the same kind of difficulties of representation in dreams as a political article in a newspaper would offer an illustrator" (Freud I900: 340). "A dream thought is unusable so long as it is expressed in an abstract form"; it has to be "transformed into pictorial language". These examples could be multiplied. Freud also notes that the causal and logical thought processes that are associated with the waking consciousness cannot appear in the dream without being reformulated as indirect representations. He even asserts that 'no' cannot be represented in dreams except in sequential visual scenarios.

Aside from its visuality the dream simply appears before one's dimmed and diminished consciousness. They are 'showings', a term that Julian of Norwich uses to describe the passive appearance of her visions. In Freud's thinking even the dark 'dream thoughts' that precipitated the manifest dream merely rise to the surface with the near-suspension of the active consciousness during sleep. The 'I' does not evoke them. In dreams "we appear not to think but to experience; that is to say, we attach complete belief to the hallucinations" (Freud I900: 83). What he means is that the protagonist believes in the truth of what he sees during the 
space-time of the dream or the vision or the psychotic delusion. The hallucinatory features of dreams appear when "some kind of 'authoritative' activity of the self has ceased" (Freud I9०0: 83). In other words Freud is asserting, I believe, that though dreams are 'completely egotistical' the 'I' appears as a picture or is externalized into images that float before us in our state of sleep. Hence in a dream the mind functions like a "compound microscope or a photographic apparatus" (Freud ı9o०: 574). The 'I' does not think and cannot think in the dream; the undefined 'dream ego' in Freud is not the ego of the waking consciousness (Freud i990: 340).

We all know that for Freud the Ego is not the master in his own house owing to the power of unconscious thought, thus implicitly at least dethroning the primacy of the Cartesian consciousness. Nevertheless, though not explicitly stated, the dream book implies an even more radical position. The 'I' or Ego does not appear in the formation of the dream in the first place. The physical person of course appears in the dream but pictorially, on a screen as it were, outside of the thinking 'I'. What is striking about the dream work - the processes that transform thoughts into images - is that condensation or metaphor and displacement or metonymy can occur without the 'I' being involved, though this is not how Freud himself formulated the issue. Even the 'censor' - the dormant conscience of the dreamer that in vetting the dream distorts it - is a kind of mechanism that operates without the silently thinking 'I' or the superego of Freud's later thought. It seems that the dream book introduces a radical model of the mind which eliminates the ego, or self or I and yet, paradoxically, introduces a form of 'agency' (if one can call it that) that is totally impersonal. Thus the Freudian model (sometimes labeled as the 'first topography') which I have extrapolated from the dream book is not the structuralist one which eliminates agency but one that entails a special form of agency.

\section{The other Nietzsche: daybreak and aphoristic thought}

Now let me consider the paradigmatic significance of the dawn watch, when the Buddha discovered the Four Noble Truths of Buddhism and the doctrine of conditioned genesis. Conditioned genesis is the doctrine that confirms the idea that there is no essence within existence by stipulating that each event is conditioned by previous ones and therefore in this relativistic world of unremitting change there is no still point. Essences are Unconditoned and not subject to change whereas even the salvific goal of Nirvana, later thinkers like Nagarjuna argued, shares the condition of change alongside samsara, the cycle of existences. The doctrine of conditioned genesis has been described in great length and with varying degrees of abstraction in Buddhist discourses but in my thinking those complex theoretical formulations could not have been the way they appeared to the Buddha during the dawn watch of his Awakening. 
To demonstrate this, I will leave the Buddha alone for the moment and consider Nietzsche's own visionary consciousness which few have noted, followed by his aphoristic thinking for which he is justly famous. Nietzschean visions were reported by Resa von Schirnhofer around mid-August I884 in Sils-Maria, about 6000 feet above sea level, where Nietzsche stayed at a hotel for several years after I884, though not continuously. She mentions that after Nietzsche had remained invisible for one and a half days owing to his endemic illness, she and a friend visited him one morning. "As I stood waiting by the table, the door of the adjacent room on the right opened, and Nietzsche appeared. With a distraught expression on his pale face, he leaned wearily against the post of the half-opened door and immediately began to speak about the unbearableness of his ailment. He described to me how, when he closed his eyes, he saw an abundance of fantastic flowers, winding and intertwining, constantly growing and changing forms and colors in exotic luxuriance, sprouting one out of the other. 'I never get any rest,' he complained, words which were implanted in my mind. Then, with his large, dark eyes looking straight at me he asked in his weak voice with disquieting urgency: 'Don't you believe this condition is a symptom of incipient madness? My father died of a brain disease'" (Gilman I987: i64). Thus it seems that in spite of his Dionysian ideals, Nietzsche seemed unable to incorporate his visions (whether spontaneously evoked or provoked by his medications) into his being. Instead, in rational fashion he related them to his inherited madness, thus pathologizing them as his middle-class contemporaries did, failing to incorporate these fantastic visions of burgeoning life into his Dionysian world-view.

Nietzsche was an ascetic wanderer living under the shadow of chronic disease and dread of madness, never in one place for long, rarely in his German homeland. Many a friend or stranger noted this. Paul Lansky, an older acquaintance, calls him 'the wandering philosopher' and 'the former professor, now a fugitive' (Gilman I987: I74, I78). Victor Helling dubbed him the 'great hermit of SilsMaria' (Gilman I987: 2I). Once Nietzsche while walking with a stranger, Sebastian Hausmann, the latter reported: "I constantly had the feeling that his thoughts spouted forth in an astonishing excess, literally crowding one another" just like, I would add, the flowers of his later vision (Gilman I987: 135). And the same observer says a bit later: "He spouted his thoughts forth, more in the form of aphorisms, always leaping one to the other" (Gilman i987: 139). Another reporter noted in September I 885 the philosopher wandering in a 'heroic landscape' of Sils Maria: "The sight of the wanderer striding with a rapid step and upright head in the evening sun will always remain unforgettable to me" (Gilman I987: I88). It was in this solitude that the aphorisms of Daybreak, The Joyful Science and Beyond Good and Evil were written according to Paul Lansky. 
I suggest that it is in such silent meditative contexts that aphoristic thinking emerges into consciousness without an intrusive 'I' and no wonder our wanderer could speak to his shadow on the importance of 'It-thinking'. Visions are not Nietzsche's forte; but not so with his non-discursive silent thoughts re-expressed by him through the literary genre of aphorisms. For Nietzsche, as for Wittgenstein, aphorisms became the vehicle for the expression of It-thoughts; needless to say they could be expressed in other ways also. Malwida von Meysenbug reports that it was Nietzsche's acquaintance with the French moralists that "led him to express his thoughts in aphorisms" (Gilman I987: 84). This observation was confirmed much later by Lou Salome: "For many years he [Nietzsche] had been walking around with a La Rochefoucauld or a La Bruyere in his pocket and he had retained this same mentality ever since in his first little book, On Vanity" (Gilman I987: II8). But it is a mistake to confuse the French model of aphorisms for Nietzsche's need or motivation to give aphoristic expression to his most profound thoughts.

The aphoristic mentality - the mentality that converts non-reflexive thought into aphorisms - does not arise from deep trance. It only requires moments when active egoistic thinking is in abeyance, as in our paradigmatic case of the third watch of the Buddha's Awakening. As in the case of dreams one cannot capture such thoughts as they emerge into consciousness but, as with dreams, one has to be satisfied with the remembered text. In I877, a year before he left the University of Basel to become a wandering ascetic, Reinhardt von Seydlitz reports that Nietzsche "kept next to his bed a slate tablet on which, in the dark, he jotted down the thoughts that came to him on sleepless nights" (Gilman I987: 9I). This was in Sorrento where there were a small group consisting of friends and disciples, including von Seydlitz. They were with him for thirty-five days but "for seventeen of them, however, our friend was sick; on eighteen days did we enjoy his company" (Gilman I987: 9I). There "he walked with his head leaned back, like a Sorrento prophet, with half-closed eyes, through the long avenues of blossoming orange trees. ... His manner of speaking was undramatic and matter of fact; in the simplest tone of voice he could pronounce sentences which were so seminal and significant that they seemed spoken sub specie aeterni" (Gilman I987: 92). I will borrow Lou Salome's phrase and label his silent thinking processes as the 'aphoristic mode of work' (Gilman ı987: II8). Much later in I884 in his favorite place Sils-Maria, Resa von Schirnhofer recounts this marvelous piece of advice given by the master himself: "keep paper and pencil in hand at night, as he himself did, since at night we are often visited by rare thoughts, which we should record immediately on awakening in the night, for by morning we usually not find them again, they have fluttered away with the nocturnal darkness" (Gilman ı987: 149). 
"The gestation of all really great creation", Nietzsche mused sentimentally, "lies in loneliness" (Gilman I987: 128). But this loneliness is not the solitude demanded by European romantics such as Wordsworth although for both Wordsworth and Nietzsche and others like them solitude is something cultivated, like Andrew Marvell's garden, the 'delicious solitude' into which the poet escapes. Our kinds of solitude seekers cultivate the space of silence that permits It-thoughts to emerge into consciousness. Thousands seek solitude; and modern packaged tours tout them; but not the cultivation of solitude which is like the cultivation of meditation. And Wordsworth it should be remembered talked of the 'inward eye' that visionaries also speak of. Yet, visions and 'waking dreams' were something impossible for Wordsworth and the Romantics to achieve after the preceding tyranny of the Enlightenment. The Romantic recollections in tranquility or their evocation of the fantastic in poetry is far removed from truth-seekers like Nietzsche and the virtuosos who inhabit my current thoughts.

Nietzsche's solitariness entailed a secular form of the dark night of the soul of those hermits, sages, shamans and ascetics well-known to us. No wonder the person who perhaps knew Nietzsche best, Lou Salome, found his thought and his solitary wandering life as an expression of a 'mystical' trait and that, at some level he was 'a religious genius' (Salome 200I: 24). Nietzsche told Ida Overbeck that though he had rejected the Christian god, he well might "perish from my passions, they will cast me back and forth; I am constantly falling apart, but I do not care" (Gilman i987: I45). His work style, as Resa von Schirnhofer noted, consisted of "intensive work in brooding solitude" (Gilman I987: I46); and an acquaintance Richard Reuter wrote of him as "a lonely man, seeking and loving loneliness, yet suffering deeply and painfully from it, lonelier of soul than any hermit ever was" (Gilman i987: 82). Naturally, one might say, for here was a man suffering from painful illnesses, from the dread of impending death and oncoming madness. When he was abandoned in I882 by Lou Salome, the one woman he truly loved (though in his own fashion) Nietzsche could say that during the winter of his gloomy discontent he had become like Timon of Athens. And owing to his sister's jealous hostility to Lou, Nietzsche mournfully noted that "this internal conflict is pushing me step by step, closer to madness" (Hayman i980: 267).

It is now time to leave Nietzsche temporarily and get back to the Buddha's paradigmatic Awakening and the discovery of the Four Noble Truths of Buddhism and dependent origination during the dawn watch. It is the latter discovery that I want to deal with here because part of my larger project pertains to the discovery of knowledge through visionary experiences. It is immaterial to me whether the historical Buddha actually had this experience; it is only necessary to recognize that the Buddha mythos recognizes the truth of It-thinking. The dawn watch is 
when thick trance is thinning out, the 'daybreak' as Nietzsche calls it, and opens one's dimmed consciousness to aphoristic thinking. In this and similar conditions there is a passive cerebral activity going on; or the condition wherein the "passive intellect' is at work, to use a phrase from John of the Cross. We can only guess the manner in which this doctrine first emerged by considering the following dense formulaic statement that appears in several early Buddhist texts:

When this is, that comes to be;

With the arising of this, that arises.

When this does not arise, that does not come to be;

With the cessation of this, that ceases (Nanamoli and Bodhi I995: 927).

To my mind this is the kind of aphoristic formula that is fully consonant with the third and final watch opening into daybreak. Aphoristic thinking condenses It-thoughts, just as dreams might be condensation of images. When I put my thoughts down on scraps of paper as I go for walks and get lost in thoughtlessness I, like the lonely Nietzsche, have condensed thoughts (sometimes insights) that I quickly jot down and then throw them out in disgust or expand them into discursive writing, although not as aphorisms. Even with Nietzsche or Wittgenstein, the written aphorism can be interspersed with I-thinking. Yet, when written aphorisms are close to their original aphoristic thoughts they possess an enigmatic quality. They are thick with meaning and frequently require exegeses, either by the author or by others, for them to be fully comprehended. In the Buddhist case, after the formula is initially stated it is later rationally elaborated and fully explicated by the Buddha and given further conceptual development in the various schools of Buddhist logic. The enigmatic, thick, often poetic nature of aphorisms defy translation and are amply demonstrated in Nietzsche's work and in the work of another wandering ascetic and so-called 'mystic,' Wittgenstein, in the opening propositions of the Tractatus Logico-Philosophicus:

I. The world is all that is the case.

I.I The world is the totality of facts, not of things.

I.II The world is determined by the facts, and by their being all the facts.

I.I2 For the totality of facts determines what is the case, and also whatever is not the case.

I.I3 The facts in logical space are the world.

I.2 The world divides into facts.

I.2I Each item can be the case or not the case while everything else remains the same (Wittgenstein I974: 5). 
And so on and so on .... But whether it is Nietzsche or Wittgenstein, aphoristic thought is hostile to footnotes or bibliographical references. These would distract from, and dilute, the power of the aphoristic message.

\section{The Fully-Awakened One: the paradigmatic significance of the attack by Mara}

The Buddha's first Awakening was powerful, although brief, if one measures time by the clock. The second was more prolonged, in which he is attacked by Mara, the Being of Death, with multiple weapons but the weapons are harmlessly deflected owing to the power of the Buddha's perfections. I want to focus on the daughters of Mara who tempt the sage with their sexual blandishments and who symbolically constitute the return of the women of the harem but without their masks and marks of disgust. They also represent the return of the repressed threatening to break through the controls imposed by asceticism. Nevertheless, eroticism cannot tempt the sage because he now beyond desire or tanha and desire or craving or greed is the cause of the world's suffering. When desire is eliminated through techniques of meditation the Buddha enters the four stages of trance. Then nirvana happens. With this happening occurs he becomes the Fully Awakened One.

To me the paradigm of the second Awakening has further implications. As a founder of an ideational system, the Buddha discovered the truth for the first time through meditative askesis. Then he has to proclaim the intuitively discovered truths to his disciples and his audience and this has to be through discursive I-thinking. The discursive representation of the visionary 'thoughts' is full of abstract language and conceptual formulations, such that one can speak of these later formulations as the 'Enlightenment' and the spiritual experience under the Bodhi tree as the Awakening. Thus in Buddhism there is a constant interplay between the It and the I. Further, like Freud the Buddha is his own guru. Perhaps the Buddha's Awakenings can help us re-reflect on Freud. One can say with some justification that Freud discovered psychoanalysis or at least some of its central features through his own dreams (Anzieu I986); and in this sense he also joins the ranks of those visionaries who will appear in my larger project. Having invented psychoanalysis Freud became his patient's guru. If indeed much of psychoanalysis was discovered through Freud's dreams, then it shouldn't surprise us that mature psychoanalytic therapy carries out its own Enlightenment project when the will has been partially suspended. In my view the ideal goal of the Freudian technique of free-association is to bring a recollection of a lost past without the mediation of the 'I', even though this ideal is rarely realized. In mature psychoanalysis the analysand lies on the couch and the analyst is the 
silent supportive being analogous to the kalyāna mitra or 'true friend' of Buddhist meditation, the guide or mystagogue who assists the seeker to overcome the terrors of the fantastic or the dark night of the soul or the terrifying cliffs of fall (or whatever you want to call it) in the early stages of deep Buddhist meditation. Like the analyst the kālyana mitra acts as a stand-in for the rational consciousness of the meditator that has been temporarily suspended, such that, the meditator can in his maturity bring about a coexistence of the I and the It. Thus, Hilda Doolittle says of her experience of recall during her psychoanalysis by the Master himself: "I wish to recall the impressions, or rather I wish the impressions to recall me." Again: "Let the impressions come in their own way, make their own sequence" (Doolittle 1956: 14). Hilda Doolittle's example suggests that other kinds of thoughts or ruminations or the voices of the passive intellect or the "not thinking of anything thought" (a nice phrase formulated by my favorite psychotic Schreber) can appear in the mind when discursive 'I-thinking' has been partially suspended as in free-association and related conditions.

The Buddhist meditative askesis is the furthermost development of 'Itthinking' and no wonder the Buddha says that one must suspend discursive thought ('I-thinking') as a prerequisite to achieving the former and this in turn entails overcoming the false notion of 'I' or the self/Self according to Buddhism. The crux of meditation is to develop 'It-thinking' both in its visual and imagistic forms and what I might tentatively call its free-associational forms such that even philosophical ideas ('truths') appear into the field of the thinker's vision or unconsciousness without the mediation of egoistic discursive thinking. William James makes a similar point in relation to the 'noetic quality' of mystical knowledge: "[M]ystical states seem to those who experience them to be also states of knowledge. They are states of insight into depths of truth unplumbed by the discursive intellect. They are illuminations, revelations, full of significance and importance, all inarticulate though they remain; and as a rule they carry with them a curious sense of authority for after-time' (James I982: 380-8I).

However, it is entirely possible, and likely, that the visions generated through meditative trance are based on prior 'thoughts' regarding which we know very little. What we do know is that once the truths have been discovered intuitively through the special agency of the 'It', there is a later process, a truly 'secondary process', whereby the thinking 'I' reappears and gives discursive meaning and significance to these intuitively discovered truths, including their formulation as abstract concepts. It is I think no accident that it is in the last watch of the night, prior to the arrival of dawn's bleak reality that the sage discovered such abstract notions as 'conditioned genesis' and the four noble truths. It is in this sense - that 
of the later rational and abstract formulation of intuitively discovered truths - that one can speak of a Buddhist 'Enlightenment" comparable with the European and the Greek.

\section{Bibliography}

Anzieu, Didier. Freud's Self-Analysis, London: The Hogarth Press, I986.

Aris, Michael, Hidden Treasures and Secret Lives: A Study of Pemalingpa (1450-1521)

and the Sixth Dalai Lama (1683-1706), London: Kegan Paul, I989

Doolittle, Hilda (H.D.), Tribute to Freud, New York: New Directions, I984

Freud, Sigmund. The Interpretation of Dreams, Standard Edition, two vols., London: The Hogarth Press, I98I.

Gilman, Sander (ed.), Conversations with Nietzsche, New York: Oxford University Press, iو87.

Hayman, Ronald, Nietzsche, A Critical Life, London: Phoenix, I995.

James, William, The Varieties of Religious Experience, New York: Penguin, I982 (I9O2).

Julian of Norwich, Revelations of Divine Love, translated by, Elizabeth Spearing, London: Penguin Books, I998, 33.

Nanamoli, Bhikkhu and Bodhi, Bhikkhu (trans.), 'Bahudhātuka Sutta [The Many Kinds of Elements]', The Middle Length Discourses of the Buddha, Kandy: Buddhist Publication Society, I995: 927.

Obeyesekere, Gananath, Imagining Karma: Ethical Transformation in Amerindian, Buddhist, and Greek Rebirth, Berkeley: University of California Press, 2002.

Salome, Lou, Nietzsche, translated and edited by Siegfried Mandel, Urbana and Chicago: University of Illinois Press, 200I (I894).

Schreber, Daniel Paul, Memoirs Of My Nervous Illness, trans., Ida Macalpine and

Richard A. Hunter, New York: New York Review of Books, 2000 (I903).

Wittgenstein, Ludwig,Tractatus Logico-Philosophicus, translated by D.F. Pears and B.F. McGuinness, London and New York: Routledge, I974. 



\title{
Area Studies in a Changing World
}

\author{
Petervan der Veer
}

The study of Asian Languages and Cultures in the Netherlands and in the rest of Western Europe has been declining for the last 30 years. Less funding is available for what are called 'exotica' and fewer students are willing to take them up. Apart from Chinese and Japanese it is not immediately clear how knowledge of an Asian language would improve one's prospects on the labour market. It is within this climate of decline that the International Institute for Asian Studies, combining social sciences and humanities, in the Netherlands has emerged. When it was founded with Wim Stokhof as its director, area studies had already received a wide array of criticism.

There are three lines of criticism. The first is that the social sciences attempt to produce universally valid knowledge rather than area-specific-knowledge. The second is that area studies directly relate to the economic and military interests of Western powers. The third is that in the era of globalization the boundaries between regions are not significant enough. I want to address some of these issues and go on to show that Asian studies in the Netherlands are important for the study of Dutch society. Mutatis mutandis this argument could also be made for Asian studies elsewhere.

\section{Dreams of universal validity}

In general social scientists attempt to produce theories as universally valid as those formulated in the natural sciences. The desire to acquire such powerful knowledge of human society is quite understandable. The natural sciences have produced knowledge in an impressive number of ways that has changed the world. Freud believed that his explanations of human behaviour were interpretive approximations of knowledge that could only be more fully understood through advances in neurobiology. Psychology combines the study of cognitive science and neuroscience to find better explanations of human action. The biologist, E.O. Wilson, has suggested ways in which genetic research could be combined with ethology to create a sociobiology that would be powerful enough to explain human behaviour. In linguistics Chomsky has formulated a research program that would 
ultimately result in understanding a universal grammar rooted in the human mind. The subjects of economics, mathematics and game theory are increasingly used to create models to predict universal human economic behaviour. Statistical manipulations of large data-sets increasingly dominate not only economics but also sociology and political science.

These attempts, however impressive and understandable, have not had universal success. Up to today sociobiology still seems very much in its infancy; Chomskeyan linguistics has been unable to fulfil its promise; our understanding of the working of the human brain is still very limited; and economics does not seem to be able to predict economic crises. Considering the state of world affairs today one may wonder whether we have a better understanding of human social behaviour than at the beginning of the terrible $20^{\text {th }}$ century, which saw huge levels of human devastation.

There are, obviously, dissident voices and they have been there from the beginning. Some scholars in the humanities and social sciences doubt that universal explanations of human behaviour are possible. They argue that they deal with aspects of human behaviour that can best be understood by interpreting texts and documents, by observing individuals or small groups of people rather than using opinion surveys or mathematical models of capital flows. An important aspect of that argument is that often societies are universal to the extent that they have culture, but particular to the extent that they have a culture. In one way or another, the argument about culture is crucial to positions that reject 'scientistic' forms of study of society. To be found in this camp are historians, cultural anthropologists, comparative linguists, philologists, students of comparative religion. It is a rather marginalized camp if one considers power in funding and influence on society, although one should not underestimate the significance of the study of culture in defining national identity. It was the dominant mode of scholarship before the spectacular expansion of the natural sciences in the second half of the $19^{\text {th }}$ century. In that sense it is also very close to 'tradition' as an object of study but also as a form of knowledge, although the methods of inquiry are being constantly innovated and are fully modern.

\section{European Modernity}

There were significant advances and breaks with the past in the rise of history, philology and linguistics as scholarly disciplines in $\mathrm{I} 8^{\text {th }}$ century Europe that were part of the Enlightenment and Romanticism streams of European modernity. We do not know whether there have been equally significant ruptures in other civilizations and one reason that that is difficult to find out is because these societies have all come under the impact of interactions with imperial and colonial 
powers from Europe. Western science, and also Western scholarly methods in the study of culture and history, spread to the rest of the world and became foundational for the new universities of the $I 9^{\text {th }}$ century. Western scholarship may not claim to be universal in its attention to plurality and diversity but it provides a model to which all other scholarship refers. The philological understanding of the Bible thus becomes a model for the philological understanding of other sacred books in other traditions. Western scholarship is not universal but it is universalizing. The consequences of this universalization of Western knowledge still have to be understood and partly are still underway, as can be seen from the violent responses to Nasr Abu Zayd's historical analysis of the Qur'an which obliged him to flee Egypt.

The development of the humanities and social sciences in the nineteenth century has to be seen in relation to the European Expansion. The founders of sociology, psychology, economics, cultural anthropology were all deeply interested in comparative research that would enable them to create universal knowledge that would extend to all mankind. That comparative method was dropped by those who chose to follow the experimental, theory-driven path of the natural sciences, as I have observed above. It was also dropped by those who saw European modernity as the destiny of all and thus saw the necessary object of study as being the modern individual and modern society. This development was further enhanced by decolonization after WWII. American social science with its focus on American industrial and later post-industrial society became the model and comparative research went out of fashion. The practical need for knowledge about colonized societies also decreased with decolonization, at least for the European powers. The Americans, however, especially in their cold-war struggle with the Soviet-Union, really only started to become interested in what they called 'Area Studies', but considering their great resources, they quickly became central in this field, as in most others.

The founding of the first area studies program in the United States is a typical story: the Department of South Asia Regional Studies at the University of Pennsylvania was founded by the Sanskritist Norman Brown in I948 and received federal money from I950. Brown pointed out that during the war far too few experts on the South Asian region could be found to serve in the US military and that in postcolonial conditions knowledge of this region would be essential to serve American interests. His view of the kind of knowledge required can be called Orientalist. Understanding the contemporary political, economic, and cultural conditions of South Asian societies had to be based on a thorough training in the study of South Asian civilization. While Brown thus firmly intended to promote understanding and exchange between South Asia and the US, his scholarly point 
of view was essentialist and steeped in American liberal moralism. Similar stories can be told of all the American area programs, such as the missionary influence on the study of China at Harvard. In I958 the National Defence Education Act, Title VI, was passed and led to considerable federal funding for area programs.

Edward Said's critique of Orientalism in the study of the East in both the colonial period and in the postcolonial period can be accepted if one looks at structures of funding and motivations for building programs. Other voices have added to this critique by claiming that areas, already difficult to delineate in the first place, are no longer prominent in the current phase of globalization - flows of goods and persons traverse the globe with incredible speed and global markets are more important than regional ones; the internet does not stop at area boundaries and English has become a global language for trade and communication. Why not study Chinese and Indian networks that are global, instead of being bound within the Asian area? While this is partly true, one should not underestimate the resilience of area and national boundaries and of linguistic diversity. One may argue that it is precisely area studies that allow one to gain a proper perspective on the variety of forms of globalization. Instead of making an opposition between studying one's own society or Western society as against studying the rest of the world it seems clear to me that the West cannot be understood without studying the rest at the same time. In the remaining part of this essay I would like to discuss one such example that is particularly relevant for a variety of social sciences and humanities disciplines, and that is both historically salient and important for current affairs: namely, the relation between the Dutch state and Islam. This is also a field in which Wim Stokhof has made a significant contribution by creating programs to train Indonesian Muslim students in the Netherlands.

\section{The Empire Strikes Back}

In the Netherlands and in other Western countries one finds a hostile image of Islam. Only recently we saw this image influencing the panicky reactions to the terrorist attack on the USA by Arab Muslims. With great speed this attack was connected to statements of a general nature on the essence of Islam and of Muslims. Dutch politicians and Islam-scholars spoke in public about the age-long frustration of Muslims that was the background of this attack. Almost immediately the question of the loyalty of Muslim immigrants to the Dutch state and to Dutch norms and values emerged in public debate. Opinion polls quickly showed how fickle that loyalty is and how methodologically shaky opinion polls are. This was followed by attacks on mosques and Islamic schools. It is self-evident that there is urgent need for a more sophisticated analysis of the relationship between the Netherlands and Islam. 
The general view is that Islam in the Netherlands is a very recent phenomenon. That is certainly true if one only looks at the Netherlands on the North Sea and at the immigrants from Turkey and Morocco. However, a more extended historical and geographical perspective demonstrates that the Dutch state, like other European states, such as England and France, has dealt with Muslim subjects for a long period. I am referring to the overseas colonies, such as of Indonesia and Suriname, whose decolonisation has been as much a part of the emergence of a postcolonial world as the new forms of labour migration to Western Europe and to other regions. A nationalist perspective in which the Netherlands on the North Sea forms the frame for understanding social cohesion in the multicultural society can never provide an understanding of processes of globalization, the rise of the network-society, and the North-South problematic. Understanding these is essential for dealing with the problems the Netherlands is facing. The simple fact that the Dutch government acknowledges only now that the Netherlands has become an immigration country shows the long-term nationalist denial of global processes. In the English literature on the multicultural society what I am stating here is expressed in the slogan 'The Empire strikes back'. In the case of the UK and France this seems more evident, since many immigrants come from former colonies, but in fact this is part of the same historical transition. In short: West-European states colonized peoples and territories overseas and modernized themselves and their colonies, a process resulting in a worldsystem of independent nation-states. In the final stages of this process a reversed migration from the South to the North has emerged, and nation-states that are in principle independent are attempting to control this flow of people.

The Netherlands is at present a postcolonial society, an immigration country with a relatively large number of immigrants who practice Islam. Not so long ago the Netherlands was a colonial society in which the majority of the population was Muslim. In my view the 'question of Islam' in the colonies can in a number of aspects fruitfully be compared with the current problematic of the integration of Muslims in the Netherlands. The present postcolonial government, as the colonial government before it, tries to make Muslims into modern citizens, but it is hard to combine this policy with the principle of the separation of church and state.

According to influential, liberal policy-makers in the early twentieth century, such as Christiaan Snouck Hurgronje, the task of the colonial state was to make Islam into a modern religion. This meant secularisation, that is to say a separation of church and state, and furthermore an opposition to militant Islam. It does not mean that the government should interfere with the religious character of Islam. In the liberal view the principle of freedom of religion has to be maintained. Freedom of religion, however, does not imply cultural relativism. It was seen 
as the task of the colonial government to effect a change in the backwardness of Muslims, which the government should do slowly and prudently. On the other hand, however, the state had to repress the mixture of religion and politics in Islam, because it obstructed progress. In short, Indonesians were allowed to be Muslim, but they should not organize themselves on the basis of Islam. Education was seen as an instrument to be used for modernizing Muslim society. Muslims had to be educated in Dutch (secularised) culture in order to get past the political and social significance of religious difference. It is interesting that these policy views were articulated in a period in which the political organization of the metropolis was still largely based on religious difference. In the Indies, however, subjects still had to be educated to become citizens.

We now know that the secularisation of the Indies has not been successful. Islamic organizations are crucial in the political constellation of postcolonial Indonesia. As in many societies, the army tries to control these organisations and sometimes this is successful for a period, as in Suharto's New Order. These Islamic organizations do not want to connect politics and religion in a medieval fashion, but want to formulate a modern Islam. They do not aim to establish an original khalifat, but are inspired by modern ideas about democracy and nationalism. Tocqueville described Christian organizations as the basis of democratic America; in Indonesia too Islamic organizations can constitute the basis for a democratic nation-state. In Western societies, such as the Netherlands and England, religious organization has been foundational in the formation of the nation-state. In contrast to the views of liberal thinkers like John Stuart Mill and Snouck Hurgronje there is no inherent opposition between religion and democratic freedom. In fact religious mass movements such as the $19^{\text {th }}$ century anti-slavery movement have played a significant role in the creation of public opinion and a public sphere. The colonial notion that the state must repress the combination of religion and politics in Islam emerges in fact from the desire to control society without being legitimated by the population. In the liberal view religion has to be transferred from the public domain to the private domain, but the state is not willing to leave the private domain alone. In postcolonial societies such as Indonesia there is a struggle between centralizing state institutions and more localized Islamic organizations to control daily life. Education is the focus of that struggle. In the end the struggle is about conflicting perspectives on civilization and political participation. Such perspectives are not static and cannot be summarized in easy dichotomies. The Indonesian case shows clearly that religious organizations can play an important role in the furthering of political participation of citizens. There is no inherent opposition between Islam and democracy. The concept of democracy, however, is far from simple 
and has to be understood in a comparative-historical manner. In Indonesia one finds a growing political participation, while in the West one finds a declining participation. Should we now introduce formal, quantifiable criteria to establish whether Indonesia becomes more democratic and Holland less? It is more fruitful to analyse changing power configurations less ideologically and to attempt an interpretation of the effects of growing or declining participation of citizens on regional and global political processes.

\section{Dilemmas of the Modern State}

In my view modern states, colonial and postcolonial, share a number of fundamental objectives. Historical analysis of the colonial period provides insight into the dilemmas of modern states. In the first place modern states have to make individuals national citizens; that is to say that educated subjects have to be made loyal to the nation-state. Secondly, the state derives its legitimacy from a process of political participation of its citizens. For that purpose it is essential to have a public sphere in which social movements and voluntary organizations operate. Thirdly the modern state needs to protect the liberty and equality of all citizens. At least this is the enlightened ideal, however much historical reality may differ from it.

The first element then is that of citizenship and loyalty to the nation-state. From the Reformation there has been a problem concerning the political loyalty of religious groups that did not belong to the state church. This problem is for a large part solved with the modern nation-state, in which national identity and not religious identity is the basis of political loyalty. Secularisation theories have assumed that this would also imply the privatisation of religion, but that is not true. Religion remained significant as a foundation for social and political organization. In the Dutch case of 'pillarisation' we find a pacification of religious and ideological oppositions, but also a model for participation in a plural society. The first social science theory of plural society, formulated by Furnivall, is based on Indonesia, and indeed Dutch pillarisation has inspired the postcolonial pancasila concept. The idea is that religious identity is the channel through which one arrives at national identity and the two remain connected. The colonial distrust of political Islam was fed by the idea that this kind of religious mobilization might bring an end to colonial domination. In contemporary Holland, Muslim citizens are still connected in more than one way to their countries of origin. Moreover, their religious identity is (not yet) connected to a Dutch national identity. Their connection with Mecca can perhaps be compared to the earlier Dutch Catholics whose loyalty to Rome was perceived as anti-national by anti-papist groups.

However, religious identity is now buttressed by ethnic difference. The state has attempted to use education to integrate Muslims into Dutch society, but one 
has to realize that the ability of the state to nationalize citizens has declined. In other words, homogeneity cannot be reached as easily as in the I950s. Like Indonesia Holland is a plural society, in which individualism and group identities make national identity one of only relative importance. This seems to be an inescapable process. It has been analysed as the emergence of the network-society or the post-national state. If networks based on group mobilization are indeed becoming more important, it would entail a bright future for religions such as Islam. The little centralized Islamic forms of organization with their shifting sites and sources of authority are pre-eminently suited for such a society.

The second important element in the development of modern society is political participation. The modern state has long excluded subjects from the democratic process on the basis of race, sex, and class. Slowly general suffrage has emerged, although an age criterion has been maintained. The most important ground for excluding colonized peoples from the political process can be found in John Stuart Mills' and Snouck Hurgronje's idea that these peoples should be considered as 'children'. This $19^{\text {th }}$-century liberal notion remained powerful until nationalist movements put an end to colonial domination. The Indies were governed through indirect rule. The elite was identified and used as brokers between government and society. Colonial society was prevented from self-organization. This procedure resembles the way in which the postcolonial government tries to find brokers in its dealings with ethnic and religious minorities. As such one can understand the sometimes comical discussion about imams in Holland: the government feels a strong need to speak to Muslims via their leaders. The problem is that these hardly exist, since imams are often poorly educated leaders of the prayer who have some influence, but which should not be exaggerated. Some universities in the Netherlands with poorly attended theological seminaries have proposed that they could give these imams a thorough theological and pastoral education. This is a perfect example of indirect rule - of groups who do not organize themselves but are represented by leaders who are the creation of the government. The government not only creates leaders, but forces people also to make use of ethnic and religious channels to voice their views vis-à-vis the government. There is a problem here in wanting to have people participate in the political process in ways they have not chosen. At present political participation in the Netherlands and in other Western countries has declined considerably and it is not to be expected that newcomers will spend a lot of energy on it. It is more likely that people will mobilize around certain issues, such as the environment, traffic and spatial mobility, education and that religious issues will also be introduced. When there is a public debate about headscarves and the like people can be mobilized around such an issue. Religious organizations will be happy to step in. In this way 
Muslims follow the pattern of involvement of their non-Muslim co-citizens.

The last element is that of freedom and equality as the ideals of the modern nation-state. An important element here is the separation of church and state. Neutrality of the state in matters of religious choice has to be guaranteed as a political principle, although one has to observe that there are vast differences between the USA, the Netherlands, France, Turkey, India, Indonesia and other modern nation-states in the implementation of this principle. The US was the first state in which the separation of church and state was rigorously applied with the paradoxical effect that public religion is of great political importance in the US. In the Netherlands the protestant Free University and the Catholic University of Nijmegen have few protestant or catholic students, but do have a religious foundation while being fully funded by the government. An old problem is the definition of freedom and the fact that procedures of freedom can be used to constrain and repress.

Everyone will be convinced of the liberating effects of modern science. The biological theory of evolution is science and creationism is a belief. In the USA religious activists try to introduce creationism in the curricula of public schools, because they are of the opinion that evolutionism and creationism are equal sets of beliefs. The polemic between these positions exists since the famous debate between the scientist Thomas Huxley and the Anglican Bishop Wilberforce in Oxford in I860. The term 'fundamentalism' originates from the important Scopes trial in the US in I925 where, so to say, the bible was pitched against Darwin. The problem of the modern state is that good education, based on scientific knowledge and a particular form of rationality, is essential to its development, but that the government has to be neutral towards religious opinions in society. The introduction of Hindu, Muslim, and Christian curricula is only then acceptable when they do not conflict with scientific knowledge. For such conflict-ridden debates there are no simple solutions and, again, people can be mobilized around issues, such as creationism.

\section{From Nation Sate to Network Society}

Thus far I have emphasized the role of the nation-state, but can the postcolonial state still be called a national state in the present era? In social science debates about globalization it is sometimes argued that the $19^{\text {th }}$ century nation-state is on its way out and is being succeeded by global actors, such as the UN and the World Bank. Such a position is going too far, in my opinion, but what we do see is a transformation of the national state and the rise of what the sociologist Manuel Castells has called 'the Network Society'. Castells' argument emphasises the declining capacity of the state to satisfy the demands and requirements of 
citizens, but he forgets that that capacity has only been available to the welfare states of the West. Those possibilities were never available in most other regions of the world. The decolonised areas that Clifford Geertz in the sixties called 'new states in old societies' have never seen an effective battle against poverty and illiteracy. In these areas one finds a general disillusion with authorities which have promised much and delivered little. What seems to connect the entire world, from the US to India, is the notion that the state does not offer the solution for problems but is itself the problem. Migrants try to avoid the state in building transnational networks. This is obviously true for large-scale illegal migration, but it is also true for legal migration. An important indication is the fact that money transfers of transnational migrants in I995 were estimated to exceed 70 billion dollars according to the IMF. National governments try to control these transfers, but are not capable of doing so. It is important to see that this kind of large-scale monetary traffic enables transnational entrepreneurship. Integration in the nation-state is not the aim of these entrepreneurs, although they may well be citizens of the states of immigration. They want to be flexible, to be able to respond quickly to changes in political and financial circumstances. They constitute transnational networks with nodes in a number of nation-states.

In cultural and religious aspects these networks are supported by transnational movements, such as the Pentecostals in Christianity, the World Council of Hindus in the case of Hinduism and the many missionary movements in the case of Islam. These movements are crucial in the creation of transnational identities that connect to the universal message of these religions. While most of them are quietist and expect salvation from the ultimate conversion of all the citizens of the world to the universal Truth there are also extremist and violent movements among them that have more direct political goals. Even in the colonial period these movements were feared by the Western governments. Especially so-called pan-Islamism was closely watched. For instance, Snouck Hurgronje's stay at Mecca was subsidized by the Ministry for the Colonies since it wanted to have information on the Indonesians who were living in Djeddah and Mecca. With the rise of independent states in Africa and Asia the political mobilisation of Muslims seemed to be channelled into nationalist movements and focused on the national arena. In that way the danger of pan-Islamism seemed to have disappeared, but, if we ever harboured such an illusion, it disappeared after the events of II September in the US. That this had been an illusion should not surprise us, since local, regional, and national conflicts constantly have international and transnational effects. It is not only nation-states that are crucial in military conflicts but also transnational networks of militant groups. This was true for the Comintern and it is also true for the pan-Islamist groups which have been fighting in several 
conflicts in Bosnia, Egypt, Afghanistan or the Moluccas. After the collapse of the Soviet Union - partly by their own doing - they are constantly confronted with the US and its allies. When one takes into account the role of the US and the West in supporting the repressive regime of Israel, some anti-Western and antiAmerican feelings might be expected. The terrorist attack has suddenly made us much more aware of the negative effects of postcolonial globalization on the Western world. One can no longer assume that conflicts in the South, in which the North and especially the US are involved, will be contained there. Moreover, with the rise of the network-society the ability of states to guarantee security within territorial borders has declined. Responses to this situation cannot be limited to conventional military and political options, but have to emerge from clear-headed analyses of the transformation of the national state. To transnational challenges one has to give transnational answers. The demonising of Muslim immigrants who are perceived as symbols of the large-scale upheavals of today's world is the opposite of such an answer. It brings us back to old nationalist reflexes that want to bring back what has already disappeared: the homogenous nation-state.

\section{Conclusion}

Where does this leave area studies? In my view area studies, as they are developed in the International Institute for Asian Studies, can contribute to a better knowledge of globalization. Although there is no doubt that when the funding is national the research interests are in some ways also tied to national interests; the great advantage of area studies is that it can put the "national" into a global context. I have tried to show that one needs an understanding of colonial Indonesia and global Islam to better grasp the dilemma of postcolonial Netherlands. In this way area studies of Asia are crucial for the understanding of Western societies. As opposed to the universalizing tendency in the social sciences, area studies can offer a comparative and historical angle that will promote better knowledge than the extrapolation of western models of the economy or the psyche to the rest of the world. The enormous personal investments in the study of language and culture in area studies bear fruit when they are part of more general discussions not only of the area but of larger global issues. 



\section{Asia as a Form of Knowledge: of Analyses, (Re)Production, and Consumption}

Shamsul A.B.

In my encounter with Asian studies in the last 30 years I have always been fascinated, sometimes perplexed, by its overwhelming 'fuzziness'. Perhaps I am the unlucky one. Most of my colleagues seemed to be quite clear in what they were doing and where they were going, but I was not. My predicament could have been the result of, and compounded by, the nature of the intellectual route that I have taken, one that continues to oscillate between certainties and uncertainties, between the macro and the micro, structure and agency, emic and etic and so on.

I partly blame history for what I have suffered from and anthropology for making it worse. Why history and anthropology? The history that I learned, on the one hand, seems to provide certainties and structure, and the anthropology that I embraced, on the other, continues to highlight uncertainties and doubts. This has been especially true in my effort to understand the plethora of explanations and discourses regarding ethnicity in the context of Asian studies: history provides me clear ethnic categories and classifications but anthropology often offers just the opposite through its continuous interrogation of the categories and classification by posing questions such as "who is a Malay?" or "who is the Lue?", "who is the majority?" and "who is the minority?"

While it is too easy to put the blame on history and anthropology for my confusion, or being dizzy and fuzzy ontologically, I thought it would be more fruitful to examine this confusion from a different angle in search for a more satisfactory reflection. My numerous discussions over the last decade, with Wim Stokhof and Thommy Svensson, my two inspiring mentors, have helped me tremendously in sorting out some of the confusion. I therefore have decided to return to epistemology to heal my ontological blues. I would like to do it in the following manner. 
I shall begin with an examination of 'Asia' as a form of knowledge followed by an exploration regarding the 'knowledge baseline' continuum that informs the construction of said knowledge. After that it is useful to have a look at the process of constituting and reproducing the knowledge that would guide my subsequent discussion on the consumption of the knowledge. Finally, as an example, I shall try to locate our knowledge on ethnicity - a topic that lives within me as much as it has embraced me all my life - within this broader analytic-conceptual discussion on 'Asia as a form of knowledge'.

Society is both real and imagined. It is real through face-to-face contact and imagined when the idea of its existence is mediated through mediums such as printed materials and electronic images. So, the term society refers simultaneously to a micro unit that we could observe and to a macro one that we could only be partially engaged with. We therefore have observable 'societies' within a macro imagined 'society', so to speak. Asia, like other regions in the world, has both. But it is the way that both of these components have been weaved into an enduring complex whole, which seemed to have made Asia and Asians thrive and survive even under adverse conditions, such as the recent financial-economic crisis, that has become the source of endless intellectual attraction and academic inquiry to both scholars and others, hence the birth, growth and flourishing of Asian studies.

Thus Asian studies, dominated by humanities and the social sciences, have been about the study of the 'society' and 'societies' in the region, in their various dimensions, in the past and at present. The complex plurality of these 'society' and 'societies', or societal forms, that do indeed co-exist, endure and enjoy some functional stability, have made it imperative for researchers to apply an equally diverse set of approaches, some discipline-based (anthropology, sociology, geography, history, political science, etc.) and others thematically-oriented (development studies, gender studies, cultural studies, etc.) in studying Asian society. In some cases, it has even involved disciplines from the natural as well as applied sciences. Through such processes 'Asia as a form of knowledge' came into being.

The greatest challenge in grasping the content and dynamics of 'Asia as a form of knowledge' that constitutes what is known as Asian studies, and to its experts, has been to keep pace with the major changes that have affected the 'society' and/or 'societies' and then narrate, explain and analyze these changes and present the analysis in a way that is accessible to everyone within and outside the region. Therefore, framing the analysis is critical in understanding as to how Asian studies constitutes and reproduces itself through the study of 'society' and 'societies' within Asia, in particular, those in Southeast Asia, a region I am most 
familiar with. The 'knowledge baseline' approach is useful in making sense of the said framing process.

\section{The knowledge baseline}

Social scientific knowledge (humanities included) on Asia has a clear 'knowledge baseline' meaning a continuous and inter-related intellectual-cum-conceptual basis, which emerged from its own history and has, in turn, inspired the construction, organization and consumption process of this knowledge. The two popular concepts that have been used frequently to characterize Asia are 'plurality' and 'plural society', both of which are social scientific constructs that emerged from empirical studies conducted in Asia by scholars from outside the region.

In historical terms, 'plurality' characterized Asia, most clearly in the Southeast Asia region, before the Europeans came and subsequently, divided the region into a community of 'plural societies'. Plurality here signifies a free-flowing, natural process not only articulated through the process of migration but also through cultural borrowings and adaptations. Politically speaking, polity was the society's political order of the day, a flexible non-bureaucratic style of management focusing on management and ceremony by a demonstrative ruler. States, governments and nation-states, which constitute an elaborate system of bureaucratic institutions, did not really exist until Europeans came and dismantled the traditional polities of Asia and subsequently installed their systems of governance, using 'colonial knowledge', which gave rise to the plural society complex.

Historically, therefore, plural society signifies both 'coercion' and 'difference'. It also signifies the introduction of knowledge, social constructs, vocabulary, idioms and institutions hitherto unknown to the indigenous population (such as maps, census, museums and ethnic categories), the introduction of marketoriented economy and systematized hegemonic politics. Modern nation-states or state-nations in Asia have emerged, mostly, from this plural society context.

It is not difficult to show that the production of social scientific knowledge on Asia has moved along this plurality-plural society continuum. When scholars conduct research and write on pre-European Asia they are compelled to respond to the reality of Asian plurality during that period; a period which saw the region as the meeting place of world civilizations and cultures, where different winds and currents converged bringing together people from all over the world who were interested in 'Gospel, gold and glory', and where groups of indigenes moved in various circuits within the region to seek their fortunes. As a result, as revealed in Southeast Asia, we have had, in Java, a Hindu king with an Arabic name entertaining European traders. In Champa, we had a Malay raja ruling 
a predominantly Buddhist populace trading with India, China and the Malay archipelago. Whether we employ the orientalist approach or not, we cannot avoid writing about that period within a plurality framework, thus emphasizing the region's rich diversity and colourful traditions. In other words, the social reality of the region to a large extent dictates our analytical framework.

However, once colonial rule was established and the plural society was installed in the region, followed later by the formation of nation-states, the analytical frame, too, changed. Not only did analysts have to address the reality of the plural society but also the subsequent developments generated by the existence of a community of plural societies in the region. We began to narrow our analytical frame to nation-state, ethnic group, inter-nation-state relations, intra-nationstate problems, nationalism and so on. This gave rise to what could be called 'methodological nationalism', a way of constructing and using knowledge based mainly on the 'territoriality' of the nation-state and not on the notion that social life is a universal and borderless phenomenon, hence the creation of 'Indonesian studies', 'Sri Lankan Studies', 'Japanese Studies' and so on.

With the advent of the Cold War and the modernization effort analysts became further narrowed in their frame of reference. They began to talk of poverty and basic needs in the rural areas of a particular nation, also focusing on resistance and warfare, slums in urban areas, and economic growth of smallholder farms. The interest of particular disciplines, such as anthropology, became narrower still when it only focuses on particular communities in remote areas, a particular battle in a mountain area, a failed irrigation project in a delta, or gender identity of an ethnic minority in a market town.

In fact, in numerical terms, the number of studies produced on Asia in the plural society context supersedes many times those produced on Asia in the plurality context. Admittedly, social scientific studies about Asia developed much more rapidly after the Second World War. However, the focus became increasingly narrow and compartmentalized not only by academic disciplines but also in accordance to the boundaries of modern postcolonial nations. Hence, social scientific knowledge on Asia became compartmentalized.

It is inevitable that a substantial amount of social scientific knowledge about Asia itself, paradigmatically, has been generated, produced and contextualized within the plural society framework, because 'nation-state' as an analytical category matters more than, say, the plurality perception of the Shans of Northern Burma, who, like their ancestors centuries ago, moved freely between Burma and Thailand, to eke out a living along with other tribal groups and outside traders, ignoring the existence of the political boundaries. In fact, anthropologists seem to have found it convenient, for analytical, scientific and academic expedience, to 
separate the Burmese Shan from those of Thailand when, in reality, they are one and the same people.

Therefore, the plurality-plural society continuum is not only a 'knowledge baseline' but also a real-life social construct that was endowed with a set of ideas and vocabulary, within which people exist day-to-day in Asia.

\section{Constituting and Reproducing the Knowledge}

There are at least four major axes along which the construction, organization and reproduction of social scientific knowledge about Southeast Asia and its societies have taken place.

The first axis is that of discipline/area studies/thematic studies. There is an ongoing debate between those who prefer to approach the study of Asia from a disciplinary perspective, on the one hand, and those who believe that it should be approached from an area studies dimension, employing an inter-disciplinary approach, on the other.

The former prefer to start clearly on a disciplinary footing and treat Asia as a case study or the site for the application of a particular set of theories that could also be applied elsewhere globally. The aim of such an approach is to understand social phenomena found in Asia and to make comparisons with similar phenomena elsewhere. Those preferring the latter approach see Asia as possessing particular characteristics and internal dynamics that have to be examined in detail using all available disciplinary approaches with the intention of unravelling and recognizing the indigenous knowledge without necessarily making any comparison with other regions of the world.

The bureaucratic implications of these two approaches can perhaps be clearly discerned in the way social scientific knowledge about Asia is reproduced through research and teaching. This brings us to the second axis, namely, the undergraduate/graduate studies axis.

Those who favour area studies often believe that Asian studies can be taught at the undergraduate level hence the establishment of Asian studies departments or programs, in a number of universities in Asia, combining basic skills of various disciplines to examine the internal dynamics of societies within the region. Acquiring proficiency in one or two languages from the region is a must in this case. The problem with this bureaucratic strategy is that these departments have to be located in a particular faculty, say, in the arts, humanities or social science faculty. This denies, for instance, those with a background in the natural sciences the opportunity to study in-depth about Asia.

Therefore, those discipline-inclined observers would argue that Asian studies should be taught at the graduate level to allow those grounded in the various 
disciplines, whether in the social or natural sciences or in other fields of study, to have an opportunity to specialize in Asian studies. Therefore, a geologist or an engineer who, for instance, is interested in the soil and irrigation systems of Asia could examine not only the physical make-up of Asia but also the humanenvironment relationship. This is particularly relevant at the present time since environmental and ecological issues have become global concerns.

This has made many individuals, institutions and governments to think carefully how they should invest their precious time and money when they are requested to support the setting up of say, a program, centre or institute of Asian studies. They often ask whether universities should continue to have the prerogative on the teaching, research and dissemination of knowledge about anything connected with Asia and its societies. Why not in non-university institutions?

This takes us to the third axis, namely, the University/non-university one. For many years, we imagined that only at the university could we acquire and reproduce knowledge about Asia, whether approached from the disciplinary or area studies perspective. However, many governments and international funding bodies felt that to obtain knowledge about Asia one need not go to the university, but could acquire it through non-academic but research-oriented institutions established outside the university structure to serve particular purposes. In Southeast Asia, for example, national research bodies such as LIPI (Indonesian Institute of Sciences) in Jakarta and ISEAS (Institute of Southeast Asian Studies) in Singapore have been playing that role. 'Think-tanks', such as the Center for Strategic Studies (CSIS), Jakarta, or the Institute of Strategic and International Studies (ISIS), Malaysia, have also played the role of the producer and reproducer of knowledge on societies in Southeast Asia outside the university framework. However, there seems to be a division of labour, based on differences in research orientation, in the task of producing and reproducing knowledge between the academic and non-academic institutions.

This fourth and final axis is an academic/policy-oriented research axis.

While academic endeavours pursued within the context of Asian studies in the universities are motivated by interest in basic research, which is by definition scholarly, those pursued outside the universities are often perceived as not being scholarly enough because they are essentially applied or policy-oriented in nature and serving rather narrow, often political, interests of the powers that be in Asia.

It is argued that the critical difference between these two approaches is that the academic one is always open to stringent peer-group evaluation as a form of quality control, but that the applied one is not always assessed academically. In 
fact, the latter is often highly confidential and political in nature, thus denying it to be vetted by the peer-group, hence the perceived inferior scholarly quality. The basic research-based academic endeavours are therefore seen as highly scholarly, whereas the non-academic ones are perceived as highly suspect as scholarly works and not considered to contribute to the accumulation of knowledge on Asian societies.

However, research institutes like ISEAS in Singapore would argue that, even though it is essentially a policy-oriented research institute mainly serving the interests of the Singaporean government, it still produces scholarly work of high quality and encourages basic research to be conducted by its research fellows either on an individual or a group basis. In other words, a non-university research institute in Asian studies, such as ISEAS, could simultaneously conduct applied and basic research without sacrificing the academic and scholarly qualities of its final product. Put in another way, it is 'policy-oriented yet scholarly'.

The moot question is who are really the consumers of knowledge on Asian societies, hence Asian studies; the Asians or outsiders?

\section{Consuming the Knowledge}

It could be argued that social scientific knowledge about Asia and its societies is a commodity with a market value. Often the 'market rationale', and not the 'intellectual rationale,' prevails in matters such as the setting-up of an Asian studies program, centre or institute, even in the government-funded academic institutions. However, the funding of research on Asian studies has often been dictated not by idealistic, philanthropic motives but by quite crass utilitarian desires, mainly political or economic ones. There are at least three important 'sectors' within which knowledge on Asia societies has been consumed: the public, the private and intellectual sectors.

Since the governments in Asia have been the biggest public sector investors in education, through public-funded educational institutions, they have been the largest employment provider. They have set their own preferences and priorities, in accordance to their general framework of manpower planning, in deciding what type of graduates and in which fields of specialization they want to employ them. The pattern in Asian countries has been well-established, that is, there is a higher demand for science graduates than the social sciences and the humanities. But amongst the latter there is no clear, expressed demand for Asian graduates. However, there seems to be a significant demand for the inclusion of the Asian studies content in all the non-natural science courses at the undergraduate level in most of the government-funded academic institutions in Asia. In the Southeast Asian case, this is not unrelated to the fact that the awareness about ASEAN as 
a community has now become more generalized amongst the public; hence, the need for a more informed description on the different countries and societies within ASEAN (read Southeast Asia).

Outside Asia, such as in the United States of America, very rarely a specialization in Asian studies, or components of, has been considered highly desired in the job market of the public sector. Perhaps having a graduate-level qualification in Asian studies is more marketable in the public sector especially in government or semi-government bodies that deal with diplomatic relations or intelligence.

In the private sector, the demand for Asian studies as a form of knowledge and the demand for a potential employer who possesses that knowledge are both limited and rather specific. However, the number could increase depending on how large the investment and production outfit a particular company has in Asia. Since some of the demand for the knowledge is rather short-term, often specific but detailed, therefore it has to be customized to the needs of a company, 'thinktanks' or 'consultant companies' which have often become the main supplier of such tailored knowledge. Many of these organizations are actually dependent on 'freelance' Asianists or academics that do such jobs on a part-time, unofficial basis.

It has been observed that the Japanese seem to be a regular consumer of knowledge on other parts of Asia. This is hardly surprising because they have massive investments in Asia, especially in Southeast Asia, South Asia and China. There is therefore a constant need to know what is happening in the region. Research foundations from Japan, such as the Japan Foundation, Nippon Foundation and the Toyota Foundation, have been very active, in the last decade, in promoting South Asian and Southeast Asian studies, academic and nonacademic, and in supporting research and exchange programs. In Asia, Taiwan and Korea are the two other Asian countries having their own South Asia and Southeast Asian studies research centres, besides in the United States, United Kingdom, France and The Netherlands, former colonial powers in Asia.

A more generalized demand for knowledge on Asian societies relates to marketing and this trend must not be underrated with the recent expansion of the middle class in the region. As the market and clients in Asia become more sophisticated, the need for in-depth knowledge on sectors of the Asia societies has increased. This in turn has increased the demand for graduates who have followed courses related to Asian studies.

In the intellectual sector, knowledge on Asia has been consumed generally by the NGOs, namely, those that are national-based ones as well as those that have regional networks. Because most of the NGOs are issue-specific interest groups, 
such as environmental protection, abused housewives, social justice and the like, and often seeking funds for their activities from the governments and NGOs in developed countries, they find it more advantageous to operate on a regional basis because they get more attention and funding from the said source. The strength and success of their operation is very much dependent on the amount of knowledge they have about Asian societies in general as well as the specific issue that they are focusing on as a cause in their struggle.

With the popularity of the Internet and its increased usage around the world and within Asia, it has now become an important medium through which academic and popular knowledge on Asian societies has become available. The sources of the knowledge could be located outside or within the region but are now much more accessible for commercial and non-commercial purposes.

It could be said that Asian studies and what it constitutes is, first and foremost, a knowledge construct that represents only part of the region's social reality. In spite of this, it is the most important element, amongst the many, that gives Asia, the geo-physical region as well as its people and environment, its history, territory and society. Because of the co-existence of different societal forms in the region, be it categorized as 'majority' or 'minority', the unevenness of the tempo of social life in the region, the speed of social change also differs from one community to the other, from one area within the region to another. Only a multidisciplinary approach could capture these complexities embedded in the societies of Asia.

As the importance of the region increases in the globalizing world, both generalist and specialist knowledge about Asia become critical to the world and the region itself. In that sense, Asian studies as a knowledge construct transforms itself into a lived reality, especially for the Asians themselves. This knowledge therefore becomes indispensable both to those who study Asia and its society as well as to the Asian themselves.

One of the salient areas or themes within Asia as a form of knowledge is the corpus of knowledge on 'ethnicity'.

\section{Locating Ethnicity within 'the Knowledge'}

There are two main areas I would like to focus on and offer a brief schematic comment within which ethnicity has become an important and, indeed, a central theme not only in our understanding of Asia as a region and cluster of societies but also as to how we imagine, organize and pursue our lives, in terms of, from my heuristic device viewpoint, the 'authority-defined' context as well as in the 'everyday-defined' manner.

First, it is in the area of 'academic analysis' which covers mainly our knowledge on ethnicity based on a conscious and declared academic pursuit, that, in turn, 
begets monographs, books, articles, working papers, either paper-based or now in digital forms. Each of these academic products presents analysis that is macro and micro in nature informed by different theoretical approaches, the data of which have been gathered utilizing different methods of enquiry as well as techniques of data collection. Without these materials the all-important literature review prior to a construction of a research proposal, either for a degree or a general academic research, is almost impossible.

Second, 'ethnicity' is important in the area of 'public advocacy' which involves mostly action-oriented activities, such as policy-making, legal undertaking, and interest groups advocacy conducted by both the State and NGOs, or by think-tanks and political parties, within and outside the Southeast Asian region. Undoubtedly, most of the public advocacy activities, including research, have to depend, in some measure, on academic analyses as a source of organizing, shaping and conducting their activities for particular pre-determined purpose or purposes. However, in general, public advocacy activities are defined as non-academic. In fact, it is these activities that have directly impacted the social life of millions of Asians.

Rarely, if any, of those produced as academic analyses have had such an impact. Let us now turn to some concrete examples from the region to elucidate the empirical position of ethnicity in the Asian societal and historical context.

To assist us to understand the location and importance of ethnicity in the realm of academic analyses, it is useful to employ the 'knowledge baseline' elaborated above. I shall also draw some examples to illustrate my point from my own research on 'identity formation in Malaysia'.

Since the term 'ethnicity' has been introduced and became popular only in the late I950s, in the pre-colonial 'plurality context' words such as 'race', 'tribes', 'peoples' were used instead of 'ethnic' or 'ethnicity'. This is evident if we were to look through Hobson-Jobson: The Anglo-Indian Dictionary compiled by Henry Yule and A.C. Burnell, published in I886. The ethnic group now known as 'Malays', for instance, was labelled by various European authors, sailors, travellers and proselytizers, quoted in Hobson-Jobson, as a 'race', 'tribe', 'people', 'community' or 'barbarism'. Such labels were based on a number of factors, such as geographical, biological, linguistics and selected cultural attributes.

However, in the 'plural society' context, both during the colonial and postcolonial period, the emphasis was clearly more on the word or term or concept 'race' with heavy biological and linguistic attributes being emphasized. Such emphasis was made in the construction 'colonial knowledge' in which terms such as 'Malay' became critical in the technology of colonial rule, mainly for 'official procedure'. Indeed, the practice of census-taking played an influential role in the 
creation of ethnic categories such as Malays. It is therefore not surprising, when a famous colonial scholar R.O. Windstedt in the dictionary he compiled in I957, called An Unabridged Malay-English Dictionary, defined Melayu 'a race name'. Implementation of laws such as the Malay Reservation Enactment of I9I3 further enhanced the utility and currency of the use of the term 'Malay race'.

I am quite certain the examples I have drawn from the Malaysian context is not dissimilar to the experience of other ex-colonies in Asia, such as those drawn up by the British in India and China, the Dutch in Indonesia, the French in IndoChina and the Americans in the Philippines. Majority and minority communities and ethnic groups were constructed throughout the colonial period for official reasons. These colonial knowledge based categories became naturalized and accepted in everyday life of the inhabitants in Asia as the European rules and laws were. Often local inhabitants modified them for their own purposes.

The rise of ethnic-based nationalist movements during the colonial period, as a form of public advocacy-oriented organizations, has been the product of the said colonial knowledge. As Anderson has argued, partly, these categories became the basis of 'imagined communities', or, in my opinion, as the basis of the creation of 'nation-of-intents' in the various Southeast Asian societies, which, in turn, was mobilized and became the underpinning political motivation for the independence movements throughout the region.

The creation and use of the term bumiputera (lit. son of the soil) or pribumi (the native son), indeed an inclusive term, in both colonial and post-colonial Malaysia and Indonesia is also an interesting example. It was used to separate the 'indigenous' from the 'migrant' populations, some for policy purposes and in other context for the purpose of popular labelling in the local press, for instance. The term simultaneously homogenizes or polarizes the otherwise heterogenous society in two opposing 'they' and 'us' positions.

Anthropological studies conducted in Southeast Asia often point out to us the fluidity of such categories. For example, the term bumiputera in Malaysia includes the Malays who are constitutionally Muslims, and the Orang Asli, the Kadazan and the Ibans who are mostly non-Muslims. But the Malays themselves are known to have many sub-groups, some of whom are Muslim Orang Asli. At the personal level, some Indian Muslims who practiced Malay socio-cultural life would like to claim to belong to the Malays. Such situational claims have made ethnicity studies in Southeast Asian an interesting one.

\section{Conclusion}

At the conceptual level, there seems to be a continuous negotiation going on in both the official and personal contexts as to who belongs to which ethnic 
category and for what purposes. This in turn has led to what could be called as majority-minority discourses in the realm of the construction and practice of ethnic identification. There is ample evidence in Asian studies which can be drawn as useful examples on such a discourse. In other words, Asian studies, over the years, have been critical in refining the substantive make-up of the general studies on ethnicity globally. In this respect, the contribution of the International Institute for Asian Studies (IIAS) and the International Convention of Asia Scholars (ICAS) as facilitators towards that end have been invaluable and shall continue to do so in the future.

\section{Bibliography}

Andaya, Barbara \& Andaya, Leornard, A History of Malaysia, Honolulu: University of Hawai'i Press, 200i [2nd ed].

Anderson, Benedict, Imagined Communities, London: Verso, I983.

Bellwood, Peter. Prehistory of Indo-Malayan Archipelago, Sydney: Academic Press, I985.

Blussé, Leonard, 'Changes of Regime and Colonial State Formation in the Malay Archipelago, I780-I830: An invitation to an international research project,' Asia Research Institute Working Paper Series, No. 4I, 2005: I-I5.

Braginsky, Vladimir, The Heritage of Malay Traditional Literature: A Historical Survey of Genres, Writings and Literary Views, Singapore: ISEAS, 2005.

Brown, David, The State and Ethnic Politics in South-East Asia, London \& New York: Routledge, I994.

Collins, James T., Malay, World Language: A Short History, Kuala Lumpur: Dewan Bahasa \& Pustaka, I996.

Cribb, Robert, 2004, 'Nationalism in Indonesia', a working paper for IAHA conference, Taiwan.

Evers, Hans-Dieter (ed.), Sociology of South-East Asia: Reading on Social Change and Development, Kuala Lumpur: Oxford University Press, I980.

Heidhues, Mary Somers, Southeast Asia: A Concise History, London: Thames \& Hudson, 2000.

Kemp, Herman, Bibliographies on Southeast Asia, Leiden: KITLV Press, I998.

Owen, Norman (ed.), The Emergence of Modern Southeast Asia: A New History, Honololulu: University of Hawai'i Press, 2005.

Lombard, Denys, Le carrefour javanais: essai d'historie globale, Paris: EHESS, I990. 
Reid, Anthony, Southeast Asia in the Age of Commerce 1450-1680; Volume 1: The Lands Below the Winds, New Haven, Con.: Yale University Press, I988.

Reid, Anthony, Southeast Asia in the Age of Commerce 1450-1680; Volume 2: Expansion and Crisis, New Haven, Con.: Yale University Press, I993.

Shamsul A.B., 'Debating About Identity in Malaysia: A Discourse Analysis', Tonan Ajia Kenkyu (Southeast Asian Studies), Vol. 34, No. 3, December I996: 476-499. (Reprinted in Cultural Contestations: Mediating Indentities in a Changing Malaysian Society, edited by Zawawi Ibrahim, London: Asean Academic Press, I998: 17-50.)

Shamsul A.B., 'The Making of a 'Plural' Malaysia: A Brief Survey', Emerging Pluralism in Asia and the Pacific, edited by D.Y.H. Wu, H. McQueen, Yamamoto Y, Hong Kong: Hong Kong Institute of Asia-Pacific Studies, I997: 67-83.

Shamsul A.B., 'Nations-of-intent in Malaysia', Asian Forms of the Nation, edited by Stein Tonnesson \& Hans Antloev, London: Curzon, I996: 426-456.

Shamsul A.B., 'Ethnicity, Class, Culture or Identity? Competing Paradigms in Malaysian Studies', Akademika, 53, July i998: 33-60.

Shamsul A.B., 'Colonial Knowledge and the Construction of Malay and Malayness: Exploring the Literary Component', Sari, No. I7, I999: 3-I7.

Shamsul A.B., “Malay' and 'Malayness' in Malaysia Reconsidered: a Critical Review', Communal/Plural, Journal of Transnational a Crosscultural Studies, Vol. 9, No. I, April 2001: 70-80.

Shamsul A.B., 'History of an Identity, an Identity of a History: The Idea and Practice of 'Malayness' in Malaysia Reconsidered', Journal of Southeast Asian Studies, Vol. 32, No. 3, October 2001: 355-366. (Reprinted in Tim Barnard, (ed), Contesting Malayness: Malay Identity across Boundaries, Singapore: Singapore University Press, 2004.)

Shamsul A.B., 'Some thoughts on how knowledge on Southeast Asia came to be', IIAS Newsletter, 36, March 2005: 3.

Shamsul A.B., 'Islam Embedded: Religion and Plurality in Southeast Asia as a mirror for Europe', Asia-Europe Journal, 3, 2005: I59-I78.

Shamsul A.B., 'The Construction and the Management of Pluralism: Sharing the Malaysian Experience', ICIP Journal, Vol. 2, No. I, 2005: I-I4.

Shamsul A.B. \& Sity Daud, 'Nation, ethnicity, and contending discourse in the Malaysian state', State Making in Asia, edited by Richard Boyd and Ngo Tak-Win, London: Routledge, 2006: I3I-I4I.

Steinberg, Joel (ed.), In Search of Southeast Asia: A Modern History, Sydney, Wellington: Allen \& Unwin, I987 [Revised Edition].

Tarling, Nicholas (ed.), The Cambridge History of Southeast Asia. Volume 1: Early 
Times to c.1800 and Volume 2: The Nineteenth and Twentieth Centuries, Cambridge: Cambridge University Press, I992.

Wallace, Alfred Russel, The Malay Archipelago, the Land of the Orang-Utan and the Bird of Paradise: A Narrative of Travel with Studies of Man and Nature, London: MacMillan, I869. 


\title{
'A Little Knowledge is a Useful Thing': Paradoxes in the Asian Studies Experience in Australia
}

\author{
Robert Cribb
}

Asian studies is a strange beast. Until the I950s there was no such thing. Scholars interested in Asia worked within disciplines such as history or anthropology, or in an esoteric field generally called Orientalism, which featured the meticulous study of classical texts from Asian religions and civilizations. Then Asia began to loom large in the world. Japan's post-war recovery seemed to herald an Asian halfcentury in which Asia would not just catch up to the West but overtake it. Chinese communism presented the world with a dramatic experiment in massive social and cultural transformation which was - to different audiences - as exciting and as alarming as the Bolshevik revolution had been earlier in the twentieth century. The message was repeated, too, in smaller Asian countries - in the revolutionary discipline of the Vietnamese, the self-reliance of India and the economic miracles of Singapore and South Korea - so that Asia as a whole seemed to have something special, something not to be found in the Middle East, Africa or South America.

\section{The Rise of Asia}

The rise of Asian studies coincided with the emergence of area studies in the United States education system (and in systems like that of Australia which were influenced by the American model). To its practitioners, however, Asian studies was something more: it was area studies that had the potential to become core studies. The rest of the area studies endeavour was dominated by the rival concepts of nation-building and dependency. The central research issue for area studies in general was finding ways in which 'backward' states might create nations, and ways in which those nations might in turn 'catch up' to the West in terms of economic development and democracy. Some scholars within the area studies approach took a more pessimistic view of the structural factors which seemed to prevent this process. There was, however, no counterpart in African 
or Latin American studies to the idea of 'provincializing Europe', later articulated by Dipesh Chakrabarty (2000).

Whereas the cases of Africa and Latin America could cast some doubt on the Western-style modernity model and on the validity of modern moral values, they did not set up an alternative model of modernity in the way that the proponents of 'Asian Values' did in the I980s and I990s (Barr 2002). Japan's victory in the Russo-Japanese War of I904-05 had inspired people in the rest of Asia to look for those elements of Japanese culture and policy that might offer them strategies for modernizing their own societies, but the remarkable feature of the Asia boom of the second half of the twentieth century was the extent to which Westerners were willing to look to Asia for strategies to deliver business success. There was no historical parallel to the eagerness with which Western management experts tried to learn the secrets of Japanese management success and of Chinese business networking. Observers sometimes predicted that the $2 \mathrm{I}^{\text {st }}$ century would be a Pacific Century, incorporating also the dynamic economy of the western seaboard of the United States, but the real leader of the future seemed to be Asia.

Even the growing post-modern angst and disillusion with a Western civilization that had delivered the world atomic weapons, the Holocaust and unprecedented environmental destruction seemed to point in the direction of lessons to be learnt from Asia. It was no accident that Foucault, wanting to show that the West did not have a monopoly on sophisticated systems of language, turned to China for the fictitious example of a provocative classification of animals which included such categories as 'embalmed', 'stray dogs', ‘drawn with a very fine camel hair brush' and 'that from a long way off look like flies' (Foucault I970).

Asia, then, was a place where important lessons could be learned, and the people to identify those lessons were called Asianists. Like the Orientalists, they spoke one or more Asian languages, but their orientation was to the present rather than to the classical past. They typically drew insights from more than one discipline, blending history, geography, politics, anthropology and a smattering of economics. They spent long periods in 'their' country as part of their training, often developing close friendships with people there, and they would return there repeatedly. And they were engaged with politics, sometimes as partisans of one view or another, more often as mediators, interpreting Asia to the West (and sometimes the West to Asia) as a way of ironing out misunderstandings and prejudices in what were increasingly complex relationships.

\section{Asian studies under siege}

Some time in the late ig80s, however, things began to go wrong. Most obviously, there was a counter-attack on area studies from those adhering to academic 
disciplines. The core of the attack seems to have been a profound irritation at the 'spoiler' role that area studies had taken on itself. That is, specialists on the West were tired of hearing Asianists stand up in conferences and seminars and say, in effect, 'Well, I work on Japan/China/Indonesia/India etc. and they don't do that'. The irritation arose from the fact that Asianists possessed language competence and local knowledge which made their objections unanswerable, yet they often had neither the interest nor the capacity to turn that knowledge into theoretical insights.

Viewed from outside, the Asian studies world seemed to have some of the characteristics of a sheltered workshop: the special qualifications required for the close study of Asia seemed to be being used as an excuse for insufficiently rigorous thinking. Asianists might argue to the academic mainstream that it was impossible to understand the world without studying Asia, but their own work rarely showed any serious comparative dimension, whether beyond, or even within, Asia. Rare and shallow comments by Asianists in the West on their own societies did not help to convince the academic mainstream that the study of Asia was likely to produce remarkable new insights. See, for example, Anderson (I972). This chapter had enormous influence in Indonesian studies because it made a plausible essentialist argument about the character of Javanese political culture, yet the crude description of Western conceptions of power set out in the chapter by way of comparison was little more than a caricature. After three decades of Asian studies, there seemed to outsiders to be a gap between Asia's promise of a new and different modernity and the intellectual products of the Asian studies endeavour.

The I980s, it will be remembered, also marked the onset of the modern era of economic rationalism in which national economies were to be opened to the cold winds of competition in order to improve quality and efficiency. The same sentiments also gained strength in academia, and powerful arguments began to be made that those studying Asia should not shelter behind the intellectual tariff barrier of a separate field. Rather they should compete with the mainstream disciplines in an open marketplace of ideas. Asian studies was by no means the only field to be buffeted by the cold winds of academic rationalism. Other fields - economic history, traditional geography, and traditional literary studies, for instance - suffered a good deal more as changing disciplinary fashions eroded their intellectual underpinnings.

The suspicion of discipline specialists towards Asian studies was exacerbated by the connection of area studies with the global interests of the US. Many scholars have pointed out that area studies at American universities was kickstarted by funding from US government agencies seeking to create a cadre of 
specialists who would be able to advise on the best way to push local conditions in the direction of American interests (Katzenstein 200I; Cumings 1997). Especially during the Cold War and the Vietnam War, many American academics developed a profound distrust for their government, and they projected this distrust on to academic enterprises that appeared to be serving the interests of the government, whether wittingly or unwittingly.

To the extent that this observation was true, and area studies was boosted by an expansionist US state keen to generate expertise about both its informal empire and the realms of its enemies, Asian studies suffered significantly from the end of the Cold War. Francis Fukuyama's pronouncement that history had come to an end (Fukuyama I989) implied that the argument in favour of a USstyle economy and polity had been won and that there was no need to pay special attention to the rest of the world, because the destiny of the rest of the world was, sooner or later, to become like America. In the eyes of some policy-makers, Asian studies suddenly had little more than archaeological interest. Of course, there was never a comprehensive turning against Asian studies, but official signals that the field was not in favour contributed to a significant downturn in funding and enthusiasm.

The tenor of the debate over area studies and Asian studies was also marred by suggestions of implicit racism amongst Asianists. Some of those who attacked Asian studies saw themselves as attacking the proponents of cultural determinism, as attacking the tendency of some scholars to retreat into culture as catch-all explanation for different outcomes. Cultural determinism, it has to be said, was one of the most common lessons which opinion-makers such as journalists drew from the Asian studies endeavour. Not only was it easy to explain complex phenomena by saying 'That's what the Chinese/Japanese/Indians/ Vietnamese do', but the arguments of cultural determinism tended to be based on a relatively sophisticated and positive view of Asian cultures. To its opponents, however, cultural determinism seemed to embody implicitly racist assumptions about the capacity of human beings. It seemed to suggest incapacity on the part of Asians to be modern (which is to say, modern in a Western way). These scholars did not want to uphold an approach which opened the possibility of endorsing a compromise of the principles of universal human rights and values. In this sentiment, the opponents of area studies were partly influenced by the specific political situation in the United States, where arguments in favour of cultural determinism seemed slide easily into notions of biological determinism and thus to endorse the continuing social difficulties faced by black Americans.

The opponents of Asian studies also perceived Asian studies as a field which lent itself to the pluralist side in what became known as the Asian Values debate. 
The pluralist view held that Asian values were different from those of the West and that Asians characteristically valued collectivity over the individual, meaning that Western conceptions of individual human rights were not entirely appropriate to Asian societies. At least in some cases, advocates of Asian Values therefore proposed a more relaxed attitude to human rights violations and to limitations on democracy than was common in the West. The universalist opponents of the Asian Values argument saw it as little more than casuistry intended to provide an intellectual defence for authoritarianism and the abuse of individual human rights in Asian countries. Although elements of the Asian Values debate had antecedents in much earlier discussions about the respective characters of East and West, the debate took a particularly lively turn in the years following the end of the Cold War when the West often seemed triumphalist. In fact, this association of Asian studies with Asian Values was mistaken: Asian studies itself was divided on the issue, and many Asianists argued passionately that parts of the pluralist position in the Asian Values debate were vacuous and self-serving. Their ability to see the complexity of the situation within Asian countries, however, often made it more difficult to present their more subtle arguments effectively.

Asianists themselves sometimes weakened their own case. One of the strongest themes in Asian studies has been the argument that a central part of the discipline ought to be the bringing to life of the perspectives of Asians themselves. J.C. van Leur's celebrated rebuke to Dutch historians for writing the history of the Indonesian archipelago from the point of view of the Dutch, rather than from that of the region's own people was an opening shot in a long battle which eventually engulfed much of the social sciences and humanities and which provided the basis for attention to groups which were not in power in society: to women, to the poor, to ethnic, religious and sexual minorities and so on. Although this argument was backed by the strong moral principle that Asian societies should not simply be the object of study by outsiders and by the intellectual-moral argument that the task of scholarship was to bring to the fore the perspectives of as many different categories of humans as possible, the effect of the argument was to endorse a kind of intellectual apartheid, in which Asia was the proper topic of study for Asians and the West the proper topic for Westerners. At its worst, the argument entailed a surrender to credentialism: to the notion that people who belong to a particular group are intellectually and morally better qualified to study it than outsiders. If Asians then were the best people to study Asia, what long term future might exist for Asian studies as a field in the West? This argument, to be sure, was only occasionally heard in terms as stark as this, but the implication was there and it did not work in favour of Asian studies as a whole. 
The rising stars of post-modern or cultural studies also attacked Asian studies, accusing it of being no more than old Orientalism in new clothes. In particular, they accused area studies of privileging categories (Asia, Southeast Asia, individual nation-states) whose analytical existence served the interests of the West, rather than those of the people of those parts of the world (Rafael I994). This attack reflected in part the fact that Asian studies had generally not tried to distinguish itself sharply from Orientalism. Rather, it had carried elements of the meticulous scholarship of the old orientalist traditions while embracing the exciting new possibilities offered by creatively combining disciplines. It was vulnerable, therefore to the cultural studies rebuke.

Finally, Asian studies was still further weakened by the character of its relationship with scholarship in Asia. Except in Japan, the study by Asians in Asia of other Asian counties was institutionally and intellectually weak. It was rare that a Western scholar of Asia would turn to Asian scholarship on other parts of Asia, and most of the small number of Asian scholars who specialized successfully in other parts of Asia found careers in the West rather than in their home countries. Although Western organizations have now put resources into encouraging the study of Asia in Asia, non-national Asian studies in Asia remains weak and it provides Asian studies in the West with little intellectual back-up. The focus of scholars in Asia on their own specific societies, rather than on other parts of Asia, meant that they were often the intellectual counterparts of precisely those discipline-based scholars in the West who were the opponents of Asian studies. The intellectual imperatives of their own academic worlds did not make them natural advocates for the Asian studies endeavour in the West.

Viewed from within Asian studies, the attacks from the disciplines seemed unprovoked and unwarranted. Convinced of the importance of studying Asia, Asianists had given little public thought to how their field might establish a recognized intellectual niche for itself in the larger academic world. Asian studies had emerged at much the same time as environmental studies, and to some extent Asian studies was carried along on the coattails of the promises of new problem-solving methodologies which environmental studies seemed to make possible. Asianists did not appreciate how much their way was smoothed by the vastly larger environmental studies juggernaut, nor how deeply discipline-based specialists could be offended by the highly empirical approach of the Asianists and by their selective and sometimes simplistic choice of methodologies and theories. In retrospect, it is probably true to say that the attack on Asian studies was no more than an exposure of a previously protected field to the rigorous intellectual and institutional buffeting that was characteristic of academic life in general. Asian studies as a field, moreover, was never subject to the vitriol hurled 
at some new academic fields such as cultural studies (or indeed the invective that was sometimes to be heard within different branches of Asian studies itself). Nonetheless, Asian studies was poorly prepared to counter the multiple attacks of the late ig80s and ig9os, and it suffered in consequence.

This debate over the importance of Asian studies took place within a characteristically intellectual-moral academic discourse. At the heart of the debate were two issues: what intellectual value did the study of Asia add to the human intellectual endeavour in general? And what were the power implications of current arrangements for the study of Asia (did Asian studies as practised in the I980s and I990s allocate power justly)? It is probably fair to say that neither question has yet been satisfactorily answered.

\section{The Australian paradox}

Of all Western countries, Australia seemed for some time to have achieved the greatest success in Asian studies. Despite its relatively small population, it produced during the I970s and early I980s a formidable cohort of Asian studies scholars and a thoroughly impressive Asia-oriented curriculum. Attention to Asia was a serious part of the curriculum in almost every university in the country and Asian languages (Japanese, Chinese and Indonesian) were widely taught in schools, including primary schools.

Australians were strongly influenced, of course, by intellectual trends in the US and Europe, and the growth of Asian studies in Australia was driven partly by the same factors that were at work in other parts of the West. The special strength of Asian studies in Australia, however, rested on two local factors. First was the sense of proximity to Asia. Of course this proximity was only relative, but from an Australian point of view the eight hour plane journey between Sydney and Singapore constituted a local excursion when compared with the 22 hour trip to Europe. Australia, moreover, was closer than Europe or the US to being in the same time zone as much of Asia (a factor which became paradoxically more important when the growth of the Internet and the availability of cheap telephone calls made real time communication easier than it had been in the past). Proximity once meant danger - the Second World War which brought Japanese forces to the Australian coastline is the only time since the start of European settlement that settler control of the Australian continent was seriously threatened. As memory of the war receded, however, proximity meant opportunity, more in particular economic opportunity. Especially when Britain's accession to the European Economic Community ended Australia's formerly privileged access to British markets, the growth of markets in Asia seemed to be Australia's lifeline.

Asia was also tied up in complex ways with the fragile Australian identity. 
Despite their profound cultural debts to Britain and the US, Australians have consistently sought to define a national identity distinct from their distant, powerful allies. As early as the period immediately after the Second World War, part of this identity was constructed on a claim - part truth, part conceit - that Australia had a special relationship with Asia. This claim began as a simple observation that Australia's strategic interests in Asia were likely to be different from those of Britain or the United States and that both good neighbourliness towards Asian countries and a sound knowledge of their societies and cultures was important to Australia in a way that it was not to other Western states. To the extent that they cared about such things, Australians were proud that any Westerner in Indonesia who spoke Indonesian was commonly assumed to be Australian, because Australians took the trouble to learn the language of their neighbours. The claim grew more ambitious, with the debateable assertion that Australia had never been a colonial power and that its mild nationalist struggle against the British and its strong egalitarian traditions gave it an affinity with formerly colonized states in Asia. In the I970s, the claim was also partly a vigorous assertion that Australia had put behind itself the notorious White Australia Policy which had been directed against Asian immigration into Australia. The most extravagant hope was that Australia would somehow be more important in the world if it could position itself as a bridge between the West and Asia.

By the I980s, the position of Asian studies seemed to have become so strong that prominent Asianists argued for 'mainstreaming' Asia in the curriculum. The plan was that the Australian education system would come to regard Asia as a natural part of every curriculum and no-one would consider himself or herself either educated or even just trained without serious exposure to Asian cases in whatever discipline he or she studied (Ingleson I989). This moment of supreme optimism, however, was short-lived. Despite the still growing importance of Asia to the West and to Australia in particular, during second half of the I980s, Asian studies appeared to enter a period of decline. Indeed, a report prepared by the Asian studies Association of Australia in 2002 painted a gloomy picture: an aging cohort of academic teachers and researchers on Asia who are not being replaced as they retire; static or declining enrolments in Asian languages and studies courses; and meagre government and institutional support (Fitzgerald et al. 2002). After the 2004 tsunami, too, which devastated the Indonesian province of Aceh and generated a massive inflow of Australian aid to Indonesia, there were complaints that Australia could not deliver enough Indonesian translators and interpreters, let alone enough language-competent engineers, health professionals and the like for the relief effort.

Identifying the precise extent of the problem is difficult. The number of 
historians of Asia working at Australian universities has declined seriously, but so has the number of historians in general. Many Asian studies departments have disappeared, but there has been a general trend in Australian universities to fold smaller departments into larger administrative units, mainly so that they can support the substantial administrative staff needed to meet the compliance requirements of the Australian university system. Enrolment in Indonesian studies, both language and non-language has declined significantly, but this decline is certainly related to the specific perception that Indonesia has become a more dangerous destination. Since the first Bali bomb in 2002, the official travel advice provided by the Australian Department of Foreign Affairs and Trade has warned Australians against travel to Indonesia in view of the threat of terrorist attacks. This advice, which is taken to have legal implications for insurance purposes and for the duty of care which Australian employers and educational institutions have towards their staff and towards students, has had a serious specific impact on interest in studying Indonesia.

Calm discussion of the problem has been hampered by the intrusion once again of the issue of racism. Because of Australia's indefensible history of open racial discrimination in its immigration policy for nearly three quarters of a century, and because of the continuing unresolved issue of the relationship between settler communities and the Australian Aborigines, Australian academics are especially sensitive to the possibility that antagonism towards, or even lack of interest in, Asia is a consequence of a deep-seated national racism. For many Asianists, the perception that ordinary Australians had been looking for a good excuse to drop Asia from their view of the world was confirmed by the outpouring of sympathy for an Australian woman, Schapelle Corby who was sentenced in 2005 to 20 years in jail in Indonesia on charges of smuggling marijuana from Queensland to Bali. A well-organized campaign to assert Corby's innocence included claims - some reasonable, some unreasonable - about the Indonesian legal system and to a brief but sharp storm of indignation directed against Indonesia. The incident, however, was tangled with issues of gender and the media manipulation of human interest stories, so that it was far from clear that racism towards Indonesia was the main factor at work.

Gainsaying the Corby story, moreover, as well as the downturn in Asian studies in some parts of the educational system, is the growing complexity of Australia's involvement with Asia beyond bilateral government relations and beyond the Asian studies world of the universities. Business engagement is growing and people-to-people contacts are multiplying in cultural, technological, religious, and social fields. For an increasing number of Australians, a sojourn in Tokyo, Beijing, Hong Kong or Singapore is as natural a part of personal and career development as was once a sojourn in London. Quite apart from the 
over-exaggerated phenomenon of mail-order brides, too, there are now tens of thousands of Australians whose spouses or partners come from Asia. Even in academia, geologists, economists, engineers, pharmacologists, medical scientists and a host of other researchers and teachers are routinely including the study of Asia in their teaching and research.

To the distress of 'real' Asianists, what most of these people discover is that a little knowledge is a useful, rather than a dangerous, thing. A few, of course, blunder in and make serious mistakes, but many of them discover that much of modern Asia is no more alien or difficult than the United States or France. They learn that speaking Korean badly is better than not speaking it at all, that an intimate knowledge of Jakarta politics is not necessary for running a health club in Bali. And they have discovered the Internet, so that the status of Asianists as dutiful keepers and generous transmitters of difficult-to-obtain knowledge about Asia has been significantly eroded. A competent internet researcher is capable of acquiring everything from a pithy comment on the Philippine police force to the identity of the Mongolian finance minister in 2002 to a detailed report on the social consequences of dam construction in Laos to the cultural significance of Khajuraho temple in India. We are coming close to the point, moreover, at which automated translation programmes will begin to erode the special advantage of language competence.

\section{Conclusion}

When Asia was a mystery, Asianists were the gatekeepers to a world of glittering promises and terrifying threats. As Asia becomes routine, those who want to take part in it feel that they can bypass us. In some respects it is as an encouraging sign of the maturity of Australia's engagement with Asia that two or three generations of Asianists have started to work themselves out of a job. The Asian studies endeavour which spearheaded Australia's engagement with Asia in the decades after the Second World War was a promise of future long-term commitment and that commitment is being fulfilled.

The risk in this turn of events is obvious: that a little knowledge will seem to be enough and that Australia will end up with insufficient specialists to address the complex issues that only those with a deep knowledge can tackle effectively. Not everyone would even see this outcome as necessarily bad: in the globalized economy, jobs of all sorts are being exported from one country to another and a narrow-minded economist might well argue that Australia's interests would be served better by buying detailed analysis of Asia piecemeal, as we need it, rather than sustaining an expensive and inflexible establishment of home-grown Asianists. 
The most obvious path for Asianists under these circumstances is to move higher up the knowledge food chain. Rather than delivering knowledge which has now become available on the Internet, we should be fulfilling our original claim that no-one wanting to understand the world can do so effective without taking account of the huge range of human experience in Asia. In other words, we have to play a more effective role as public intellectuals, using the insights derived from Asian studies to make contributions to issues within our own societies. If this means that Asia specialists will also be able to apply a deeper understanding of their own societies to the study of Asia, that is all to the good.

\section{Bibliography}

Anderson, Benedict, 'The Idea of Power in Javanese Culture', Culture and Politics in Indonesia, edited by Claire Holt, Ithaca: Cornell University Press, I972: I-69.

Barr, Michael D., Cultural Politics and Asian Values: The Tepid War, London: RoutledgeCurzon, 2002.

Chakrabarty, Dipesh, Provincializing Europe: Postcolonial Thought and Historical Difference, Princeton: Princeton University Press, 2000.

Cumings, Bruce, 'Boundary Displacement: Area Studies and International Studies During and After the Cold War', Bulletin of Concerned Asian Scholars, Vol. 29, I997: 12.

Fitzgerald, John et al., Maximizing Australia's Asia Knowledge: Repositioning and Renewal of a National Asset, http://coombs.anu.edu.au/SpecialProj/ASAA/ asia-knowledge-book-v70.pdf, 2002.

Foucault, Michel, The order of things, New York: Vintage Books, I970.

Fukuyama, Francis, 'The end of history?', The National Interest, ,

http://www.wesjones.com/eoh.htm, Summer I989.

Ingleson, J., 'Asia in Australian' Higher Education: Report of the Inquiry into the Teaching of Asian Studies and Languages in Higher Education, Vols. I \& 2, Canberra: Asian Studies Council, I989.

Katzenstein, Peter J., 'Area and Regional Studies in the United States', PS: Political Science and Politics, Vol., 34, No. 4, December 2001: 789-791.

Rafael, Vicente L., 'The Cultures of Area Studies in the United States', Social Text, Vol. 4I, Winter I994: 9I-III. 



\title{
The Ebb and Flow of ASEM Studies
}

\author{
Yeo Lay Hwee
}

When the first summit meeting among leaders from the fifteen European Union (EU) member states plus the President of the European Commission and their counterparts from ten East and Southeast Asian countries - China, Japan, South Korea and Brunei, Indonesia, Malaysia, Philippines, Singapore, Thailand and Vietnam - took place in Bangkok in March 1996, it generated quite a lot of interest from several quarters. Because of its high profile nature there was a lot of attention from the media, especially the Asian media.

The fact that ASEM was not a one-off meeting, but was seen as signalling the start of a serious, long term process, generated enough curiosity and desire to comprehend the underlying rationale of ASEM. Following the development of ASEM and predicting its future became a possible intellectual pursuit for academics and analysts from both Asia and Europe.

Broadly, research, studies and articles on ASEM can be classified into the following: those written by political scientists from an international relations angle using either realist, functionalist or constructivist approaches to explain and speculate on the usefulness and effectiveness of such a framework as ASEM for developing cooperation between Asia and Europe; those written by economists using empirical data to examine the trade and investments flows between $\mathrm{EU}$ and East Asian states and extrapolating on the potential of economic ties between the two regions; those written by a multitude of scholars from different disciplines taking a comparative look at regionalism and regional integration processes within each region and evaluating how the regional processes would impact on inter-regional cooperation and vice versa; and those written by journalists, commentators, policy advocates and analysts focusing on specific policy aspects and offering evaluations and assessments of the effectiveness and efficiency of the ASEM process and initiatives.

While there are many books, monographs and articles that specifically focus on ASEM and have used ASEM as the central theme, many more are situated within a broader framework of Europe-East Asia, or Europe-Asia Pacific relations, or within a specific issue area such as human rights, security dialogue, financial 
and monetary cooperation, global governance, etc. The proliferation of papers and articles on ASEM in part has to do with the way the ASEM process developed. The ASEM process is an informal dialogue forum that relies on initiatives and activities to form an important and integral part of the visible output of ASEM. Since most of these initiatives take the form of conferences, workshops and seminars, the corresponding result is a host of papers written on various aspects of ASEM. Some of these were then published in journals or in-house publications of the Asia-Europe Foundation (ASEF), the most visible institution of the ASEM process whose primary mission is to facilitate intellectual, cultural and people-topeople exchange between ASEM member states.

Below is an attempt to cluster and analyse the various key studies and writings on ASEM, and separate the more informed and academic pieces from the opinion pieces and media commentary.

\section{ASEM within International Relations (IR) and International Political Economy (IPE) Framework}

ASEM was officially framed as a forum for promoting cooperation between Asia and Europe, to close the missing link and strengthen an evolving tripolar economic order powered by three engines of the global economy. The three engines were North America, Europe and East Asia. According to this line of reasoning, strong transatlantic ties already existed between America and Europe, and transpacific ties were also increasingly dense because of the Asia Pacific Economic Cooperation (APEC) framework and a series of bilateral ties between US and its various Asian partners. The relations between Europe and East Asia, however, were much weaker, and hence the need to create a forum in which linkages could be built and strengthened.

The official raison d'être has provided the underlying framework in which ASEM has been studied and dissected. It is therefore not surprising that the majority of the studies and articles on ASEM are written by political scientists and IR specialists who approached ASEM as a framework for international cooperation and diplomacy. Political scientists and IR specialists have used all the three main schools of international relations - realism, institutionalism and constructivism - to explain the genesis and development of ASEM.

\section{Realism and ASEM}

Realism has dominated the study of politics and international relations (IR) since World War II. Even with the emergence of the concept of complex interdependence in the I970s, following the popular development of a subfield of world politics known as International Political Economy (IPE), realism 
and its variant, neo realism or structured realism, maintain their relevance in the field of IR and IPE.

What are the fundamental assumptions of realism with regards to IR? For realists, the main actors in the world stage are states which are legally sovereign. Sovereignty means that there is no actor above the states that can compel it to act in a specific way, hence the international system is in a state of anarchy. Other actors such as transnational corporations, regional and international organizations all have to work within the framework of inter-state relations. States are furthermore conceived as rational, self-interested and unitary (coherent) actors. Each will try to maximize their national interests and act to prevent any one state from achieving dominance. Thus world politics is about bargaining and alliances, with diplomacy and the threat of force being the key mechanisms for balancing various national interests. While the attainment of national interests can be achieved through cooperation, the potential for conflict is ever present (Baylis and Smith I997:4).

Realists also assumed a certain hierarchy of issues in world politics - "high" politics of military security and 'low' politics of economics and social affairs. The leading norms of the realists are: autonomy, security, balance of power, rationality and national interests. States are preoccupied with power and security and are therefore predisposed towards conflict and competition. International institutions therefore only marginally affect the prospects for cooperation.

For realists, ASEM is an intergovernmental forum in which cooperation will take place when major national interests coincide. ASEM is also about balancing. Indeed it has been argued by some scholars that the creation of ASEM in itself was an act of balancing. Juergen Rueland, for instance, argued that by the mid-I990s, the Europeans felt increasingly besieged by what they perceived as a gravitational shift in world economics and politics from the Atlantic to the Pacific. This fear was sparked by a decade of rapid growth of East Asian economies in contrast to the protracted recession in Europe in the I980s and early I990s. Compounding the problem is the declining share of European investments into East Asia compared to the US and Japan, suggesting that the EU is losing out in the Triad competition (Rueland 2000:I86). ASEM was thus seen by the Europeans as a forum to gain a foothold in East Asia and a balance to the APEC that linked East Asia to North America. For the Asians, it was also hoped that drawing the EU into the region would provide some sort of balance to the US' role in the region, and a way to diversify their economic links.

\section{Institutionalism and ASEM}

In the realm of IR, liberalism, sometimes referred to as pluralism, is a major challenger to realism. There are many variants of liberalism such as functionalism, 
insitutionalism and transnationalism, but they all question the idea of the state as the main actor on the world political stage. Although not denying that the state is an important actor, they also see multinational corporations, international organizations and other transnational actors as important players especially in some areas of world politics. They also reject realism's pessimism about international institutions, believing instead that institutions such as international regimes and inter-governmental organizations can have an important impact on state behaviour and policy outcome.

Specifically, institutionalists try to explain the continued existence and growing number of international institutions and focus on cooperation in IR rather than competition and conflict. By providing information to actors (and not by enforcing rules in a centralized manner), institutions could enable states to achieve their own objective more efficiently. Institutions matter because they could provide information, monitor compliance, facilitate issue linkages and offer salient solutions to problems of international cooperation. Institutionalists do not deny the importance of power and in fact also accept the realists' anarchical conception of the international system. The essential difference is that they believe that even in the state of anarchy, states could reap gains from cooperation by designing appropriate institutions (Katzenstein, Keohane and Krasner 1999:22).

Institutionalist theory also accepts that states are important actors in world politics and that they behave on the basis of their conceptions of their own selfinterests. Relative capabilities - realism's distribution of power remain important, and states must rely on themselves to assure themselves of gain from cooperation. However, institutionalist theory also emphasizes the role of international institutions in changing conceptions of self-interest (Keohane I993:27I).

Institutionalists examine ASEM with regard to its role as an institutionbuilder, agenda setter and rationaliser in regional and global politics. They ask: Has ASEM contributed to evolution of norms and regimes in governing the cooperation between Asia and Europe? Has ASEM had an impact on the behaviour of individual member states and influenced the way the member states conceive its national interest? Does ASEM provide a platform for cooperation by improving the flow and quality of information and enhancing communications and understanding of each party's position?

\section{Constructivism and ASEM}

Cultural and sociological perspectives in international relations have opened up new ways of looking at inter-state relations and the formation of international norms and institutions. Often known as constructivism, it questions the assumption of rationalism and rationality that underlies realism. Constructivist 
scholars argue that the materialist assumption of realist analysis prevented it from explaining the rapid changes observed in the post-Cold War world. According to these scholars, historically constructed norms, ideas, and discourses need to be analysed before one can make sense of patterns of stability and change in world politics (Katzenstein, Keohane and Krasner, I999:30-38).

The basic argument of constructivism is that reality is created and constructed by beliefs and behaviour. Whenever ideas spread and people believe and act on them, part of the world and the ideas portrayed actually come into being. In this way, realities are constructed. As certain rules and norms are obeyed, institutionalized and enforced through a variety of social control mechanisms, a reality comes into existence (Vasquez I995:22I-222). Therefore constructivist studies have focused on critical historical junctures from which new structural or institutional arrangements, norms and identities emerge and on interactions between existing structures, institutions, norms and agents.

From a constructivist standpoint, conditions such as anarchy and power politics are not permanent features of international relations but are socially constructed. International relations are shaped not just by material forces such as power and wealth but also by inter-subjective forces including ideas, culture and identity. The construction and ascription of identities play significant roles in international politics.

Constructivists essentially viewed ASEM from the angle of identity building. They noted that though officially states still participate in an individual capacity in ASEM, in practice they frequently act along regional lines based on existing or incipient collective identities. Identity building occurred primarily on the Asian side. Here, ASEM has helped to construct the notion of an East Asian region through a series of coordinating mechanisms and the fact that the East Asian countries are dealing with a much more defined regional entity like the European Union. Although the ro East Asian states of ASEM do not constitute a formalized region, EU acceptance and treatment of the Io East Asian states as a collective entity has reinforced the conception of East Asia as a region.

\section{Selected Literature on ASEM from IR/IPE Perspectives}

Within the IR and IPE framework, ASEM is often discussed in relation to regionalism, inter-regionalism, multilateralism and global governance. At times, it is framed in the context of the EU's external relations or its Common Foreign and Security Policy, or East Asia's integration process and identity building.

Examples are Julie Gilson's Asia Meets Europe: Inter-regionalism and the AsiaEurope Meeting published by Edward Elgar; Heiner Hanggi's 'Regionalism through Inter-regionalism: East Asia and ASEM' in Fu-Kuo Liu and Philippe 
Regnier's co-edited book, Regionalism in East Asia: Paradigm Shifting published by RoutledgeCurzon; Christopher Dent's 'The Asia-Europe Meeting and Interregionalism: Toward a Theory of Multilateral Utility' published in the Asian Survey; Richard Higgott's 'ASEM: Toward the Institutionalisation of the East Asia-Europe Relationship' in a co-edited book on Regionalism / Multilateralism and the Politics of Global Trade published by University Of British Columbia Press; Paul Cammack's "Interpreting ASEM: Inter-regionalism and the New Materialism" in the Journal of the Asia-Pacific Economy; Jürgen Rüland's The European Union as an Inter-and Trans-regional Actor: Lessons for Global Governance, a working paper published by the National Europe Centre in Australian National University; Christopher Dent's 'The ASEM: Managing the New Framework of the EU's Economic Relations with East Asia' in the Pacific Affairs; Stephanie Lawson's 'ASEM and the Politics of Regional Identity' in an edited book on Europe and the Asia-Pacific: Culture, Identity and Representation of Regions published by RoutledgeCurzon, and Gerald Segal's ‘Thinking Strategically about ASEM: The Subsidiarity Question' in Pacific Review.

A comprehensive work on ASEM that discusses the three images of ASEM as framed by realists, institutionalists and constructivists, which also looks the into genesis and development of ASEM is the academic book by Yeo Lay Hwee, Asia and Europe: The Development and Different Dimensions of ASEM published In London and New York by Routledge. In this book, the author examines in detail ASEM as Summit diplomacy as seen by realists; ASEM as a meta-regime as seen by institutionalists and ASEM as a constructivist tool for regional integration. The book also offers three scenarios of the future of ASEM depending on which school of international relations prevails.

\section{ASEM and APEC compared}

ASEM was said to be Europe's answer to the Asia Pacific Economic Cooperation (APEC) forum which was launched in I989. Beginning as an informal dialogue, APEC was a response to the growing interdependence among Asia-Pacific economies. It was the primary vehicle for promoting open trade and practical economic cooperation. It took on a higher profile when the then US President, Bill Clinton, hosted the first APEC Summit in Seattle.

At the second Summit held in Bogor, Indonesia, APEC leaders adopted the specific goal of free and open trade and investment in the Asia-Pacific region by 2010 for industrialised economies and by 2020 for developing economies. The Bogor declaration raised the apprehension among Europeans that they would be disadvantaged in economic competition in the Asia-Pacific, and jolted the Europeans to come up with a New Asia Strategy to engage the Asians more 
comprehensively. The alacrity at which the idea of ASEM was taken up and the speed in which it was launched after the idea was floated in late I994 was a testimonial to the observation that ASEM was a reaction to APEC.

The fact that both APEC and ASEM are seen as trans-regional dialogue in response to the forces of globalization inevitably meant interest in comparing the two forums to find similarities, analysing their differences and assessing their impact on international cooperation. Both are seen from an IR perspective as an additional layer in an evolving structure of global governance to deal with complex interdependence. Some of the main articles comparing ASEM and APEC are Hanns Maull's and Noria Okfen's 'Inter-regionalism in International Relations: Comparing APEC and ASEM' published in the Asia-Europe dialogue; John L.V. Avila's 'Regional Cooperation in APEC and ASEM: An Institutionalist Perspective', a discussion paper published by the Philippines APEC Study Center network and Patrick Kollner's 'Whither ASEM? Lessons from APEC and the Future of Trans-regional Cooperation between Asia and Europe'.

While there are ups and downs in both the APEC and ASEM processes, what is perhaps striking is how both forums have shown considerable longevity and durability. Dialogue in both forums has widened but not necessarily deepened. It is also interesting to note that APEC, which started as an economic forum, has widened to take on security issues, particularly non-traditional security issues in response to events after September II, SARS, avian flu, etc. However, without deepening the institutional arrangements, both forums remain limited in their impact on the international arena, and continue to be of "limited relevance" to “management of international relations” (Maull \& Okfen 2004: 247).

\section{ASEM from Country Specific Perspectives}

There is a small cluster of articles that examine the motivations behind a particular ASEM member state's participation in the ASEM process. The three countries that have been more frequently featured in these writings are China, Japan and Korea. The motivations of China and Japan in participating in ASEM are particularly interesting since both countries, in view of their size and economic power and potential, are important partners for the European Union in their own right. EU-Japan dialogue has been established since I970s and the first summit meeting took place in I991. EU-China relations took off only in the late I980s, but have developed rapidly since the mid I990s. EU-Korea relations though slow to take off nevertheless developed slowly but surely after the establishment of the EC delegation office in Seoul in I989.

China's interest and participation in ASEM offers an interesting look into how ASEM has offered a platform for the smaller countries in Asia to engage China 
and socialize China about multilateralism, and at the same time, how China has skillfully used such a multilateral forum to serve its interests by allaying fears of its 'rising power'. Chinese scholars such as Feng Zhongping, Zhu Liqun, Pan Guang, Yang Baoyun, etc, have contributed articles to conferences and workshops which provide deeper insights into Chinese interest in the ASEM process. An outsider look and objective assessment of China's participation in ASEM was written by Sebastian Bersick in 'China and ASEM: Strengthening Multilateralism through Inter-regionalism' in the co-edited volume, 'The Eurasian Space: Far More Than Two Continents' published by the International Institute for Asian Studies (Leiden) and the Institute for Southeast Asian Studies (ISEAS).

A substantive piece on Japan's perception of the ASEM process is Julie Gilson's Japan's Role in the ASEM: Establishing an Inter-regional and Intra-regional Agenda" in the Asian Survey. This article started the whole debate about whether Asian countries such as Japan and others are using the ASEM framework to push for intra-regional integration and as a catalyst for identity building within Asia. In 'Japan and ASEM', Kazuhiko Togo expresses the view that Japan sees "ASEM with its comprehensive agenda including political and security dialogue offered an opportunity for Japan to step up overall relations with its East Asian neighbours in a less sensitive framework" (Togo 2004:I57), and reinforces Julie Gilson's view of Japan's motivation for participating in the ASEM process. Togo's article also elaborated on Japan's contribution toward the ASEM process and also offered another reason for Japan's interest in ASEM - that it offered an opportunity for Japan to rethink its relations with Europe, which though the oldest within East Asia, was not exactly the most vibrant and progressive.

Korean perspectives on ASEM were far and few betwen. The most comprehensive piece was David Camroux's and Park Sunghee's joint article on 'Korea and ASEM' and the commissioned research piece 'Ten Years of ASEM and Korea's Role: A Retrospective Assessment' by Kim Heungchong and Yoo Jung Ha. Camroux and Park argued in their paper that ASEM has added value to South Korea's diplomacy, and has been a useful platform for raising South Korea's international profile and enhancing its relations with the EU. They foresee that Korea will strive to play a more pivotal role within ASEM, something which Kim and Yoo also implied in their research paper.

Though Australia and the US are not members in the ASEM process, their reactions to ASEM offer interesting insights into the problems and potential of such a dialogue forum. Robyn Mudie's research monograph, ASEM and Australia: Implications and Challenges published by the University of Hull, looked into the likely impact and value of ASEM to its members, and henceforth the implications these would have on Australia which has been excluded from the forum. Being the 
first significant regional forum to include both Asian and non-Asian members, there were concerns that ASEM would pose a challenge to Australia's primary foreign policy objective of close engagement with its East Asian neighbours, and undermine the role that Australia could play as middle-man or honest broker between Asians and Europeans.

Davis Bobrow in 'The US and ASEM: Why the Hegemon Didn't Bark?' in The Pacific Review, noted that ASEM's birth and development has not aroused much attention from the US. This could be an indication that ASEM was not seen as a threat to American interests. It could also reflect an "overly self-absorbed and self-centred US, whose parochial perspective ignores any events in which there is a lack of direct or indirect US involvement" (Bobrow I999:Io4-Io6). However, Bobrow further ventured what he deemed was a better explanation for the US opting not to 'bark' at the ASEM process: First, the US are confident that ties between Asia and itself and between the EU and itself have become so established that ASEM participants would be unwilling to endanger them. Second, that ASEM participants were and are too divided to take meaningful collective action on any issues that might pose potential threats to US policies. And finally, that some of ASEM's agenda might actually aid US policy (Bobrow I999:I06-I25). This astute analysis has proven to be quite close to reality judging from where ASEM stands now.

\section{The Issued-oriented Approach}

The official ASEM process comprises three pillars - there is a political pillar that clusters political dialogue and security cooperation; an economic pillar in which all trade and investments and financial issues are clustered, and finally a socio-cultural pillar that encompasses dialogue and cooperation in a wide arena of issues from health and traditional medicine to environment and culture. The framing of the ASEM process has also impacted on the way studies have been made about ASEM. The economic pillar of ASEM has been the most extensively written on and discussed relative to the other issues under the political and sociocultural pillars.

Enhancing trade and investments between the EU and the East Asian states that comprise ASEAN + 3 has been one of the key motivations that led to the birth of ASEM. It is therefore not surprising that studies and articles on economic cooperation within the ASEM framework have attracted considerable attention. Many economists using data and empirical studies on the level of trade and investments between the two regions have written on how the ASEM forum could or could not help engender expansion in economic ties between Europe and East Asia. 
Much less has been written about security cooperation between EU and East Asia as the EU's Common Foreign and Security Policy (CFSP) is still in its infancy, and foreign and security policies remain very much the domain of individual member states. Bilateralism is still preferred when it comes to security issues.

However, with the widening of 'security' to include many non-traditional issues such as human trafficking, migration, international terrorism, pandemic diseases, political and security dialogue has been stepped up in the official ASEM process. But preceding this, Shin Dong-Ik's and Gerald Segal's 'Getting serious about Asia-Europe security cooperation' published in Survival in I997 was the first article that urged Asians and Europeans to "become much more serious about security cooperation" (Shin and Segal I997:138). This was particularly forward looking considering the fact that economics was the underlying motivation, and following the first summit, "there was a great deal of optimism that ASEM can create a serious agenda for economic relations" but there was "far less detailed thought about its security agenda" (ibid:138).

It is interesting to note how much the political and security dialogue between Asia and Europe has broadened to become a central element of the ASEM process, while accomplishments in ASEM's economic pillar have remained below expectations. This in turn has led to more conferences, seminars and workshops that focused on security cooperation within the ASEM framework, and a proliferation of papers that broadly discussed the constraints, as well as the possibilities and potential of greater security cooperation between the two regions.

The official ASEM process has also inspired NGOs to have their own equivalent of an Asia-Europe People's Forum. European and Asia-Pacific trade unions' network have also been convening Asia-Europe forums focusing on labour issues and the social agenda. These forums produced their own plethora of advocacy papers, policy statements and declarations, but they have also given rise to quite a few academic papers that examine the role of civil society in AsiaEurope relations. Gareth Api Richard's 'Challenging Asia-Europe Relations from Below? Civil society and the politics of inclusion and opposition' in the Journal of the Asia-Pacific Economy (I999), explores the significance of politics from below for current efforts to institutionalize inter-regional cooperation through ASEM.

There are also many issue-oriented papers that examine in detail issues such as energy security, resource competition, migration challenges, environmental degradation, etc, with an eye on how Asia and Europe can use different frameworks of cooperation, including ASEM, to engender better management of these challenges.

The events of September is and the war against terrorism have also fuelled 
the need to address cultural and religious issues. ASEM, a forum that links two greatly diverse regions, which are host to some of the world's oldest civilizations, was thus seen as a forum most suited to add value to inter-faith dialogue, and dialogue on cultures and civilizations. ASEM-initiated endeavours to address some of these differences and create better understanding among different cultural and religious groups include the Conference on Cultures and Civilisations and the Interfaith Dialogue which in turn spawned a series of policy papers and statements on these topics.

\section{Critique and Accolades - Commentaries and Analysis}

The bulk of what has been written about ASEM can be classified as opinion pieces and commentaries carried in media, magazines and newsletters. Many of these used an event, a meeting as a starting point to comment on the overall progress, or targeted at a particular outcome.

Leaders such as Goh Chok Tong, Lee Kuan Yew, Mahathir, Chris Patten, Pascal Lamy, Jacques Santer, Romano Prodi and many others have contributed to the many speeches made and published in the media, and occasionally in policy magazines and journals.

There have also been many empirical or prescriptive articles written by officials, diplomats, politicians and business leaders involved directly in the official ASEM process one way or another. Victor Pou Serradell (then Deputy Director-General of DG I of the European Commission) wrote a piece on "The Asia-Europe Meeting (ASEM): A Historical Turning Point in Relations between the Two Regions" in the European Foreign Affairs Review (I996). This was the very first article to provide an insightful account into the genesis of the ASEM and went into great detail on the preparations for the inaugural ASEM summit and its outcomes.

Percy Westerlund (then Director-General of the European Commission's External Relations Directorate) in his paper presented at an academic conference (subsequently published in the book co-edited by Wim Stokhof and Paul van der Velde ASEM: The Asia-Europe Meeting - A Window of Opportunity captured the essence of how ASEM process was initially perceived (at least from the Commission's perspective). In his paper, he reiterated that "ASEM should not and will not replace or overshadow our various bilateral relationships with Asian partners. On the contrary, I would hope that ASEM would help further vitalize bilateral relationships. This follows from the informal nature of ASEM. It is an excellent forum for sending political signals and for the concerting of efforts, but the end results will often depend upon implementation at the bilateral level" (Westerlund i999:25). 
This modest image and expectation of ASEM has been repeated by several European Union officials and leaders in the early years of ASEM. Jacques Santer, then president of the European Commission had this to say about ASEM in his address at the Inaugural Asia-Europe Lecture organized by ASEF: "It was clear from the beginning that the ASEM process cannot replace or substitute for the other bilateral, regional and multilateral forums in which Asia and Europe interact. It would rather complement and stimulate these other forums, with a special added value based on ASEM's unique comparative advantage, and reflecting in particular its multidimensionality, its informality and its high political profile"(Santer 1998).

However, it was only to be expected that perceptions and expectations of ASEM varied, particularly within the academic and policy community. And as the years went by, more and more commentaries and analysis have become critical of the ASEM process for its limited policy relevance and its lack of concrete achievement.

The enlargement of the European Union from 15 to 25, and the impact of enlargement on the ASEM process is also a topic that has attracted attention in recent years. The issue of Myanmar's membership had also led to many debates, but has never been comprehensively treated or discussed in any major articles or commentaries on ASEM.

\section{Conclusion}

ASEM is into its tenth year. A Google search will perhaps reveal that close to I0०० articles, commentaries and a handful of books (in English) have been published on the subject of ASEM and Asia-Europe relations. There is no doubt that the official ASEM process has helped to engender greater interest amongst scholars to examine more closely the state of relations between Europe and East Asia. ASEM as a framework or institution for cooperation and governance has been analysed using various theoretical premises and compared to other similar frameworks or institutions such as APEC. But both academic and policy interests on ASEM began to wane as the official ASEM process languished due in part to rapid enlargement without significant deepening, and in part to the crowded agenda of political leaders. ASEM is now on auto-pilot driven by bureaucrats and while it is likely to continue it is unlikely to create any excitement.

Studies on different aspects of East Asia and Europe relations will continue to grow because of the reality of a rising China, a resurgent Japan, an increasingly confident Korea, and an ASEAN that is serious about deeper regional integration. Common challenges and increasing interdependence will push East Asia and Europe towards each other, ASEM or no ASEM. Which frameworks and forums 
will become the theatres in which East Asia and Europe can act in concert remains to be seen. But the reality of two regions of growing importance and the need for the actors in these two regions to coordinate and collaborate more will become an imperative and no longer a luxury. ASEM studies may disappear, but the need for Asian scholars and policy makers to understand Europe, and for European scholars and policy makers to make out what is Asia will remain.

\section{Bibliography}

Aggarwal, V.K. and M.G. Koo, 'The Evolution of APEC and ASEM: Implications for the New East Asia bilateralism', European Journal of East Asian Studies, Vol. 4, No. 2, 2005: 233-262.

Avila, John L.V., 'Regional Cooperation in APEC and ASEM: An Institutionalist Perspective', Philippines APEC Study Center Network (PASCN) Discussion Paper, No. 99-18, I999.

Bersick, Sebastian, 'The Role of Civil Society in the Asia-Europe Meting Process', Dialogue and Cooperation, No.7, 2003: 55-64.

Bersick, Sebastian, 'China and ASEM: Strengthening Multilateralism through Inter-regionalism', The Eurasian Space: Far More Than Two Continents, edited by Wim Stokhof, Paul van der Velde and Yeo Lay Hwee, Singapore and Leiden: Institute of Southeast Asian Studies and International Institute for Asian Studies, 2004: I38-I54.

Bobrow, Davis B., 'The US and ASEM: Why the hegemon didn't bark', The Pacific Review, Vol.ı2, No.I, I999: I03-I28.

Cammack, Paul, 'Interpreting ASEM: Interregionalism and the new materialism', Journal of the Asia Pacific Economy, Vol.4, No.I, I999: 13-32.

Camroux, David and Christian Lechervy, 'Close encounter of a third kind? The inaugural Asia-Europe Meeting of March I996', The Pacific Review, Vol.9, No.3, I996: 442-453.

Camroux, David and Park Sunghee, 'Korea and ASEM', The Eurasian Space: Far More Than Two Continents, edited by Wim Stokhof, Paul van der Velde and Yeo Lay Hwee, Singapore and Leiden: Institute of Southeast Asian Studies and International Institute for Asian Studies, 2004: I73-I94.

Chirac, Jacques, 'Europe-Asia solidarity reaffirmed', Straits Times, I April I998. Dent, Christopher M., 'The ASEM: managing the new framework of the EU's economic relations with East Asia', Pacific Affairs, Vol.70, No.2, Winter I997: 405-516. 
Dent, Christopher M., The European Union and East Asia: An Economic Relationship. London and New York: Routledge, I999.

Dent, Christopher M., 'ASEM and the Cinderalla Complex of EU-East Asia Economic Relations', Pacific Affairs, Vol.74, No.I, 200I: 25-52.

Dent, Christopher M., 'From Inter-regionalism to Trans-regionalism: Future Challenges for ASEM', Asia-Europe Journal, Vol.I, No.2, 2003: 223-235.

Dent Christopher M., 'The Asia-Europe Meeting (ASEM) and Inter-regionalism: Toward a theory of multilateral utility' Asian Survey, Vol.XLIV, No.2, March/April 2004: 213-236.

Forster, Anthony, 'Evaluating the EU-ASEM relationship: a negotiated order approach', Journal of European Public Policy, Vol.7, No.5, December 2000: 787-805.

Fort, Bertrand, 'ASEM's role for cooperation on security in Asia and Europe', Asia-Europe Journal, Vol.2, No.3, October 2004: 355-363.

Fouquet, David, 'ASEM Summit in Seoul: In search of both direction and impact', EIAS Bulletin, August-September 2000: 3-5.

Freeman, Michael, 'Asia, Europe and human rights: from confrontation to dialogue', Journal of the Asia Pacific Economy, Vol.4, No.I, I999: I00-I22.

Gilson, Julie, 'Japan's role in the Asia-Europe Meeting: establishing an interregional and intra-regional agenda', Asian Survey, Vol.XXXIX, No.5, September/October I999: 736-752.

Gilson, Julie, 'Considering Inter-regional Relations: The Political Economy of the Asia-Europe Meeting (ASEM)', ASEM 2000: New Cooperation between Asia and Europe in the $21^{\text {st }}$ Century, edited by Institute of Foreign Affairs and National Security, Seoul, 200 I.

Gilson, Julie, Asia Meets Europe: Inter-regionalism and the Asia-Europe Meeting, Cheltenham: Edward Elgar, 2002.

Gilson, Julie, 'Making uncommon cause: Forging identities on the margins of ASEM', Europe and the Asia-Pacific: Culture, Identity and Representation of Region, edited by Stephanie Lawson, London and New York: Routledge, 2003 .

Godement, François, 'The role, significance and prospects of the ASEM initiatives', paper presented at Inaugural Conference of Asia-Pacific Security Forum, Taipei, I-3 September I997.

Hänggi, Heiner, 'ASEM and the construction of the New Triad', Journal of the Asia Pacific Economy, Vol.4, No.I, I999: 56-80.

Hänggi, Heiner, 'Regionalism through Inter-regionalism: East Asia and ASEM', Regionalism in East Asia: Paradigm Shifting, edited by Fu-Kuo Liu and Phillipe Reigner, London and New York: RoutledgeCurzon, 2003. 
Higgott, Richard, 'The Pacific beyond: APEC, ASEM and regional economic management', Economic Dynamism in the Asia-Pacific: The Growth of Integration and Competitiveness, edited by Grahame Thompson, London and New York: Routledge, I998: 335-355.

Higgott, Richard, 'ASEM: Towards the institutionalization of the East Asia-Europe relationship' Regionalism / Multilateralism and the Politics of Global Trade, edited by Donald Barry and Ronald C. Keith, Toronto and Vancouver: University of British Columbia Press, I999: I94-2I2.

Islam, Shada, 'ASEM struggles to find a cause', Business Times, 20 October I999.

Islam, Shada, 'Focus on Politics and Trade gives new life to ASEM', EurAsia Bulletin, Vol.6, No.9, 2002: IO-II.

Koh, Tommy, 'ASEAN and the Asia-Europe Meeting', ASEAN Towards 2020: Strategic Goals and Future Directions, Stephen Leong, Kuala Lumpur: Institute of Strategic and International Studies, I998: I35-I52.

Koh, Tommy and Lee Tsao Yuan, 'An Asian-European Encounter of the third kind', International Herald Tribune, I March I996.

Kollner, Patrick, Whither ASEM? Lessons from APEC and the Future of Transregional Cooperation between Asia and Europe, Seoul: Friedrich Ebert Stiftung Cooperation Office, 2000.

Lechervy, Christian, 'Overcoming the obstacles to Europe-Asia political dialogue', Asia Times, I9 September I996.

Lee, Chong-wha (ed), The Seoul 2000 Summit: The Way Ahead for the Asia-Europe Partnership. Seoul: Korea Institute for International Economic Policy, 2000.

Lee Tsao Yuan, 'APEC and ASEM in comparative perspective', paper presented at APEC Roundtable I997, Singapore, 6 August I997.

Lim, Paul, 'Analyzing the ASEM Process', Asia-Europe Journal, Vol.I, No.I, 2003: I2I-I4I.

Machetzki, Rudiger, 'ASEM 2000: Some Background Consideration', Sudostasien Aktuell, special issue, Hamburg: Institute of Asian Affairs, September 2000: 5-8.

Maull, Hanns W and Nuria Okfen, 'Inter-regionalism in International Relations: Comparing APEC and ASEM', Asia-Europe Dialogue, Vol.I, No.2, 2003: 237-249.

Mudie, Robyn, ASEM and Australia: Implications and Challenges. Monograph on Southeast Asian Politics and International Relations, No.4, Hull: University of Hull, I998.

Park, Sung-Hoon, 'ASEM and the Future of Asia-Europe Relations: Background, Main Characteristics and New Challenges', Enlarging European Union and 
Asia, edited by Zainal Mantaha and Toshiro Tanaka,. Singapore: AsiaEurope Foundation and Keio University, 2005.

Pereira, R.W., 'The $5^{\text {th }}$ Asia-Europe Meeting: An Assessment', Asia-Europe Journal, Vol.3, No.I, 2005: 17-23.

Preston, P.W. and Julie Gilson, The European Union and East Asia: Inter-regional linkages in a changing global system. Cheltenhem: Edward Elgar, 200I.

Richards, Gareth A., 'Challenging Asia-Europe relations from below: civil society and the politics of inclusion and opposition', Journal of the Asia Pacific Economy, Vol.4, No.I, I999: I46-I70.

Reiterer, Michael, Asia-Europe: Do They Meet? Reflections on the Asia-Europe Meeting (ASEM). Singapore: Asia-Europe Foundation, 2002.

Robles, Alfredo C, Jr., 'ASEM and Asia-Europe Relations: Between Investment Promotion and the Financial Crisis', Institute Universitari D'estudis Europens, Working Paper No.9, October 200I.

Rueland, Juergen, The Asia-Europe Meeting (ASEM): Towards a New Euro-Asian Relationship. Rostock: Rostocker Informationen zu Politik und Verwaltung Heft 5, Universitat Rostock, I996.

Rueland, Juergen, 'The future of the ASEM process: who, how, why and what?', paper presented at Wilton Park Conference on The Europe-Asia Relations: How could it be improved?, West Sussex, I-5 September 1997.

Rueland, Juergen, 'Asia-Europe Cooperation - The ASEM process: A European view', Asia and Europe: Regional cooperation in a globalizing world, edited by Magnus Jerneck and Ulrich Niemann, Singapore: Asia-Europe Foundation, 2000: 183-I97.

Rueland, Juergen, 'The EU as an inter-regional actor: The Asia-Europe Meeting', Asia-Europe on the Eve of the $21^{\text {st }}$ Century, Suthiphand Chirathivat, Franz Knipping, Poul Henrik Lassen and Chia Siow Yue, Bangkok and Singapore: Centre for European Studies, Chulalongkorn University and Institute of Southeast Asian Studies, 2001: 43-56.

Segal, Gerald, 'Overcoming the ASEMeteries of Asia and Europe', Asia Times, I9 November 1996.

Segal, Gerald, 'Thinking strategically about ASEM: the subsidiarity principle', The Pacific Review, Vol.Io, No.I (1997): I24-I34.

Segal, Gerald, 'Assessing ASEM', Bangkok Post, 2I June I998.

Serradell, Victor Pou, 'The Asia-Europe Meeting (ASEM): a historical turning point in relations between the two regions', European Foreign Affairs Review, No.2, I996:185-210.

Shin, Dong-Ik and Gerald Segal, 'Getting serious about Asia-Europe security cooperation’, Survival, Vol. 39, No.I, Spring I997: I38-i66. 
Stokhof, Wim and Paul van der Velde (eds.), ASEM: The Asia-Europe Meeting - A Window of Opportunity. London and New York: Kegan Paul International and International Institute for Asian Studies, I999.

Stokhof, Wim and Paul van der Velde (eds.), Asian-European Perspectives: Developing the ASEM Process, Richmond: Curzon Press, $200 \mathrm{I}$.

Stokhof, Wim, Paul van der Velde and Yeo Lay Hwee (eds.), The Eurasian Space: Far More Than Two Continents, Singapore: Institute for Southeast Asian Studies and International Institute for Asian Studies, 2004.

Svennson, Thommy, 'The impact of the rise of Pacific Asia: the Asia-Europe summit in perspective', NIASNytt, No.2, I996: 5-9.

Synnottt, Hilary, 'The Second Asia-Europe Summit and the ASEM Process', Asian Affairs, Vol.30, No.I, March I999: 3-Io.

Takashi, Sadahiro, 'Outline of ASEM: a regional forum as a jealousy-driven mechanism', Journal of Japanese Trade and Industry, No.5, I997: 8-16.

Togo, Kazuhiko, 'Japan and ASEM', The Eurasian Space: Far More Than Two Continents, edited by Wim Stokhof, Paul van der Velde and Yeo Lay Hwee, Singapore and Leiden: Institute of Southeast Asian Studies and International Institute for Asian Studies, 2004: I55-I7I.

Westerlund, Percy, 'Strengthening Euro-Asian relations: ASEM as a catalyst', ASEM: The Asia-Europe Meeting - A Window of Opportunity, edited by Wim Stokhof and Paul van der Velde, London and New York: Kegal Paul International and International Institute of Asian Studies, I999: I8-26.

Yepes, Cesar deprado, 'The Effect of ASEM on European Foreign Policies', AsiaEurope Journal, Vol.3, No.I, 2005: 25-35.

Yeo, Lay Hwee, 'The Bangkok ASEM and the future of Asia-Europe Relations', Southeast Asian Affairs, I997, 33-45.

Yeo, Lay Hwee, 'London ASEM and a vision of Asia-Europe ties', ISEAS Trends, No.9I, I998.

Yeo, Lay Hwee, 'ASEM: Beyond Economics', Panorama, No. 4, I999: 5-38.

Yeo Lay Hwee, 'ASEM: Looking back, looking forward', Contemporary Southeast Asia, Vol.22, No.I, April 2000: II3-I44.

Yeo, Lay Hwee, 'The Asia-Europe Meeting (ASEM): From selective engagement to comprehensive partnership', Sudostasien Aktuell, special issues, Hamburg: Institute of Asian Affairs, 2002: 7-I5.

Yeo, Lay Hwee, The Asia-Europe Meeting Process - ASEM: From Sexy Summit to Strong Partnership?, Copenhagen: Danish Institute of International Affairs, 2002.

Yeo Lay Hwee, Asia and Europe: The development and different dimensions of ASEM, London and New York: Routledge, 2003. 
Yeo Lay Hwee, 'Future Direction of the ASEM Process and Implications for Inter-Cultural Dialogue', Asia and Europe: Towards Greater Inter-cultural Exchanges, edited by Zainal Mantaha and Charit Tingsabadh, Singapore: Asia-Europe Foundation and Centre for European Studies, Chulalongkorn University, 2003.

Yeo Lay Hwee, 'Dimensions of Asia-Europe Cooperation', Asia-Europe Journal, Vol.2, No.I, 2004: I9-3I.

Yeo Lay Hwee, 'ASEM Enlargement: For Better of For Worse?', Liberty, Security and the New Global Order, edited by Ramon Molina and Marian Pok, Singapore: Asia-Europe Foundation and Institute d'Etudes Politiques, 2005. 


\title{
Re-orienting Asian Studies
}

\author{
Paul van der Velde
}

This contribution will outline the developments in cooperation between the actors in the field of Asian Studies over the past thirteen years - a period which coincides with Wim Stokhof's directorship of the IIAS. In describing these developments we should keep in mind that he has played an important role as an initiator and as a facilitator. However, this article is not solely about Stokhof per se but about the world of Asian studies in which he has operated. When using the terms Asia and Asian studies, Asia is meant here as the area east of the Indus River up to and including Japan and Asian studies is seen as the set of disciplines and sub-disciplines pertaining to the humanities and social sciences which focus on Asia and whose researchers have a special area-related expertise and a thorough knowledge of the language, culture and history of their area.

\section{Asian Studies in Europe up to 1950}

Four distinctive features of Asian Studies in Europe can be distinguished: The first is that Europe has a long tradition in Asian studies spanning more than 500 years. The institutionalization first took place in Asia itself with the foundation of the Dutch Asian Learned Society in Jakarta in I778, followed soon after by its British equivalent in Calcutta in 1784 . The French established their Institut National des Langues et Civilizations Orientales (INALCO) in Paris in I795. A second distinctive feature of Asian Studies in Europe is that it was born out of the colonial encounter. (An exception is Germany where Orientalism was fuelled by Romanticism.) A third feature is the growing quality of Asian studies which developed into specializations such as Indology, Japanology and Sinology (Chairs for Indology were founded in Paris (I8I5), Bonn (I8I8), and Oxford (I833). The fourth characteristic is the predominant focus of Asian studies in Europe on philology, history, ethnography, and religion.

A clear and demonstrable decrease in interest in Asian studies took place in the aftermath of World War Two. This decrease was caused by several factors. The granting of independence to the Dutch, British and French colonies in Asia, shortly after the end of the war, put an end to the opportunities for young scholars 
to work as civil servants in the colonial administration. Before the war a host of them had the opportunity to develop a thorough knowledge of, and expertise in, topics related to their sphere of work. Upon their return to Europe many held professional chairs in Asia studies. They used learned journals and conferences to exchange their views in a European context. This process of accumulating knowledge about Asia in loco and disseminating it in Europe came to a halt after the independence of the colonies. The journals led an increasingly precarious existence and focused almost completely on classical Asian studies.

In the immediate post-war period, Europeans became more and more involved in the reconstruction of their national states. The war had left them penniless and their infrastructure was in ruins. Endeavours to reconstruct their countries confronted the Europeans with two crucial insights. Firstly, without the US and its Marshall Plan, the European countries would have been extremely weak in a political as well as economic respect. Secondly, to avert disasters such as future wars, steps were to be taken to build a strong economic Europe. The predominant focus on the Atlantic relationship and a profound preoccupation with the convergence of national forces in Europe further distracted Europe's attention from Asia. Add to this the growing tension in the framework of the Cold War and you may understand that it was only after the fall of the Berlin Wall, coupled with the slowly developing perception of an Asian miracle, that Europe's renewed interest in Asia was jumpstarted. It will come as no surprise that motivation fuelling EU's interest in Asia stems from an unambiguous combination of economic and strategic considerations. Asia in this century will account for more than half of the world's population and has the potential to become both the world's most powerful economic region and, consequently, a political powerhouse of the first order.

To sum up: the loss of the colonies, the Cold War and the preoccupation of the national states with reconstruction in a wider European framework resulted in an persistent disinterest by the national authorities in the study of Asia and a consequent lack of funding for Asian Studies.

\section{Asian studies in Europe from 1950 to the present}

The decline in Asian Studies in the post-war era could be seen in academic circles among the former European colonial powers and this had a ripple effect stretching to other countries in Europe which had not had a colonial presence in Asia, such as the Scandinavian countries, Austria and Italy. A host of eminent scholars (many of them were practically oriented) were forced to leave. Many took up positions in American universities and were instrumental in setting up study centres at their new places of employment, which eventually resulted in the 
burgeoning of contemporary Asian studies in the United States. The founding of the Association for Asian Studies (I94I) gave Asian studies in the US a focus, it became an academic meeting point and recruitment centre, certainly at its Annual Meetings at which the majority of American Asia scholars gathered.

If we take a look at Asian studies in Europe during the second half of the $20^{\text {th }}$ century, we ineluctably have to acknowledge a quantitative and qualitative decline. Asian studies in Europe has been very specialized, idiosyncratic and disproportional, focused on philology, history and anthropology. The Guide to Asian Studies in Europe, published in I998, gives a telling picture of the nature of Asian studies in Europe. Only I5\% of the research conducted can be labelled contemporary and geared to the present-day situation in Asia; in terms of discipline, history accounts for more than $40 \%$ of the total output. Cogently, in Asian studies in Asia, we see the reverse: $85 \%$ of the studies conducted deal with contemporary issues, in the field of economy, politics, law and development.

Contemporary studies is meant here as the disciplines such as political sciences, strategic studies, international relations studies and social sciences. It is beyond doubt that the study of a region demands an intimate knowledge of the language, culture and history of the area under investigation. La longue durée is a prerequisite for insightful research. However, Asian studies in Europe tend to be conservative and more concerned with the uniqueness and cultural diversity of the countries and peoples in the region. A survey of Asian studies in the Netherlands and Europe taken in conjunction with a review of the infrastructure and resources applied in this field of study reveals a hard core consisting of languages and cultures, social sciences and history.

Concealed within these disciplines, there is a great diversity of approaches born of the different research traditions of the countries in which these studies have been established. Another feature of European Asian studies is the opposition between 'universal' and 'area-specific' approaches, which exposes the field to misguided notions derived from 'Orientalism' or leading to unwarranted claims of uniqueness. It is not necessary to elaborate on the well-known discussion of the pros and cons of the area studies approach versus the pure disciplinary approach because it is a non-discussion. An exclusive area studies approach could fragment disciplinary coherence and limit the scope and quality of research. Asia should be studied from a thematic i.e. interdisciplinary and comparative perspective.

As far as the field of Asian studies has demonstrated an interest in public policy and strategic studies, it has been and still is dominated by colonial practices. In the post-colonial period, public policy studies of Asia have taken on the guise of developmental studies, concerned with state interventions for the benefit of specific target groups in the less developed parts of the region. 
It is estimated that in Europe between six to eight thousand people currently work in Asian studies. They are part-time or fulltime Asia scholars - they have area-specific knowledge and master an Asian language. Asia scholars are dispersed over many universities, institutes and area study centres. The amount of knowledge is considerable but dispersed. Further, if you take into account the many large sets of data on Asia in European libraries, collections and archives, you can imagine what a huge potential there is to further develop Europe's Asia expertise.

The question arises, why have Asian studies not played a dominant role in the Asia-Europe relationship or to phrase it differently, why have they not contributed to the cultural dimension in the Asia-Europe relationship? Possible answers could be: European Asia scholars are mostly individualists; they work in isolation in small departments; and they are not used to organizing themselves so as to create greater visibility. Apart from this, there is the dichotomy between scholars from the classical, philosophical tradition and the contemporary Asia researchers. Studies by Asia scholars tend to focus on small-scale, long-term research and they are not used to large-scale programmes, or taking into perspective the wider picture. In Asian studies there is much diversity in terms of scientific approaches. While this is an asset to the field, it does not help to organize people into cooperative research programmes. Quite a number of Asia scholars abhor the idea of multidisciplinary research, where, for instance, social sciences and humanities would complement each other.

Perhaps this draws a too despondent picture of the state of the art of Asian studies in Europe. There are clear indications that in the last two decades of the $20^{\text {th }}$ century, a greater interest developed in contemporary studies combined with a gradual retreat from the formerly dominant focus on linguistics and on philology. Institutes such as the South-Asia-Institute in Heidelberg (I960) and the Nordic Asian Studies Center in Copenhagen (1967) carried the banner as advocates for contemporary studies in Europe. At many universities and institutions there is now a demonstrable tendency to offer courses in the classical disciplines as well as teaching contemporary issues.

A short check of dissertations defended at European universities since I990 reveals that the following themes have been most popular: labour relations, democracy, economic relations, regionalism/globalism, ethnicity, identity and/or nationalism, the rural versus urbanity, minority rights, migration, state / nation / regions, tradition and modernity, women and gender, international relations, and of course post 9-II security.

Bearing this in mind we should now elaborate on the endeavours made to arrive at the organization of Asian studies at a European Level. Three major 
initiatives will be singled out for that purpose and elaborated on: I. the European Science Foundation Asia Committee; 2. Programme for Europe-Asia Research Linkages and: 3. the European Alliance for Asian Studies.

\section{European Science Foundation Asia Committee (ESF-AC)}

In I992, the Ministers of Education and Research from France and the Netherlands approached the European Science Foundation in Strasbourg. The ESF is the European association of more than 70 major national funding agencies devoted to scientific research in 29 (European) countries. It represents all scientific disciplines - from the exact and engineering sciences, to the humanities and social sciences. In their joint letter to the president of the ESF, the two ministers asked the ESF to stimulate co-operation in the so-called Asian studies, in particular in the humanities and the social sciences. It is puzzling that these two ministers asked for special assistance from an international European institution in matters which clearly pertain to the sphere of their own national responsibility. How did this come about?

At the time when the ministers approached the ESF, the national authorities responsible for Asian studies had become acutely aware of the importance of Asia, heightened by their continuous neglect of the field and the necessity to co-operate and co-ordinate Asian studies in Europe. In reaction to the ministers' plea, the ESF established the Asia Committee in I994 which aimed to bring together the fragmented forces of Asian studies in Europe, thus improving its standards of research and expertise and benefiting the participating countries and the European Union as a whole. Delegates on the Committee itself represented a wide range of research councils, scholarly institutions and constituencies. This variety and breadth of experience has enabled the Committee to obtain an unusually comprehensive and considered view of the resources, strengths and weaknesses of Asian studies in Europe. Such a view was certainly beyond that available to any national or other European body. The Committee, which operated successfully for six years, adopted a variety of scientific instruments to achieve its goals: fifty-five interdisciplinary workshops were organized jointly by European and Asian partners; publication grants and travel grants were given; a postdoctoral fellowship scheme for promising young scholars was designed to promote mobility among researchers, and professional European Associations for Asian studies were supported.

Through these activities, the ESF-AC developed Europe-wide research strengths and improved links between European centres and researchers and their counterparts in Asia. This support has been firmly based in both the humanities and social sciences arenas, and a substantial share of it has focused 
on contemporary issues of importance to European policy makers. In this context it is elucidating to emphasize that the humanities and social sciences are not independent fields of study, but are closely related and both are indispensable to understanding the workings of Asian societies in the broad sense. The functioning of governments, economies, management, and scientific systems, for example, all involve research that embraces both fields of study. Supplementary to the direct results of the committee's activities, European and Asian networking has been greatly improved with real but unquantifiable results.

One of the most important results of the ESF-AC has been the creation of new networks at various levels. Through the ESF-AC, isolated scholars in small institutes scattered over Europe have become able to establish new links at a disciplinary or interdisciplinary level. It also supported scientific gatherings connecting and engaging European scholars in Europe-wide, Atlantic or AsiaEurope networks.

One other feature of the ESF-AC's work is the scope of the European group that has benefited and been drawn into the wider field of Asian studies. The ESF-AC's role in the establishment of associations of Asian studies in several European countries such as the Netherlands, Spain, Germany, and, more recently, France clearly reflects this. In addition, the ESF-AC has established a platform for the six European Associations for Asian studies to strengthen their roles and enable them to fulfil their missions more effectively.

Any appraisal of the Committee's record would confirm that it has had an impact in the field of Asian studies of a kind qualitatively different to what any member country could have obtained individually. And, judged by contemporary research standards, this has been achieved at extremely small cost. What the ESF-AC has done, therefore, is to enhance the value of local research funding by building bridges within Europe and between Europe and Asia. Through the work of the ESF-AC there is now some Asian studies presence in almost every European country and expertise in contemporary studies and social science based work has improved enormously.

Even before the ESF-AC was disbanded, some of its members came up with the idea to involve Asian participation in setting up a multilateral research project. In a meeting in Seoul in October 1998 the Programme for Europe-Asia Research Linkages (PEARL) was established. The following institutes were involved: Centre for Strategic and International Studies, Jakarta; Department of Political Science, Yonsei University, Seoul; European Studies Programme, Chulalongkorn University, Bangkok; Faculty of Social Science and Humanities, National University of Malaysia, Bangi; Institute of Southeast Asian Studies, Singapore; École Française d'Extrême Orient, Paris; Institute of Asian Affairs, 
Hamburg; International Institute for Asian Studies, Leiden; Nordic Institute for Asian Studies, Copenhagen and School of Oriental and African Studies, London. PEARL was to be a network of researchers from Asia and Europe, representing leading Asia and Europe studies departments in the field of the humanities and social sciences. The need for this was felt both in Asia and Europe in order to boost the research interaction between the two continents which seemed opportune against the background of the Asia-Europe Meeting (ASEM) which was established I996.

At the time of the launch of PEARL it had already become abundantly clear that the focus of Asia-Europe relations was on politics, economics and security. According to the members of PEARL research should be much higher on the agenda of ASEM. A broad-based research partnership encompassing the humanities and social sciences at the two ends of the Eurasian continent would deliver enormous intellectual benefits to scholarship at the national, regional and global levels. This would gradually develop into a shared research culture which would enable attention to be more effectively directed to issues which are shared between the two regions, as well as globally. But when it came down to basics the representatives of these institutes were not able to deliver the organizational and financial back-up for PEARL once the ESF pulled out. They then reasoned: Why leave a perhaps uncertain but comfortable national environment and swap it for an unsure future oriented experiment?

\section{The European Alliance for Asian Studies}

Another example of co-operation in Europe is the so-called European Alliance for Asian Studies, or the Alliance as it came to be known, which began as a cooperation between the Nordic Institute of Asian Studies (NIAS) in Copenhagen and the International Institute for Asian Studies in Leiden in I997. The initiative taken to enlarge the partnership in I998 was inspired by the new world order that emerged during the last decade of the 2oth century. This was an order in which Asia developed very rapidly in every respect: cultural, economic and technological.

A more profound mutual understanding between the two continents is essential to future academic research. Existing expertise on Asia in Europe has to be improved and optimized to meet the needs of Europe and equally those of Asia. The Alliance is hence aimed at restructuring Asian studies where necessary by combining the individual strengths and endeavours of the various existing institutes of Asian studies.

The policy of the Alliance is aimed at the establishment of scholarly excellence in central areas of research and expertise on Asia by building up high quality, 
border-transcending research with a strong focus on contemporary issues; creating networks with Asian and other research institutions and scholars; strengthening the links and communication between academic research on Asia and non-academic institutions and actors.

Much has been achieved in the past nine years, because of its broad range of activities. The Alliance has grown into a well-known international network bringing together expertise in Asian studies in Europe and facilitating scholarly excellence to the benefit of research institutions and the European community at large. The Alliance was enlarged with new members such as the Institute of Asian Affairs in Hamburg (current name: Institute of Asian Studies), the European Institute for Asian Studies in Brussels, the Asia-Europe Centre at Science-Po in Paris (now called CERI-Sciences Po), the Centre for East-Asian Studies in Madrid, the School of Oriental and African Studies in London and the Swedish School for Advanced Asia Pacific Studies in Stockholm.

The network is expanding not only in Europe but also in Asia. Upon the initiative of the Alliance a joint Annual Asia-Europe Workshop Series was set up in 200I in co-operation with the Asia -Europe Foundation (ASEF). The series supports workshops which focus on contemporary topics that are of relevance to both Asia and Europe. Moreover, the Alliance is seeking co-operation with a yet-to-be-formed alliance of Asian institutes in Asia. The initiative to constitute such an alliance has been taken by the Chinese Academy for Social Sciences in Beijing. Once the Asian Alliance has been created, close links will be fostered with its European sister organization and eventually this will lead to an AsiaEurope Alliance for Asian Studies.

\section{Asia-Europe Meeting}

In 1994 the European Commission published Towards a New Asia Strategy, in which the idea of a first get-together of EU countries and ASEAN countries was launched. The initiative came at the right time: absorbed in its own integration process and in developing a strategy towards its eastern neighbours, the EU had simply neglected its relations with Asia for a long time. In the meantime the European Commission had gradually become aware of the unprecedented economic developments in the ASEAN region and of the growing strategic role ASEAN intended to play in that part of the world.

From the very beginning the IIAS looked upon the idea of rapprochement between Asia and Europe as a potentially very effective vehicle for closer cooperation between the two continents. Therefore the IIAS did not hesitate when it was asked for input in the preparatory meetings of the Asia Europe Meeting (ASEM) in Venice and Manila in I995. On the basis of these meetings Goh Chok 
Tong, the then Prime Minister of Singapore, produced a document in which he envisaged a rapprochement between Asia and Europe in three stages: I. Filling the knowledge gap / obtaining 'mutual understanding'; 2. Engaging in a process of constructive dialogue, and 3. Reaching consensus on the basis of shared values and goals.

The first meeting of Heads of State took place in Bangkok in I996. In the following years ASEM developed into an interregional platform for consultation and discussion between Asia and Europe. For a time, the momentum was nearly lost due to the Asian economic crisis. During the London meeting (I998) it became increasingly clear that ASEM remained useful to both regions as a forum to stimulate dialogue at a range of levels. The aims of ASEM are quite vague and somewhat ostentatious. Moreover, there seems to be little connection between the measures taken or the instruments chosen by the heads of state to obtain these goals. Basically, the whole ASEM process is still waiting for a crucial idea or concept that will boost its development.

Unfortunately the ASEM process has been hampered by unexpected events such as the Asian financial crisis, the political problems in Indonesia, the Myanmar problem, the tsunami catastrophe, SARS, Avian Flu, the dramatic events in the Balkans and the institutional crises in the European Commission and the European Parliament and recently, the negative vote of the French and Dutch populations concerning the European constitution. Although these events have caused a higher mutual awareness, it was not always in a very positive sense. It is striking that in cases where a concerted action between ASEM countries could probably have been effective (e.g. the Asian crisis), the cooperation between European and its Asian partners has been quite limited, unproductive or sometimes even lacking.

\section{The pillars of ASEM}

ASEM has three pillars: the economic domain, the political domain, and 'the rest', in which civil society issues, culture, education, and research are heaped together. Needless to say, ASEM is first and foremost an economically driven forum. This can clearly be seen from the plethora of meetings concerning trade, investment, finance, and business, as well as from the activities developed within this first domain: the Asia-Europe Business Forum, Trade Facilities Action Plan, Investment Experts Group Meetings, Investment Promotion Active Plan, the ASEM trust fund, and the European Financial Expertise Network, to mention a few.

In the political domain the situation is less concrete: the Asian partners appear to be apprehensive whenever such topics as human rights and good governance are suggested for the agenda. At the third summit in Seoul, however, 
commitments were made to strengthen the political dialogue, giving special attention to human rights issues, and to address the global implications of such problems as illegal trade in weapons, drugs, and workers of regional and interregional migration. At the Copenhagen meeting (2002) a joint declaration on Cooperation Against International Terrorism was adopted. However, it is difficult to perceive what has actually been done about these issues in the ASEM framework. Reports cannot easily be found linking the chairman's statements and intentions with what actually has been accomplished and what the results are. The parties involved thus mainly consider the ASEM process a way to deepen relations between Asia and Europe and as such it is a time-consuming exercise in building mutual confidence.

It is the third pillar which in fact is often treated in a somewhat step-motherly way, or in other words: culture and civil relations in ASEM are seen by most politicians merely as functional prerequisites for successful economic relations. Fortunately the ASEF has done a lot to promote better mutual understanding through intellectual, cultural and people-to-people exchanges. A cascade of all sort of initiatives and actions has flooded both regions, ranging from cultural festivals, young entrepreneurs forums, meetings for editors, young leader and academic symposiums (e.g. the Asia-Europe Workshop Series), Asia-Europe Young Artists Painting competitions and last but not least the establishment of the ASEMDUO fellowship programme. ASEF has, given its limitations and objectives, done a great job on the cultural dimension of the ASEM process but it misses - inevitably given its brief and scope - a clear focus and depth. Moreover, ASEF runs the constant risk of becoming an entity on its own - no longer perceived by the public as a (partial) actualization of the ASEM process.

Pointing to the free exchange of views between European and Asian heads of government, the EC is always quick to proclaim the ASEM process a success. Still, sceptics might point out that economic relations between Asia and Europe would have prospered without ASEM anyway. In the second domain, less progress can be demonstrated. In the third domain many opportunities have neither been seen nor seized upon.

ASEM should concentrate on the third pillar. It is from this very diverse and varied storehouse that new joint activities are to be expected. Right now, the existence of ASEM is barely noticed by the people of the ASEM member states. If we would like to improve this situation and make our 'ASEM people' more aware of each other and of ASEM, we should choose for a more bottom-up trajectory, i.e. ASEM should be more engaged in the numerous initiatives ventured by various sectors from civil society such as universities, research groups, professional associations, labour unions, NGOs, parliamentarians, artists and think tanks. 


\section{A new perspective for ASEM?}

Until now relations between Asia and Europe have been dominated by policies that place economic growth above all else. However, a more balanced policy with special attention to the third pillar of the ASEM process will in the end yield a more promising cooperation. ASEM is still in need of a long-term internally driven strategic vision that can be translated into clear and concrete objectives, backed up by all ASEM members. This is of course not an easy task; ASEM is like a patchwork quilt, a mixed bag of 35 different countries (plus the EC) with many dissimilarities in their cultural, ethnic, ethic, political, economic and societal systems; some have a shared history, while others have nothing in common in terms of the past. However, this rich tapestry of ASEM is also its biggest asset.

In ASEM we have created a unique mechanism for dialogue between two regional concentrations of a different nature and with rather different objectives. It is still a very frail instrument: there is a danger that the momentum built up in the first decade will disappear. It is therefore no wonder that Wim Stokhof in his lecture on the occasion of receiving a honorary doctorate from the Universitas Indonesia in Jakarta (July 2006) entitled Beberapa catatan tentang jaringan Studistudi Asia khususnya di Indonesia pleaded for the following steps to be taken in order for ASEM to become more effective and more visible: "I. Reformulate ASEM's objectives; 2. Establish a new format of rules of engagement; 3. Start institutionalization through setting up joint institutes and programmes with well defined objectives, concrete deliverables, good monitoring, evaluation and reporting procedures, and a clear financial commitment; 4 . Install a joint interregional secretariat with two main tasks: to monitor the new format of rules of engagement and to facilitate and implement jointly taken decisions".

In this lecture Stokhof also made a strong plea for the foundation of ASEM Institutes for Advanced Studies in Asia and Europe where young scholars from both regions work together. This aims to replace the lopsided Eurocentric Euro Studies Programmes introduced by the EC in China, Thailand, the Philippines, Vietnam and Singapore. He also argues for an ASEM research council with the following tasks: monitoring and facilitating the ASEM Institutes for Advanced Studies; creating a network of existing centres of expertise and institutes in Asia and Europe; initiating activities (in close cooperation with ASEF) such as symposiums and master classes and increasing the visibility of Asian studies in Europe and Asia and Europe Studies in Asia.

To implement these proposals one could build on experiences derived from initiatives related to ASEM such as the Asia-Europe Network of Museums (ASEMUS), which was formed in 2000 on the basis of a concept launched by the IIAS. The ASEMUS was started as a co-operative project between museums in 
Asia and Europe with the support of the ASEF. Its objectives are: to increase the sharing and joint use of museum collections in Asia and Europe; to share and transfer professional museum competence; to make repositories of documentation and databases jointly available and to develop joint exhibitions. ASEMUS is run by an executive committee which is backed by a secretariat. The membership of ASEMUS consists of museums in Asia and Europe and the website provides a wide variety of information on the participating museums.

Looking back from the vantage point of 2006 we can conclude that ASEMUS has organized a series of meetings between museum curators from Asia and Europe; this has helped them get to know each other better, share their problems and successes, and even find common solutions to technical problems. This network is operating quite well. In ASEMUS the first steps have been taken to create what Wim Stokhof and others have been striving for: a global collection, not a series of sets of objects belonging to a certain nation, ethnic group, museum or person, but a set identifying mankind in all its various representations. The same idea was behind the ASEM Research Platform and the ASEMeeting place.

\section{ASEM Research Platform and ASEMeeting Place}

In the Chairman's statement of the Fourth ASEM Foreign Ministers' Meeting (June 2002) the Foreign Ministers called for the establishment of a portal linking all existing ASEM related websites. They viewed such a portal as an important tool in facilitating and deepening the ASEM process. In January 2002, the IIAS had already launched the idea of setting up such a portal and by the time of the Foreign Ministers' Meeting try-outs of the website had been executed.

This was by no means a coincidence. Since its foundation in I993 the IIAS had been involved in improving and facilitating the relations between Asia and Europe in the academic and cultural fields. From the outset the IIAS has worked closely together with ASEF. To name a few examples: the IIAS has set up an Asia specialist database for ASEF; ASEF and IIAS co-organized the cultural manifestation surrounding ASEM 2 in London (I998); it has covered the activities of ASEF in its IIAS Newsletter and is co-organizing the Asia-Europe Workshop Series with ASEF: IIAS organized the Young Leaders Meeting, the ASEM Summer University and will co-organize the Young Parliamentarians Meeting in 2007 in The Hague. On the basis of these past and future cooperative projects working together on the further development of the ASEM portal could have been construed as a logical next step in the development of the ASEF-IIAS cooperation.

The ASEM website, which was an integral part of the ASEM Research Platform (ARP), was launched a couple of weeks before ASEM 4 in Copenhagen 
(September 2002). It embraced diverse aspects of the ASEM process. One of the main goals of ARP was to sensitize people at all levels of society in Europe and Asia to the Asia-Europe Meeting process. One of its first activities was to create an ASEM portal meant to facilitate the search for information and research on ASEM by structuring all relevant information about this process. It contained: texts of official documents pertaining to ASEM; all available electronic publications and titles of other relevant publications in the digital library; the ASEM agenda and the civil society activities within ASEM and other relevant information pertaining to ASEM.

An equally important goal was to inform the scientific community about ASEM research and facilitate contacts among scholars studying ASEM. It aimed at a division of labour between the ASEF division of intellectual exchange, which could concentrate on short-term projects, and the ARP, focusing on long-term projects. The ARP could build on the expertise in Asia-Europe relations it had built in the past. In this way it would have been able to engage the efforts of thousands of scholars across the ASEM community. The spin off from their endeavours would have been considerable. It derives its influence, on the one hand, from the formulation and analysis of the issues that move Asian and European governments and the media, and, on the other hand, through the students trained and educated in this culture who move outside academia to other positions in society. Developing and sustaining such a Eurasian research culture would have presented a small financial investment in comparison to the benefits that would have been gained.

This ARP initiative was welcomed by persons and institutions involved and interested in ASEM such as officials, diplomats, journalists, representatives of civil society organizations, scholars and so on. By 2004 the website offered a wide variety of information and documentation on ASEM and the number of visitors to the website grew both from a qualitative and quantitative point of view. This meeting place should have become an interactive environment where it is easy to come into contact with representatives of all layers of society in Asia and Europe and react to their ideas and opinions concerning ASEM. It would have contributed to a higher degree of awareness of the ASEM process because the main idea behind this environment is making people at all levels of society in Asia and Europe increasingly conscious of the existence of the process.

The further development of this ASEMeeting Place under the aegis of ASEF would have been a logical next step in view of the many possibilities that constructing such a repository / database offers. However, only the information pertaining to the agenda and official documents were incorporated in the ASEM Information Board which is now operated by ASEF. This more narrow 
interpretation of the idea of disseminating factual information is a missed opportunity to boost the ASEM process in general and the visibility of the process in particular.

\section{International Convention of Asia Scholars}

Whereas the ESF-Asia Committee solely consisted of representatives of Asian studies centres in Europe, PEARL included both members from Asia and Europe studies institutes in both continents. The Alliance consisting of European institutes always strived for a mirror organization in Asia which will become a reality at the end of 2006 . While all these initiatives are about cooperation between Europe and Asia, the International Convention of Asia Scholars (ICAS) tries to involve the entire world in the study of Asia.

ICAS was at the outset an experiment in terms of the parties involved, the nature of the participants, the contents, the manner of organization, and its size in terms of participants. How did the ICAS come about? As of I995 the Association for Asian studies (AAS) and the IIAS had been thinking of ways of internationalizing Asian studies. This transatlantic dialogue gradually matured and was thought of as a process involving American and European Asia scholars. Its main goals are to transcend the boundaries between disciplines, between nations studied, and between the geographic origins of the Asia scholars involved.

The idea of ICAS was officially launched in I997 by the IIAS, in close cooperation with the AAS. Apart from the AAS and the IIAS the six European Asian studies Associations also joined and a programme committee was established consisting of representatives of all parties involved. There was never any doubt that Asia scholars from all over the world should have the chance to participate and once the convention was announced, enthusiastic replies came from every quarter of the world, especially Asia. Thus ICAS became a platform on which Asia researchers from all corners of the world could study problems of interest to all.

ICAS has grown into the largest biennial Asian studies event outside the US and covers all subjects of Asian studies. There ICAS has now become the only major, regular Asian studies event to take place. On average the number of participants now varies from Iooo-I500 people.

The organization of ICAS I was put into the hands of the IIAS and it was held in Leiden in I998. More than 350 universities, institutes, and organizations were represented. There were nearly I000 participants from 40 countries; I30 panels were held; and there was a remarkably equal distribution continent-wise. New cooperative initiatives were developed. ICAS 2 was hosted by the Freie Universität Berlin and took place in 200I. About 800 scholars attended around roo panels 
and 500 papers were presented. During this convention the ICAS secretariat was founded. The secretariat co-organizes the events with local partners, guarantees the continuity of ICAS and it organizes the ICAS Book Prizes. It was also decided to have future meetings of ICAS in Asia and make it a biennial meeting.

The Faculty of Arts and Social Sciences and the Asia Research Institute, National University of Singapore jointly hosted ICAS 3 in 2003. Over I,000 scholars from 54 countries participated and some 940 papers were presented in 250 sessions, on a wide variety of topics. ICAS 3 also provided a platform for scholars to explore ways of coordinating Asia research in Asia. ICAS 4 was hosted by the Shanghai Academy of Social Sciences in 2005 in the Shanghai Exhibition Centre. It had slightly more participants and number of panels than ICAS 3. At the opening ceremony of ICAS 4, the ICAS Book Prizes (humanities, social sciences, best $\mathrm{PhD}$ ) were awarded for the first time. Also the publication of selected proceedings of ICAS was announced.

ICAS 5 will be hosted by the Institute of Occidental Studies (IKON) and the Institute of the Malay World and Civilization (ATMA), Universiti Kebangsaan Malaysia in August 2007. It will be held in the Kuala Lumpur Convention Centre and is expected to draw I500 specialists in the field of Asian studies to Kuala Lumpur.

Each convention has been organized by respected academic institutions such as the Freie Universität Berlin, the National University of Singapore and the Shanghai Academy of Social Sciences. During the conventions prominent Asia scholars hold keynote addresses. Among the speakers, for instance at ICAS 4, we counted Prof. Wang Ronghua, Prof. Barbara Andaya, Prof. Jean-Luc Domenach who talked on such varied topics as 'The future of Asia', 'Cross-Cultural Conversations in History', and 'Towards a European Point of View on Asia'.

In the panels virtually every topic important in the field of Asian studies has come to the fore. A cross-disciplinary border transcending approach is stressed which enhances a fruitful dialogue among the participants who originate from more than 50 countries in Asia, Europe and America which represent about 500 institutes working in the field of Asian studies. This encounter between researchers coming from different cultural and paradigmatic backgrounds results in new insights in the way they will approach their topics in future research. On a personal level this leads to long-term academic friendships that stimulate a global approach to research on Asia.

ICAS does not perceive itself as an isolated academic event. ICAS clearly links to the city and the country wherein it is held. This is brought about by connecting ICAS to the city and vice versa by way of a wide variety of cultural events such as exhibitions, performances, concerts and films. 


\section{Asia Studies Meet}

It is no wonder that Wim Stokhof will remain involved in this ICAS process as Secretary General till 20II. ICAS will put the network which he has built up over the years in the field of Asian studies and beyond to good use. 20 II will probably see the greatest gathering of Asia scholars. This event will be the outcome of twenty years of developments in Asian studies which brought scholars from Asia, Europe and America closer together in their study of Asia in a global context. Wim Stokhof has played a major role in creating the platform at which this Asia Studies Meet can take place.

\section{Bibliography}

Asia Committee, European Science Foundation, Asia and Europe towards the $21^{\text {st }}$ Century, Strasbourg, Leiden, I997.

Asia Committee, European Science Foundation, Asian Studies: An ESF interdisciplinary programme in the Humanities and the Social Sciences, Strasbourg, Leiden, 2000.

Asia-Europe Vision Group Report, For a better Tomorrow: Asia-Europe Partnership in the $21^{\text {st }}$ Century, Seoul, I999.

Bersick, Sebastian, Wim Stokhof and Paul van der Velde (eds), Multiregionalsim and Multilateralism: Asian-European Relations in a Global Context, Amsterdam: Amsterdam University Press, 2006.

Busquin, P., 'Towards a European Research Area. Contributions to the debate and commentary from the commission organised according to the action lines indicated in the communication (I8/I-25/2/2000)', http://www.europa. eu.int/comm/research/area/comments.html, 2000: I-8.

European Commission, 'Towards a new Asian strategy', http://www.europe. eu.int/comm/external_relations/asem/asem_process/com.htm, I994.

Gilson, J., 'Asia meets Europe: the view from Europe', Enlarging European Union and Asia, edited by Z. Mantaha and T. Tanaka, Singapore: Asia-Europe Foundation and Keio University, 2005.

Goh Chok Tong, 'The Asia-Europe Dialogue: The Road to Greater Understanding', Cultural Rapprochement between Asia and Europe: Five Essays on the AsiaEurope Relationship, edited by Paul van der Velde, Leiden: International Institute for Asian Studies, I997: 15-22.

Kesavapany, K. and M.C. Anthony, 'A report prepared for the ASEM Regional Assessment Project, Coordinated By Japan Center of International 
Exchange (JCIE), Japan in collaboration with the Institue of Southeast Asian Studies (ISEAS)', ASEAN at Ten: Reflections from Singapore, 2005.

McVey, R., 'Change and Continuity in Southeast Asian Studies', Journal of Southeast Asian Studies, 26, March 1995: I-9.

PEARL, 'Programme for Europe/Asia Research Linkages (PEARL): The Need for Research in ASEM: a Proposal presented by the programme of Europe/ Asia Linkages', IIAS Newsletter, 20, November I999: 4I-45.

Staal, F., et.al., Krisna in de delta. De Azië-studies op weg naar de $21^{\text {ste }}$ eeuw, Amsterdam: Koninklijke Nederlandse Akademie van Wetenschappen, I99I.

Stokhof, W.A.L., 'Editorial', IIAS Newsletter, 20, (November) I999:2.

Stokhof, W., Van der Velde, P. (eds.), ASEM: The Asia-Europe meeting: A window of opportunity, London \& New York, Leiden \& Amsterdam: International Institute for Asian Studies, I999.

Stokhof, W., Van der Velde, P. (eds.), Asian-European Perspectives: Developing the ASEM process, Richmond, Surrey: Curzon, 200I.

Stokhof, W., Van der Velde, P. and Yeo Lay Hwee (eds.), The Eurasian Space. Far more than two continents, Singapore: Institute of Southeast Asian Studies, 2004 .

Stokhof, W., Beberapa catatan tentang jaringan Studi-studi Asia khususnya di Indonesia, Jakarta: UIN, 2006.

Velde, P. van der (ed.), Cultural Rapprochement between Asia and Europe. Five essays on the Asia-Europe Relationship, Leiden, Amsterdam: International Institute for Asian Studies, I997.

Velde, P. van der (ed.), Guide to Asian Studies in Europe, Leiden, Richmond, Surrey: International Institute for Asian Studies, Curzon, I998.

Velde, P. van der and Rima Sondaite, 'The Asia-Europe Meeting and the ASEM', Research Platform, 29, (November) 2002: 3. (www.iias.nl/asem) 



\section{Abbreviations}

\begin{tabular}{ll} 
AAS & Association for Asian Studies \\
APEC & Asia Pacific Economic Cooperation \\
ARP & ASEM Research Platform \\
ASEAN & Association of Southeast Asian Nations \\
ASEF & Asia-Europe Foundation \\
ASEM & Asia-Europe Meeting \\
ASEMUS & Asia-Europe Network of Museums \\
ATMA & Institute of the Malay World and Civilization \\
CFSP & Foreign and Security Policy \\
CSIS & Center for Strategic Studies \\
EC & European Commission \\
ESF & European Science Foundation \\
ESF-AC & European Science Foundation - Asia Committee \\
ICAS & International Convention of Asia Scholars \\
IIAS & International Institute for Asian Studies \\
IKON & Institute of Occidental Studies \\
INALCO & Institut National des Langues et Civilizations Orientales \\
IPE & International Political Economy \\
IR & International Relations \\
ISEAS & Institute of Southeast Asian Studies \\
ISIS & Institute of Strategic and International Studies \\
LIPI & Indonesian Institute of Sciences \\
PEARL & Programme for Europe-Asia Research Linkages \\
NGO & Non-governmental organization \\
NIAS & Nordic Institute of Asian Studies \\
SARS & Severe Acute Respiratory Syndrome \\
EU & European Union \\
\hline
\end{tabular}





\section{Contributors}

Robert Cribb, Senior Fellow, Division of Pacific and Asian History, Research School of Pacific and Asian Studies, Australian National University.

Gananath Obeyesekere, Professor of Anthropology, Emeritus at Princeton University.

Shamsul A.B., Professor at and Director of Institut Alam dan Tamadun Melayu and Institute of Occidental Studies, Universiti Kebangsaan Malaysia.

Josine Stremmelaar, Executive Manager, International Institute for Asian Studies, Executive Officer, International Convention of Asia Scholars.

Peter van der Veer, University Professor at Utrecht University, Chairman of the Board, International Institute for Asian Studies.

Paul van der Velde, Senior Consultant, International Institute for Asian Studies, Secretary, International Convention of Asia Scholars.

Yeo Lay Hwee, Executive Director and Senior Research Fellow, Singapore Institute of International Affairs. 
